UNIVERSIDADE DE SÃO PAULO

INSTITUTO DE GEOCIÊNCIAS

\title{
QUANTIFICAÇÃO DA INCERTEZA VOLUMÉTRICA NA MODELAGEM GEOLÓGICA
}

THYAGO DE OLIVEIRA DA SILVA

Orientador: Prof. Dr. Jorge Kazuo Yamamoto

\section{DISSERTAÇÃO DE MESTRADO}

Programa de Pós-Graduação em Recursos Minerais e Hidrogeologia

São Paulo

2016

Versão Corrigida 

UNIVERSIDADE DE SÃO PAULO

INSTITUTO DE GEOCIÊNCIAS

\title{
QUANTIFICAÇÃO DA INCERTEZA VOLUMÉTRICA NA MODELAGEM GEOLÓGICA
}

THYAGO DE OLIVEIRA DA SILVA

\begin{abstract}
Dissertação apresentada ao Instituto de Geociências da Universidade de São Paulo para obtenção do título de Mestre em Recursos Minerais.

Orientador: Prof. Dr. Jorge Kazuo Yamamoto
\end{abstract}

São Paulo 
Autorizo a reprodução e divulgação total ou parcial deste trabalho, por qualquer meio convencional ou eletrônico, para fins de estudo e pesquisa, desde que citada a fonte.

Ficha catalográfica preparada pelo Serviço de Biblioteca e Documentação do Instituto de Geociências da Universidade de São Paulo

Silva, Thyago de Oliveira da

Quantificação da incerteza volumétrica na modelagem geológica. / Thyago de Oliveira da Silva.

- São Paulo, 2016.

140 p.: + anexo.

Dissertação(Mestrado): IGc/USP

Orient.: Yamamoto, Jorge Kazuo

1. Incerteza volumétrica 2. Quantificação da incerteza 3 . Simulação sequencial de indicadoras 4 . Modelagem geológica I. Título 
À minha família. 



\section{AGRADECIMENTOS}

Este trabalho é fruto da dedicação e empenho não só apenas de quem o escreveu, mas sim de diversas pessoas que me apoiaram e sustentaram ao longo de minha vida pessoal, acadêmica e profissional. Um trabalho de dois anos, mas que se construiu ao longo de minha vida e é representado pelas pessoas que aqui agradeço.

Agradeço em primeiro lugar à minha família, base de tudo que sou e sei. Tudo em minha vida foi por eles e através deles. À minha mãe Cleonilde e ao meu pai Geraldo meus mais sinceros agradecimentos por terem aberto os caminhos da minha vida, que mesmo em diversos momentos de adversidade sempre estiveram ao meu lado, me apoiando, me criticando e me fazendo crescer. Aos meus irmãos Saulo e Lucas pelo compartilhamento dos bons e difíceis momentos em nossas vidas.

Também dedico este trabalho à minha companheira e amada Marília Lopes, com quem dividi dias maravilhosos durante o período deste trabalho, alguém em que me apoiei e me ancorei em momentos de tormenta. Sem ela, tudo isto teria sido muito mais difícil. À minha segunda família, Lopes, pessoas que entraram em minha vida recentemente e que guardo com muito carinho, desde a simpatia da Fátima Lopes à sempre bem humorada e afiada Liana.

Agradeço também aos meus amigos, que apesar da distância sempre se fizeram presentes, Stefan, José Lopes (Jabá) e Carol (Michê).

Enfim, agradeço aos que contribuíram diretamente na execução deste trabalho. Ao meu orientador, Prof. Dr. Jorge Kazuo Yamamoto, pela confiança depositada em meu trabalho e pelas várias discussões acerca da vida profissional e acadêmica. Aos professores Marcelo Rocha e Ricardo Azevedo pelas inúmeras correções e revisões que só fizeram enriquecer meu trabalho. Ao Santiago Diaz, pelas preciosas dicas e 
ensinamentos nos tortuosos cálculos matemáticos. À Multigeo pelo apoio material, na pessoa do Tetsuo Akabane. Aos colegas de profissão Jorge Higa, Ruy Proença, Carlos Oba, Vinicius, Gabriel, Camila e Carla, obrigado pelo apoio e discussões no período em que aí estive. Em especial agradeço ao amigo geólogo Márcio Oliveira, com quem muito aprendi, este trabalho aqui também tem muito de você. À Mineração Caraíba, na pessoa do geólogo Maximiliano de Paula Reato e da geóloga Bianca Leone, obrigado pela confiança e apoio no desenvolvimento do trabalho.

Tudo de bom apresentado neste texto vêm destas pessoas, tudo de ruim, de minhas falhas. 


\section{RESUMO}

SILVA, T. O. Quantificação da incerteza volumétrica na modelagem geológica. 2016. 147 fls. Dissertação (Mestrado) - Instituto de Geociências, Universidade de São Paulo, São Paulo.

Gerenciar riscos é fundamental para que investimentos estejam protegidos de quaisquer fatores que possam modificar um cenário idealizado. Imprevistos não podem ser controlados, mas seus impactos podem ser minimizados se forem tomadas medidas de planejamento considerando diversos cenários da realidade. A indústria mineral se encaixa neste paradigma, pois diversas de suas áreas são estocásticas, desde flutuações econômicas e políticas até fenômenos relativos ao clima e à geologia.

Uma destas características de difícil previsão é o volume das mineralizações em um depósito. Um cenário ideal é aquele em que é conhecido o valor esperado da variável de interesse, bem como sua dispersão, com mínimo e máximo definidos. Isto pode ser obtido a partir da combinação dos resultados de estimativa, que resultam em um valor esperado, aliados ao resultado das simulações, em que pode ser obtida a variância entre todos os cenários equiprováveis.

Este trabalho propõe uma técnica para quantificar a incerteza dos volumes na modelagem geológica de domínios mineralizados em dois modelos geológicos, interpolado e interpretado, através da transferência da variância obtida nos resultados da simulação, e desta forma criar uma ferramenta de gerenciamento de risco e planejamento a partir dos resultados de incerteza. Para isto foram utilizados os dados de descrição geológica de 168 testemunhos de sondagem de um depósito de cobre, localizado no norte da Bahia.

Os resultados mostraram a possibilidade em se utilizar os dados de variância da simulação para quantificar a incerteza em cada domínio do depósito. A partir do volume esperado em determinado modelo, e com os valores da variância da simulação, foi possível identificar uma gama de possibilidades volumétricas. Adicionalmente, a probabilidade de que cada bloco faça parte de um domínio foi calculada, e os volumes dos domínios foram parametrizados para auxiliar na avaliação da incerteza.

Palavras-chave: Incerteza volumétrica; gerenciamento de risco; simulação sequencial indicadora; modelagem geológica; interpolação multiquádrica. 



\begin{abstract}
SILVA, T. O. Quantifying geological modelling uncertainty. 2016. 147 pgs. Dissertação (Mestrado) - Instituto de Geociências, Universidade de São Paulo, São Paulo.
\end{abstract}

Managing risks is essential for investments being safe from any factors that may modify an idealized scenario. Unpredictabilities cannot be controlled, but their impacts can be minimized if planning measures are taken considering various scenarios of reality. The mining industry fits this paradigm, since several of its fields are stochastic, from economic and political fluctuations to phenomena related to climate and geology.

One of these characteristics, which are difficult to predict, is the volume of mineralization at the deposit. An ideal scenario is the one in which both the expected value and its dispersion are known, with defined minimum and maximum. This can be achieved with the combination of results from estimates and simulations, the first providing the expected value and the last providing the variance of the variable.

This research proposes a technique to quantify the volumetric uncertainty in geological modeling of mineralized domains on two geological models, interpreted and interpolated, by transferring the variance obtained in the simulation results, thus creating a risk and planning management tool from the uncertainty results. For that, we used a geological logging from a database set with 168 drillholes of a copper deposit located north of Bahia state, Brazil.

The results showed that it is possible to use the variance from simulation to quantify the uncertainty in each deposit domain. Using the expected volume value in a specific model with the variance values of the simulations, it were able to identify a range of possibilities for the volumetric content of each domain. In addition, the probability of each block being a domain was calculated, resulting in a volume parametrization by probability that can assist in the uncertainty analysis.

Keywords: Volumetric uncertainty; risk management; sequential indicator simulation; geological modeling; multiquadric interpolation. 



\section{LISTA DE FIGURAS}

Figura 1.1 - Mapa de localização da área em estudo (Fonte: SEI, 2012)...............22

Figura 2.1 - Mapa de localização das sondagens utilizadas nesta pesquisa. ..........32

Figura 2.2 - Fluxograma das etapas desenvolvidas no trabalho de

quantificação de incerteza volumétrica para o depósito de Surubim.

Figura 2.3 - Seções mestres utilizadas para a confecção das seções

geológicas

Figura 3.1 - Mapa geológico esquemático do Cráton São Francisco, com destaque para o (OISC). O retângulo corresponde ao segmento norte desse orógeno. Modificado de Barbosa et al. (2003).

Figura 3.2 - Mapa geológico do segmento norte do OISC, modificado de Marques et al. (2005). 41

Figura 3.3 - Mapa geológico simplificado do vale do Rio Curaçá, mostrando as áreas de ocorrência de corpos máfico-ultramáficos. Modificado de Delgado e Souza (1981). 46

Figura 3.4 - Mapa geológico local no entorno do depósito Surubim, demarcado no quadrado pontilhado em vermelho. (Modificado de Reis et al., 2013). 52

Figura 3.5 - Seções esquemáticas com a geologia no entorno do depósito Surubim. (Reis et al., 2013) 54

Figura 3.6 - Exemplo esquemático do modelo universal de variação espacial (modificado de Hengl, 2009).

Figura 3.7 - Curvas de volume de mineralização acima de cutoff em simulação de diversos cenários equiprováveis. (Adaptado de Goodfellow et al., 2012) 69 
Figura 3.8 - Fluxograma para a realização da SSI (Modificado de Juang et al., 2004)

Figura 3.9 - Passos da SSI para k categorias $(k=1, \ldots, 4)$, utilizando equações multiquádricas. MQ: Multiquádrica; $W$ : pesos da multiquádricas; $\varphi$ : norma entre os pontos destacados; $\mu$ :variável adicional para condição de não viés. Passos 3 e 4 se repetem até que todos os nós do domínio tenham sido simulados. (Modificado de Emery, 2004).

Figura 3.10 - Representação da incerteza tipo 2 e 3, à esquerda a definição de um contato entre dois domínios, $\mathrm{A}$ e $\mathrm{B}$, a partir de uma amostra de sondagem. Dada variabilidade espacial, definida pelo variograma, a região de contato passa a ter uma probabilidade de ocorrência, imagem à direita, em que na região escura a probabilidade de ocorrência de A é maior que 0,8 e na região rachurada é menor que 0,2. (POMIANSRZEDNICKI, 2002).

Figura 4.1 - Localização das sondagens em planta e em perspectiva. 79

Figura 4.2 - Histogramas e gráficos P-P para as variáveis Cu e Ni de todos os domínios do depósito. 80

Figura 4.3 - Histograma com frequência relativa dos domínios descritos no depósito de Surubim.

Figura 4.4 - Boxplot para o elemento cobre nos domínios geológicos. 83

Figura 4.5 - Boxplot para o elemento níquel nos domínios geológicos. 84

Figura 4.6 - Histogramas e frequência acumulada em escala logarítmica para as variáveis Cu e Ni no domínio (III). 85

Figura 4.7 - Histogramas e frequência acumulada em escala logarítmica para as variáveis Cu e Ni no domínio (VI). 86 
Figura 4.8 (cont.) - Análise de Contato para os Domínios I, II, III, IV, V e VI. 88

Figura 4.9 - Seções desenhadas a partir do banco de dados do depósito

Surubim. 90

Figura 4.10 - Esquema de seção geológica interpretada para dois corpos. Em vermelho domínio dos hidrotermalitos (III) e em verde domínio das ultramáficas $(\mathrm{VI})$. 91

Figura 4.11 - Seções geológicas em perspectiva. Em vermelho os hidrotermalitos (III) e em verde as ultramáficas (VI). 92

Figura 4.12 - Resultado da modelagem geológica para o depósito de Surubim, vista ortogonal (acima), planta (abaixo à esquerda) e em seção (abaixo à direita). 93

Figura 4.13 - Resultado da modelagem geológica para o depósito de Surubim, em vermelho o domínio dos hidrotermalitos (III) e em verde o domínio das ultramáficas $(\mathrm{VI})$.

Figura 4.14 - Função de distribuição acumulada para a variável domínio, com 6 tipos 98

Figura 4.15 - Resultado da interpolação multiquádrica para os domínios de Surubim. 99

Figura 4.16 - Resultado da interpolação multiquádrica para os domínios mineralizados dos hidrotermalitos (III) em vermelho e ultramáficas (VI) em verde. 100

Figura 4.17 - Resultado da simulação de indicadoras por multiquádricas para o depósito de Surubim 102

Figura 4.18 - Proporção dos domínios simulados nas realizações número 11

(a) e número 56 (b). 103 
Figura 4.19 - Resultado da litologia mais provável por bloco para os domínios mineralizados dos hidrotermalitos (III) em vermelho e ultramáficas (VI) em verde.

Figura 4.20 - Volumes nas 101 realizações, para os domínios I, II, III, IV, V e $\mathrm{VI}$ 104

Figura 5.1 - Painéis utilizados para o cálculo dos swath-plots nos 03 modelos gerados. 106

Figura 5.2 - Swath-plot para os volumes esperados nos modelos geológicos para o domínio (III)

Figura 5.3 - Swath-plot para os volumes esperados nos modelos geológicos para o domínio (VI) 107

Figura 5.4 - Amostras disponíveis para a modelagem dos domínios (III), em vermelho e $(\mathrm{VI})$, em verde.

Figura 5.5 - Comparação visual entre o modelo geológico interpretado (linhas contínuas) com os modelos interpolado (a, d), cenário de mínimo (b, e) e máximo (c, f) do domínio (III) nas bandas 8941680N (esquerda) e 8941780N (direita). Em laranja, domínio I; em vermelho, domínio III; em rosa domínio IV; em verde escuro, domínio V; e em verde claro, domínio VI. Traços pretos, sondagens

Figura 5.6 - Distribuição de probabilidades e diagrama P-P por bloco para os domínios (III) e (VI) 113

Figura 5.7 - Probabilidade de ocorrência obtida a partir das simulações para o Domínio (III), à esquerda, e (VI), à direita.

Figura 5.8 - Mapa de probabilidades para o domínio (III), com cortes de $25 \%$
(a), $50 \%$ (b) e $75 \%$ (c) 
Figura 5.9 - Mapa de probabilidades para o domínio (VI), com cortes de $25 \%$

(a), $50 \%$ (b) e $75 \%$ (c) 116

Figura 5.10 - Parametrização do volume do domínio (III) (acima) e (VI) (abaixo)

para determinados cortes de probabilidade

Figura 5.11 - Média e incerteza do volume para o domínio (I). Modelo interpretado (linha pontilhada) e interpolado (linha contínua) 120

Figura 5.12 - Média e incerteza do volume para o domínio (II). Modelo interpolado

Figura 5.13 - Média e incerteza do volume para o domínio (III). Modelo interpretado (linha pontilhada) e interpolado (linha contínua) 121

Figura 5.14 - Média e incerteza do volume para o domínio (IV). Modelo interpretado (linha pontilhada) e interpolado (linha contínua) 121

Figura 5.15 - Média e incerteza do volume para o domínio (V). Modelo interpretado (linha pontilhada) e interpolado (linha contínua) 122

Figura 5.16 - Média e incerteza do volume para o domínio (VI). Modelo interpretado (linha pontilhada) e interpolado (linha contínua) 122

Figura A.1 - Histogramas e gráficos P-P em escala logarítmica para as variáveis Cu e Ni no domínio (I). 141

Figura A.2 - Histogramas e gráficos P-P em escala logarítmica para as variáveis Cu e Ni no domínio (II). 142

Figura A.3 - Histogramas e gráficos P-P em escala logarítmica para as variáveis Cu e Ni no domínio (IV). 143

Figura A.4 - Histogramas e gráficos P-P em escala logarítmica para as variáveis Cu e Ni no domínio (V). 144 


\section{LISTA DE TABELAS}

Tabela 3.1 - Exemplo de codificação binária de pontos hipotéticos.

Tabela 3.2 - Funções de base radial mais utilizadas 64

Tabela 4.1 - Estatística descritiva das amostras do depósito de Surubim 80

Tabela 4.2 - Proporção dos domínios a serem modelados e simulados. 83

Tabela 4.3 - Estatística descritiva dos domínios previamente definidos, em destaque os domínios mineralizados III e VI. 86

Tabela 4.4 - Volumes obtidos para os domínios modelados. 95

Tabela 4.5 - Atributos do modelo de blocos utilizado na interpolação. 96

Tabela 4.6 - Parâmetros de busca utilizados 97

Tabela 4.7 - Volumes obtidos para os domínios interpolados. 100

Tabela 4.8 - Volumes obtidos para os domínios simulados no cenário mais provável e nos cenários de mínimo, máximo e de mediana para os domínios. 102

Tabela 5.1 - Diferença relativa dos volumes obtidos para os volumes do modelo geológico interpretado e interpolado em relação ao cenário de mínimo no domínio (III) 108

Tabela 5.2 - Diferença relativa dos volumes obtidos para os volumes do modelo geológico interpretado e interpolado em relação ao cenário de mínimo no domínio (VI).

Tabela 5.3 - Probabilidade de ocorrência, em \%, para os domínios, por bloco, nas 101 realizações.

Tabela 5.4 - Parametrização dos volumes a partir de diferentes cortes de probabilidade no domínio (III). 
Tabela 5.5 - Parametrização dos volumes a partir de diferentes cortes de probabilidade no domínio $(\mathrm{VI})$. 116

Tabela 5.6 - Esperança e variância para os volumes da simulação, modelo interpretado (geo) e interpolado (mq) 119

Tabela 5.7 - Incerteza calculada para cada domínio modelado 119 


\section{LISTA DE ABREVIATURAS E SIGLAS}

$\begin{array}{ll}\text { CODELCO } & \text { Corporación Nacional del Cobre de Chile } \\ \text { CPRM } & \text { Companhia de Pesquisa de Recursos Minerais } \\ \text { CSC } & \text { Cinturão Salvador-Curaçá } \\ \text { DNPM } & \text { Departamento Nacional de Produção Mineral } \\ \text { DOCEGEO } & \text { Rio Doce Geologia e Mineração } \\ \text { FastRBF TM } & \text { Fast Radial Basis Function } \\ \text { FDAC } & \text { Função de distribuição acumulada condicional } \\ \text { ETRL } & \text { Elementos Terras Raras Leves } \\ \text { OFCO } & \text { Depósitos de Óxidos de ferro-cobre-ouro } \\ \text { OISC } & \text { Orógeno Itabuna-Salvador-Curaçá } \\ \text { SSD } & \text { Simulação Sequencial Direta } \\ \text { SSG } & \text { Simulação Sequencial Gaussiana } \\ \text { SSI } & \text { Simulação Sequencial Indicadora }\end{array}$




\section{SUMÁRIO}

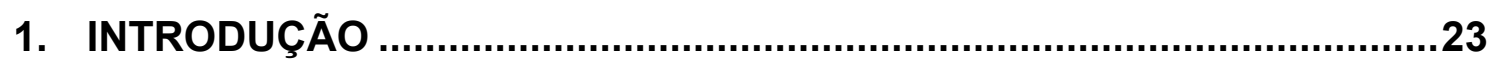

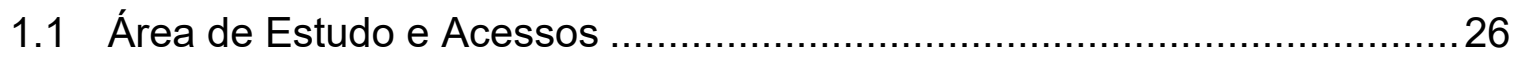

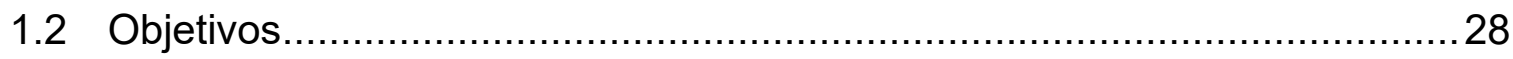

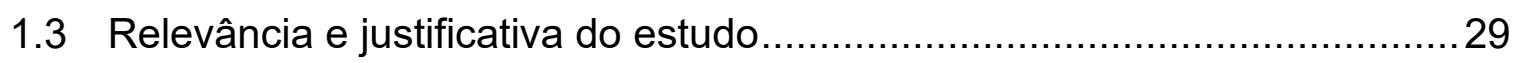

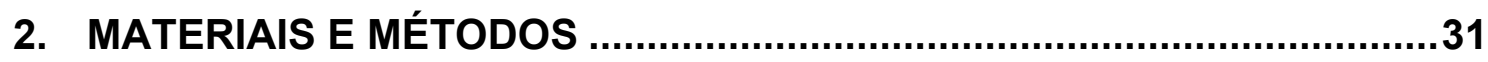

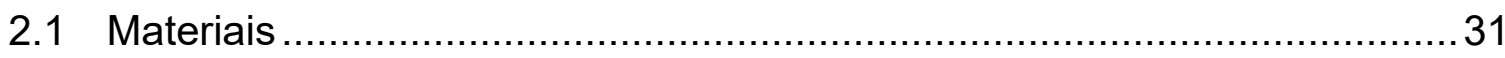

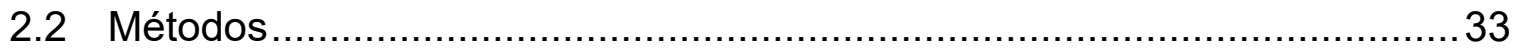

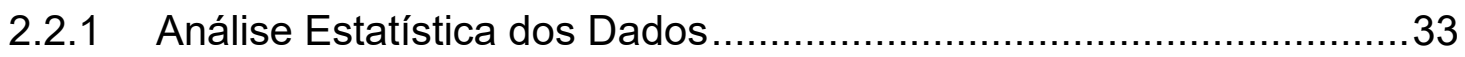

2.2.2 Delimitação dos domínios geológicos ………..................................35

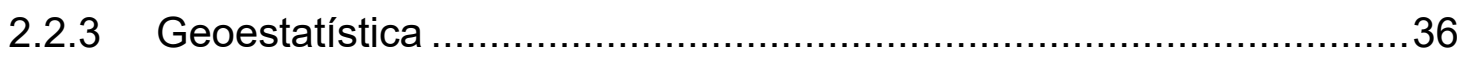

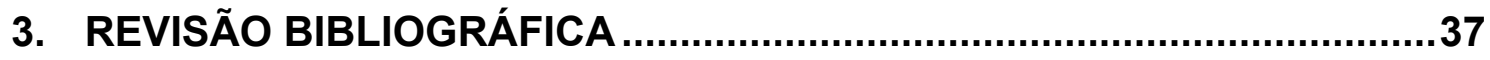

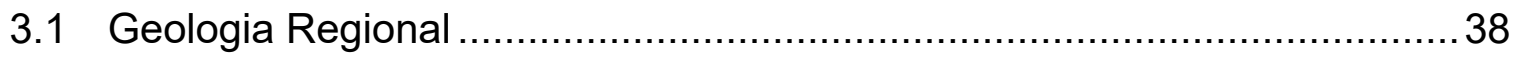

3.1.1 Síntese da Geologia do Vale do Rio Curaçá ......................................40

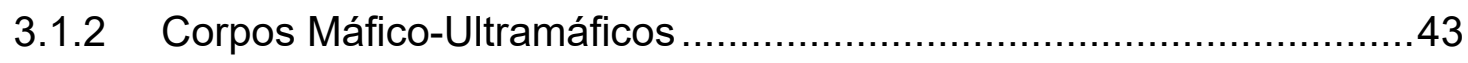

3.1.3 Granito e Sienito Paleoproterozoicos …………...........................4

3.1.4 Deformação e Metamorfismo ………………................................4

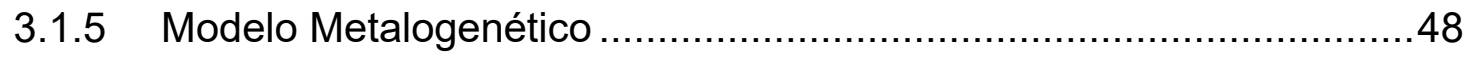

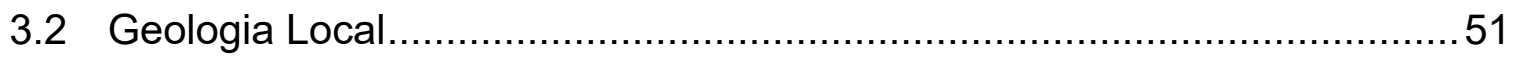

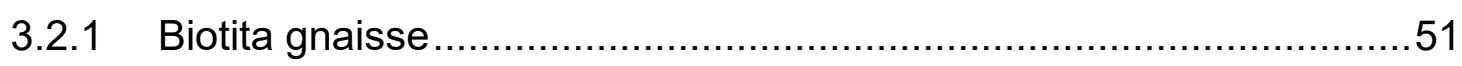

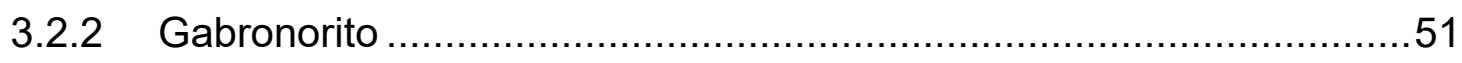

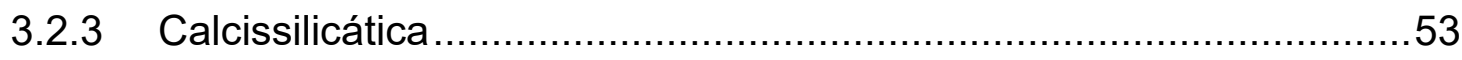

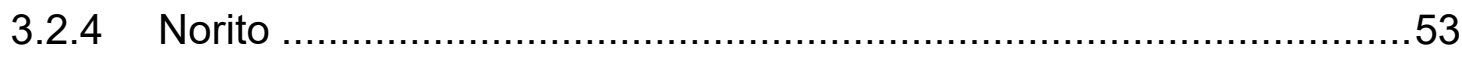

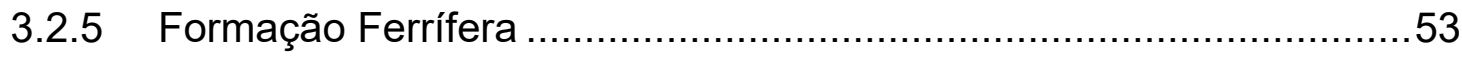

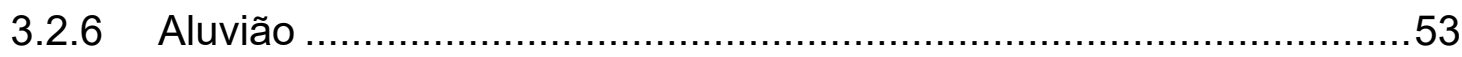




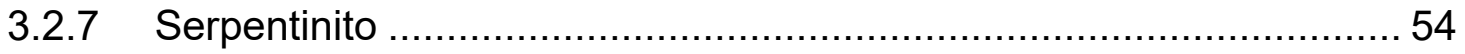

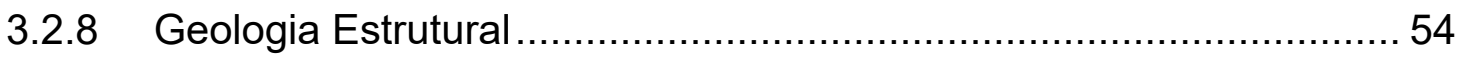

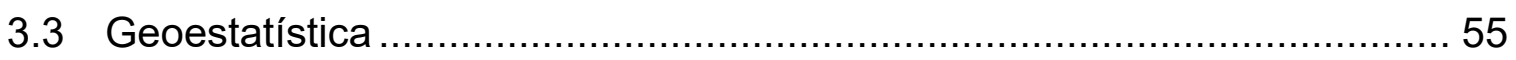

3.3.1 Variável Regionalizada e Função Aleatória .......................................56

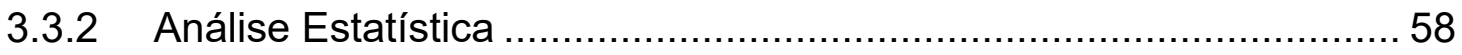

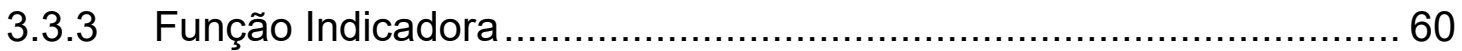

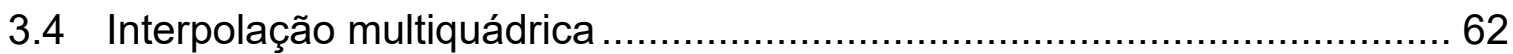

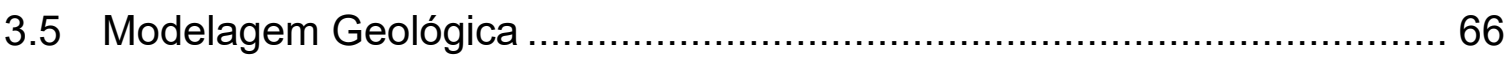

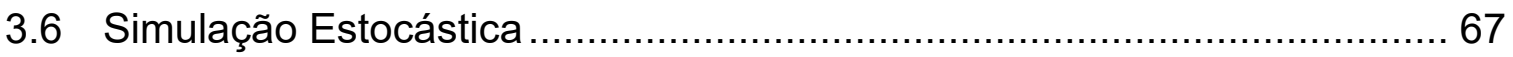

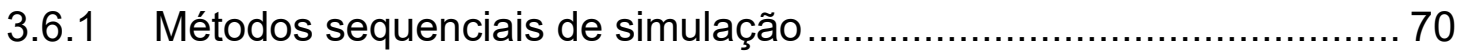

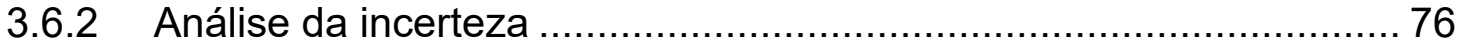

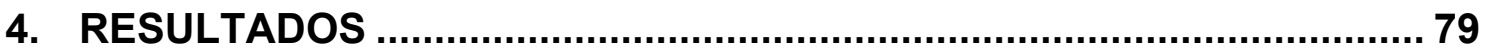

4.1 Validação e análise estatística dos dados .............................................. 79

4.2 Interpretação do Modelo Geológico ……………................................... 89

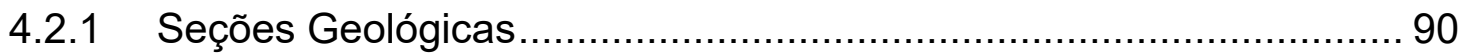

4.2.2 Triangularização do Modelo Geológico Interpretado ……................. 92

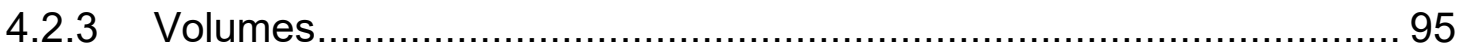

4.3 Interpolação multiquádrica de Indicadoras............................................... 96

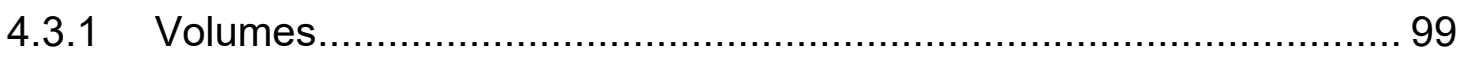

4.4 Simulação Sequencial de Indicadoras .................................................... 101

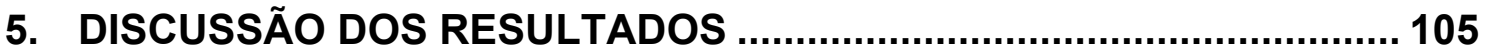

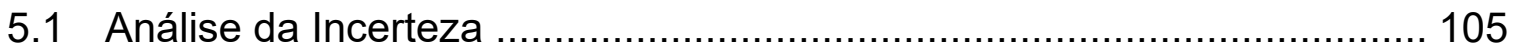

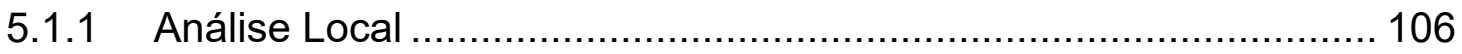

5.1.2 Parametrização das probabilidades ………………………........ 113

5.2 Quantificação da Incerteza Volumétrica por tipo de modelo ..................... 118 
6. CONCLUSÕES

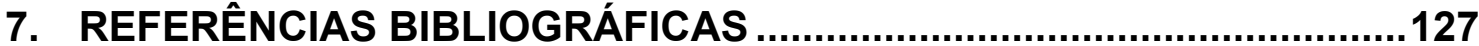

ANEXO A - Histograma e diagrama P-P para os domínios do depósito ANEXO B - Resultados de volume por simulação $\left(10^{3} \mathrm{~m}^{3}\right)$ 



\section{INTRODUÇÃO}

A indústria da mineração opera em um ambiente complexo, incerto e de alto risco. Em diversas etapas desta atividade, decisões precisam ser tomadas com base nos volumes e teores de minério presentes no depósito avaliado. Os valores de volumes e teores são variáveis desconhecidas, mas podem ser estimadas a partir de uma amostra. Mesmo que a base amostral seja robusta, os resultados não reproduzirão os valores reais do depósito, pois a amostragem dificilmente capta a variabilidade da realidade. Desta forma, conhecer a incerteza destas estimativas é fundamental para que se avaliem os riscos e as decisões que devem ser tomadas referentes ao prosseguimento de qualquer empreendimento.

Neste cenário, as simulações estocásticas têm se tornado uma ferramenta fundamental em gerenciamento de riscos na indústria mineira, que é um dos setores com maior risco econômico associado à sua atividade dada a complexidade de fatores geológicos, políticos, ambientais, sociais e econômicos. O aumento do uso de tais ferramentas no mercado da mineração ocorre devido a alguns fatores, dentre os quais pode-se citar: os avanços de processamento de computadores, que tornaram os complexos cálculos das simulações possíveis e mais rápidos; a versatilidade das informações, pois podem trabalhar com diversas variáveis utilizadas da indústria mineral, tanto contínuas como discretas; e a possibilidade de avaliação da incerteza a partir dos resultados obtidos. Apesar de ser uma área consolidada da geoestatística, ela ainda é pouco presente na indústria mineral brasileira.

A simulação estocástica se tornou um dos métodos mais valiosos para a quantificação da incerteza espacial. No setor mineral é uma ferramenta poderosa que permite ao usuário obter informações sobre forma e distribuição das variáveis em estudo, relações entre as variáveis simuladas, estatísticas globais representativas e 
diversos cenários equiprováveis de ocorrência e que permitem a avaliação da incerteza em determinado ponto. As simulações diferem dos métodos de estimativa uma vez que os resultados destas buscam reproduzir valores médios, já o resultado das simulações são diversas realizações equiprováveis, do qual pode ser retirado a variância entre os diferentes cenários. O método fornece globalmente resultados estatisticamente acurados, porém localmente imprecisos, e proporciona um resultado que pode ser avaliado ponto a ponto entre todas as imagens geradas e, com pósprocessamento, ser utilizado para quantificação e avaliação da incerteza.

O método mais difundido e de larga aplicação refere-se à simulação sequencial, sendo as mais utilizadas a Simulação Sequencial Gaussiana e a Simulação Sequencial Indicadora, sendo esta última a que mais se adequa ao objetivo deste trabalho.

O banco de dados utilizado para este projeto é referente à mineralização de cobre do depósito de Surubim. Localizado no nordeste do estado da Bahia é um depósito com forte controle estrutural, geologia complexa e diversas associações litológicas. Ele ocorre na Faixa Orogênica Itabuna-Salvador-Curaçá que, em sua porção norte, contém importantes mineralizações cupríferas em uma região denominada Vale do Curaçá, havendo diversos depósitos de cobre, tais como Caraíba e Vermelhos. As rochas que contém a mineralização em cobre são essencialmente ultramáficas, tais como piroxenitos, melanoritos e um grupo de litologias que sofreram alteração por processo hidrotermal, entre elas biotititos e flogopititos. Estas rochas estão encaixadas em rochas metamórficas de alto grau, fácies anfibolito a granulito, representadas por gabros e gnaisses. Todo este conjunto é controlado regionalmente pela estruturação do orógeno, com direção de N015E, mergulhando aproximadamente $50^{\circ}$ para $\mathrm{W}$. As fases minerais presentes na mineralização são 
basicamente de calcopirita e bornita, subordinadamente ocorrem calcocita, covelita e cubanita. Estes sulfetos estão remobilizados em fraturas e venulações nas rochas ultramáficas ou disseminados nas rochas hospedeiras e encaixantes.

Como em diversos depósitos localizados em faixas orogênicas, as deformações e obliterações de domínios geológicos e mineralizações tornam a geometria dos corpos muito complexa, o que acaba refletindo em uma baixa continuidade, alta variabilidade e baixa previsibilidade da ocorrência dos domínios litológicos. A modelagem tridimensional em um ambiente deste tipo é desafiadora e cheia de riscos, uma vez que a análise e desenho dos corpos a partir das amostras é subjetiva e dependente da interpretação da equipe de modelagem. Soma-se a isto o fato de que usualmente a modelagem gera apenas um resultado possível para a geometria e volume dos corpos modelados, o que inviabiliza uma análise dos riscos e erros associados aos valores obtidos. Com uma avaliação de volumes de minérios incerta em um cenário de longo e médio prazo, investimentos acabam sendo realizados com elevado grau de incerteza, muitas vezes inviabilizando depósitos minerais.

Visando suprir estes obstáculos, este trabalho propõe que sejam realizadas simulações que representem os domínios relacionados às encaixantes e às mineralizações, nominalmente as ultramáficas e os hidrotermalitos. Estes domínios foram simulados em $n$ cenários, respeitando o banco de dados categórico do depósito. Para fins de controle dos resultados obtidos foram gerados modelos dos mesmos domínios da maneira convencional, ou seja, pela interpretação a partir dos contatos resultando em sólidos tridimensionais de todos os domínios, e também foram gerados modelos através da interpolação multiquádrica. Seus volumes foram, então, discretizados para cada domínio, quantificados e utilizados como referência para os resultados obtidos nas simulações. 


\section{1 Área de Estudo e Acessos}

O vale do Curaçá é uma feição geomorfológica de grande porte, encaixada em serras do orógeno Salvador-Itabuna-Curaçá. Neste vale são encontradas diversas ocorrências de cobre, entre elas o depósito deste projeto.

O depósito de Surubim está localizado na região nordeste do estado da Bahia, no município de Curaçá, 87 km a sudeste de Juazeiro.

As instalações de apoio das atividades do depósito são baseadas no vilarejo de Pilar, município de Jaguarari. O acesso para a área a partir de Juazeiro via Jaguarari inclui rodovias federais, estaduais e acessos locais. Os acessos locais são estradas de terra bem preservadas.

A partir de Juazeiro segue-se por $100 \mathrm{~km}$ pela BR-235, chegando ao distrito de Pilar. Segue-se à esquerda em estrada local por mais $35 \mathrm{~km}$ até a BA-120, atravessando a BA-235. A partir deste ponto percorre-se mais $03 \mathrm{~km}$ até o acesso à esquerda do depósito de Surubim.

A Figura 1.1 contém a planta de localização do depósito e as vias de acesso. 


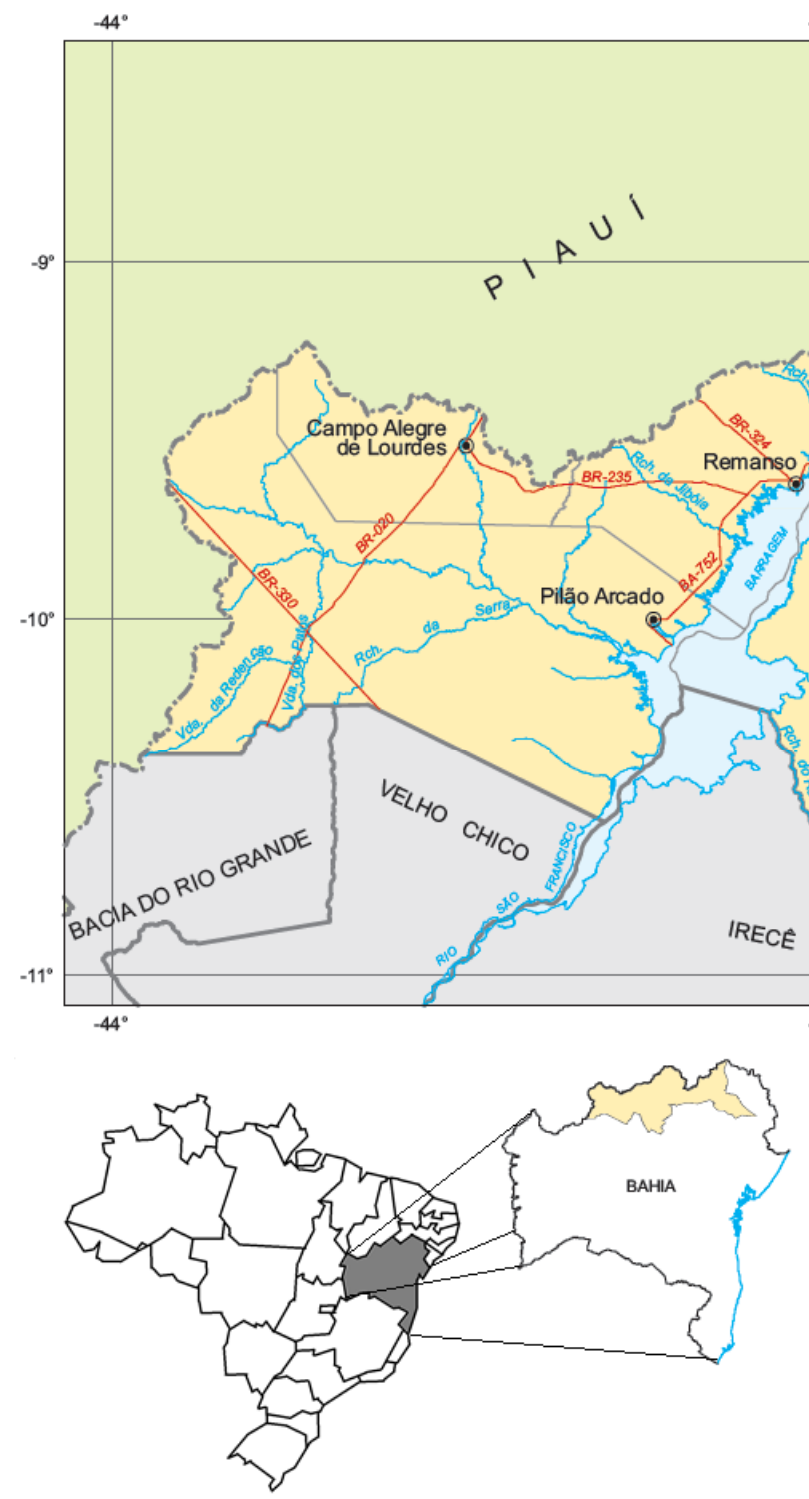

$42^{\circ}$

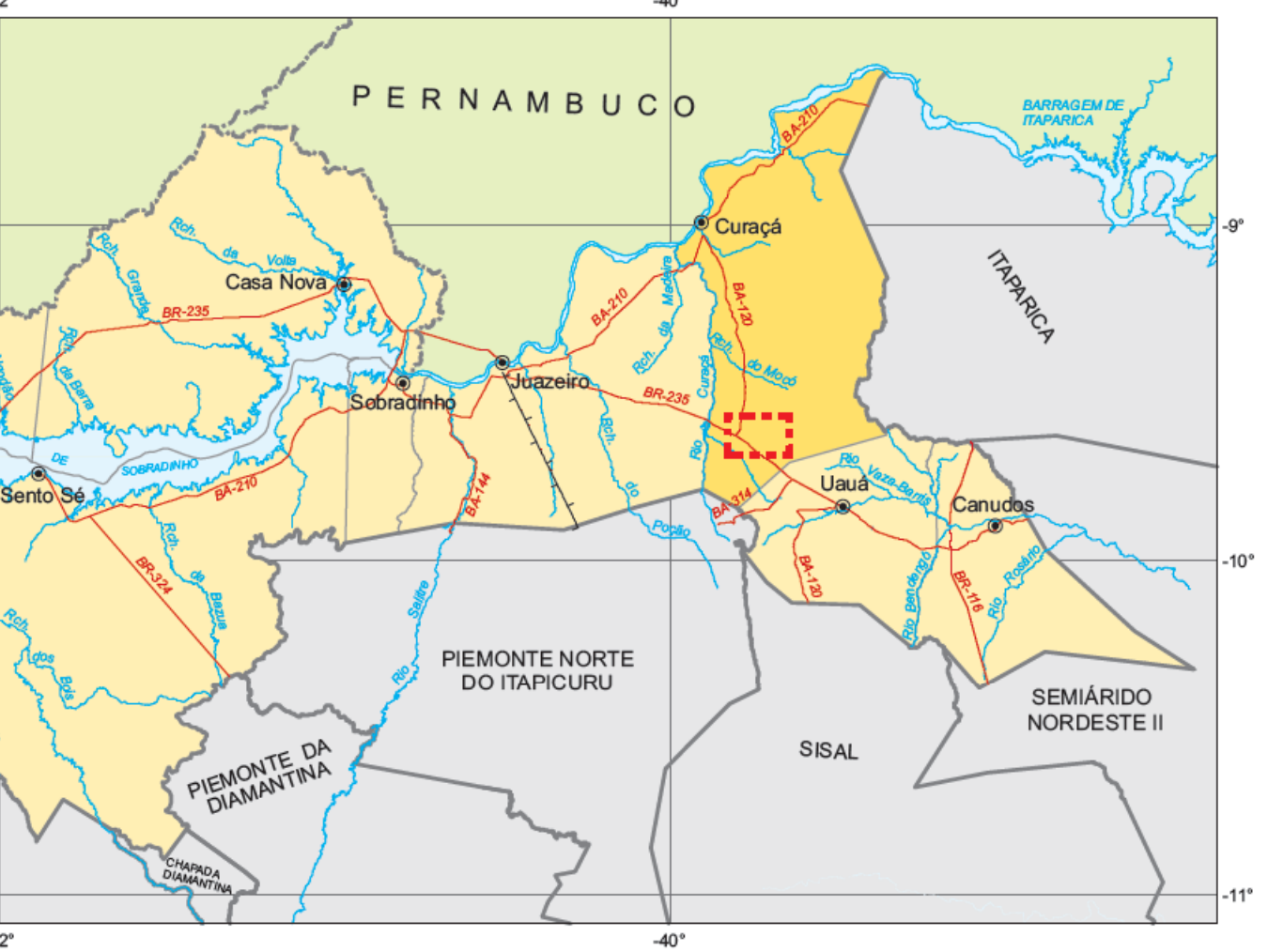

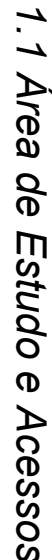

Figura 1.1 - Mapa de localização da área em estudo (Fonte: SEI, 2012)

Local da área de estudo

un Cursos de água

T- Rodovias

- Municípios

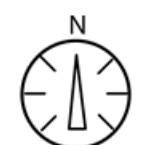

ESCALA 1: 3.000 .000

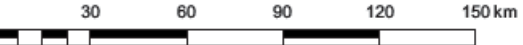




\subsection{Objetivos}

Este trabalho visa apresentar ferramentas de análise da incerteza para auxiliar no gerenciamento de riscos, e discutir sua aplicação na indústria mineral, a partir de um estudo de caso desenvolvido no depósito de cobre de Surubim, Bahia. O objetivo geral deste trabalho é implementar uma ferramenta para quantificação da incerteza na modelagem geológica das mineralizações, contribuindo com trabalhos já existentes sobre o tema.

Para alcançar este objetivo geral, o projeto foi dividido em etapas com objetivos específicos. Na primeira etapa objetivou-se identificar os volumes esperados para cada domínio, obtidos a partir de dois modelos geológicos, um modelo interpretado e um interpolado. A segunda etapa buscou reconhecer a variância dos volumes em cada modelo criado utilizando a curva de distribuição de frequência gerada a partir dos resultados da Simulação Sequencial Indicadora.

Adicionalmente este trabalho tem como objetivo analisar a incerteza volumétrica através de dois métodos: análise de incerteza local a partir de um gráfico de médias móveis; e a probabilidade de ocorrência dos domínios em cada nó simulado.

Para se obter a quantificação proposta os seguintes objetivos são apresentados:

1. Resultado dos modelos geológicos interpolado e interpretado;

2. Realização das simulações para:

a. Quantificação a incerteza a partir da variância por domínio;

b. Quantificação da probabilidade de ocorrência dos domínios, por nós;

c. Quantificação local da incerteza e comparação com os modelos obtidos.

3. Análise das incertezas em cada domínio apresentado;

4. Resultados obtidos. 


\subsection{Relevância e justificativa do estudo}

Os métodos de simulação estocástica têm atualmente importante papel no setor petrolífero, devido ao potencial em representar heterogeneidades nos reservatórios e de representar as características físicas amostradas. Apesar de sua teoria ser consolidada e sua prática ser realizada rotineiramente em unidades petroleiras, ela ainda encontra resistência na atividade mineira, principalmente no Brasil. Diversos fatores contribuem para esta ausência na indústria brasileira, dentre as quais é possível citar a maior complexidade de execução em relação a métodos tradicionais de interpolação, a falta de pesquisas técnicas na literatura nacional, a necessidade de, no dia-a-dia da lavra, as equipes se interessarem apenas pela média local e não a variabilidade e até mesmo falta de conhecimento teórico do assunto.

Um fator positivo para a aplicação de técnicas de simulação para variáveis qualitativas é a facilidade de obtenção destas variáveis em relação às variáveis quantitativas. É conhecido que a obtenção de variáveis contínuas, como dados de teor, é bem mais onerosa e complexa que a obtenção de variáveis discretas, como a litologia, uma vez que a obtenção dos teores necessita de análises químicas que, por sua vez, necessitam da execução de diversos protocolos de amostragem. A litologia, por sua vez, costuma ser obtida diretamente no testemunho de sondagem a partir da análise do geólogo. Por este motivo, é usual uma maior quantidade de informações nos bancos de dados de variáveis discretas, dado que os teores, por terem custo mais elevado, são estudados e conhecidos apenas nas regiões de interesse das sondagens.

É essencial para qualquer atividade mineral conhecer com a mais acurada projeção quais são os recursos que estão contidos na área de implantação de uma atividade extrativa. Estas quantidades não podem ser determinadas precisamente, 
tendo em vista que elas são baseadas em extrapolações de amostras limitadas de uma população desconhecida. Questões como a probabilidade de ocorrência de determinada tonelagem de estéril e minério precisam ser claras para que os esforços sejam direcionados da melhor forma possível para a extração econômica do material. 


\section{MATERIAIS E MÉTODOS}

As atividades propostas nesta pesquisa foram executadas a partir de um banco de dados de um depósito de cobre identificado como Surubim.

Toda a base de dados foi planejada, adquirida, tratada, armazenada e fornecida pela equipe técnica da Mineração Caraíba, detentora dos direitos sobre Surubim.

As atividades neste trabalho se iniciaram com a revisão bibliográfica da área de estudo, através de pesquisa em artigos científicos, livros temáticos, relatórios internos da mineração Caraíba e em aulas ministradas sobre o tema proposto. Esta etapa de levantamento de informações também contou com uma visita de campo entre a primeira semana de novembro de 2013 e primeira semana de dezembro do mesmo ano, acompanhada pela equipe local. Nesta visita foram realizados o reconhecimento das litologias e estruturas em campo e a verificação dos testemunhos e logs de sondagem.

\subsection{Materiais}

O banco de dados utilizado nesta pesquisa foi fornecido pela Mineração Caraíba, detentora dos direitos minerários de Surubim. O banco de dados contém 168 sondagens direcionais que contêm a variável de interesse nesta pesquisa, a litologia.

O banco de dados foi manipulado utilizando-se o software StudioRM ${ }^{\circledR}$, da CAE Mining (antiga Datamine), em arquivo de texto composto por 04 arquivos:

- Collar: contém a identificação e localização em UTM da boca das sondagens;

- Survey: arquivo contendo a identificação de cada sondagem, bem como sua direção e mergulho por intervalo perfurado;

- Litologia: arquivo contendo a identificação de cada sondagem, bem como as litologias definidas para cada intervalo; 
- Assay: arquivo contendo a identificação de cada sondagem, com o resultado das análises químicas dos intervalos amostrais

As sondagens utilizadas são apresentadas na Figura 2.1. As 168 sondagens utilizadas nesta pesquisa perfazem um total de aproximadamente 24.100 metros de perfuração. O número de intervalos descritos para litologia no banco de dados utilizado é de 2.845. Como os intervalos são definidos pela litologia presente no testemunho, a espessura das amostras varia de centímetros à dezenas de metros.

Para a realização da modelagem tridimensional e realização das estimativas foram utilizados os softwares Leapfrog $\mathrm{Geo}^{\circledR}$ e $\mathrm{ModGeo}^{\circledR}$, respectivamente.

Adicionalmente, para compreensão dos controles estruturais e regionais da mineralização do depósito, foi realizado um levantamento de trabalhos cartográficos na região, que incluíram levantamento de imagens de satélite, mapas de pesquisas regionais e locais, mapas gerados pela equipe técnica da Caraíba, bem como levantamentos regionais e locais realizados pelos órgãos públicos e privados, entre eles DNPM, CPRM, DOCEGEO e Codelco.

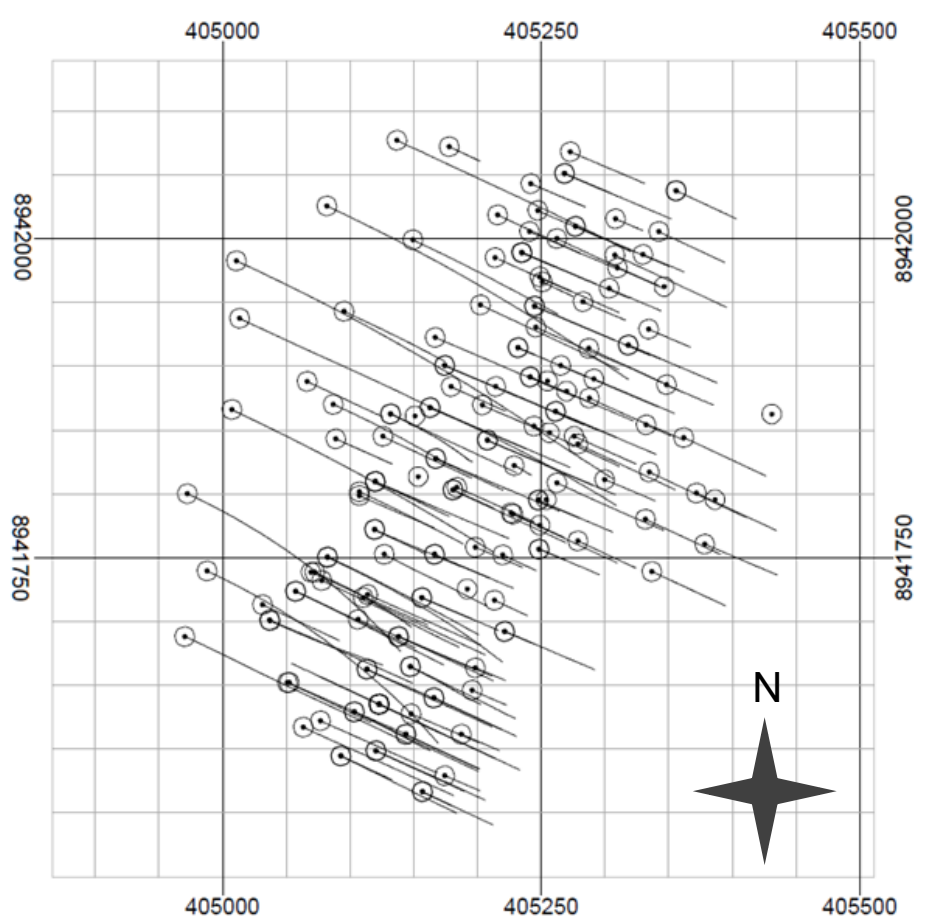

Figura 2.1 - Mapa de localização das sondagens utilizadas nesta pesquisa. 


\subsection{Métodos}

Este trabalho consistiu na execução de simulação estocástica para a quantificação da incerteza de volumes de determinados domínios geológicos no depósito de Surubim. Foram utilizados domínios em vez de litologias pois estes se apresentam mais contínuos ao longo do depósito. Os domínios foram definidos a partir de litologias que apresentassem características semelhantes em relação à sua gênese, geometria, continuidade e mineralização. As seguintes etapas foram realizadas: análise estatística dos dados; desenho tridimensional dos corpos; interpolação de indicadoras das variáveis; e simulação das variáveis. Cada uma destas etapas contém técnicas próprias que serão elucidadas a seguir. As etapas deste trabalho se encontram discriminadas no fluxograma da Figura 2.2.

\subsubsection{Análise Estatística dos Dados}

A análise estatística dos dados é uma etapa fundamental, que inclui as etapas de validação dos dados e resumo das informações obtidas para melhor compreensão, e foi realizada utilizando-se o software StudioRM ${ }^{\circledR}$.

Esta análise utiliza basicamente estatística descritiva para sua realização, e tem como principal objetivo descrever as características gerais da amostra, bem como servir de guia para definição de novos domínios amostrais para que a condição de estacionaridade seja assumida, pois assume-se que dentro de cada domínio sua população tenha as mesmas características. As técnicas utilizadas foram o cálculo da média, variância, mínimo, máximo, mediana, quartis e coeficiente de variação para os volumes dos domínios e probabilidade de ocorrência e moda para as variáveis discretas. Ferramentas gráficas como histogramas, boxplots, análise de contato, probabilidade acumulada, entre outras, foram utilizadas nesta etapa do trabalho. 


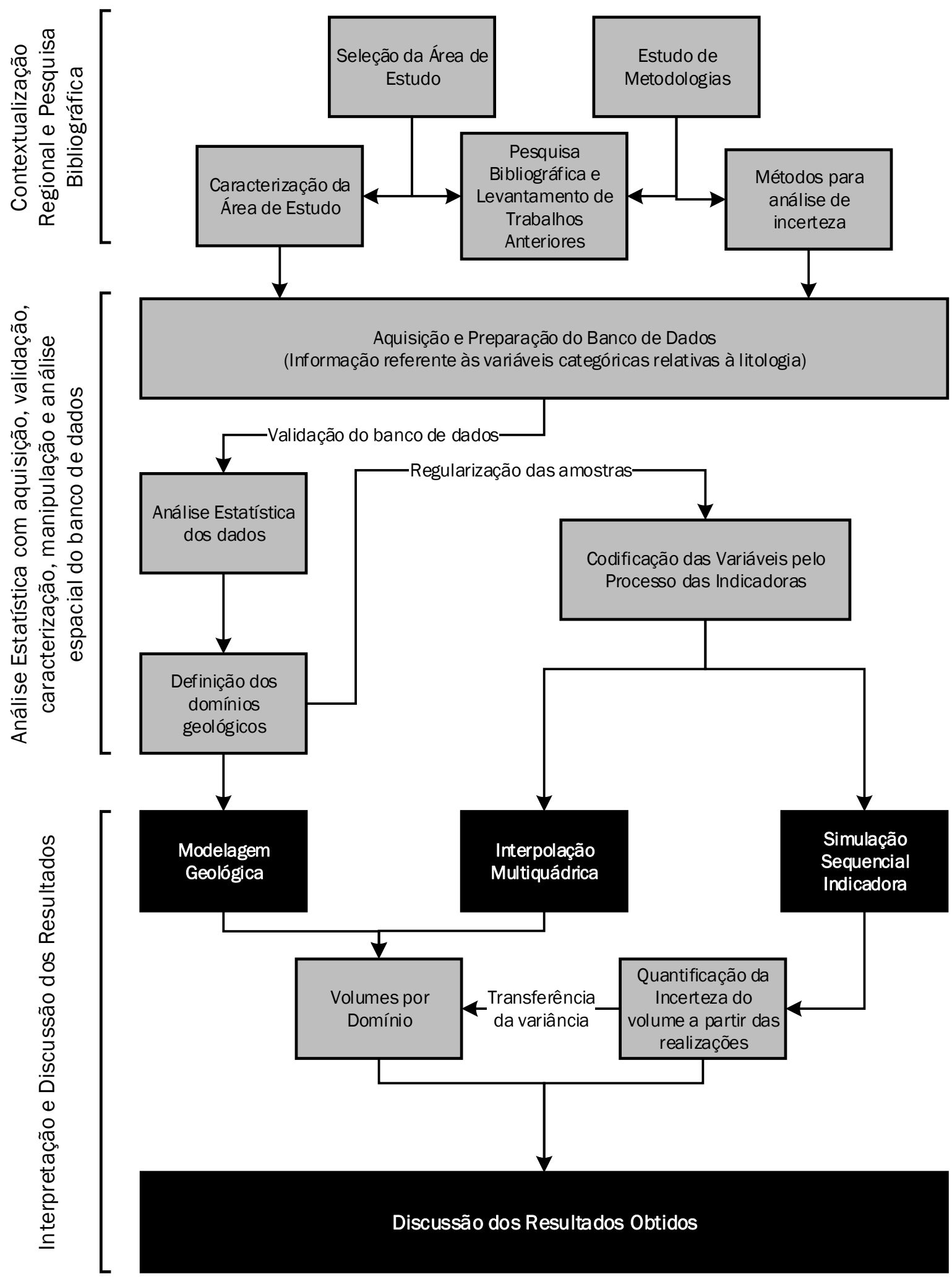

Figura 2.2 - Fluxograma das etapas desenvolvidas no trabalho de quantificação de incerteza volumétrica para o depósito de Surubim. 


\subsubsection{Delimitação dos domínios geológicos}

Neste trabalho foram 06 os domínios propostos para avaliação, definidos a partir das semelhanças genéticas, estruturais e espaciais das litologias. Esta etapa foi realizada nos softwares Leapfrog ${ }^{\circledR}$ e StudioRM ${ }^{\circledR}$, e consiste na modelagem tridimensional dos domínios geológicos previamente definidos.

O Leapfrog ${ }^{\circledR}$ realiza modelagem implícita dos dados categóricos que podem ser auxiliadas por interpretações geológicas através de seções. Desta forma, foi planejado um conjunto de 23 seções geológicas de direção N115 no programa StudioRM ${ }^{\circledR}$, que serviram como base para a interpretação de todas as seções. A Figura 2.3 contém a localização das seções utilizadas para a interpretação geológica.

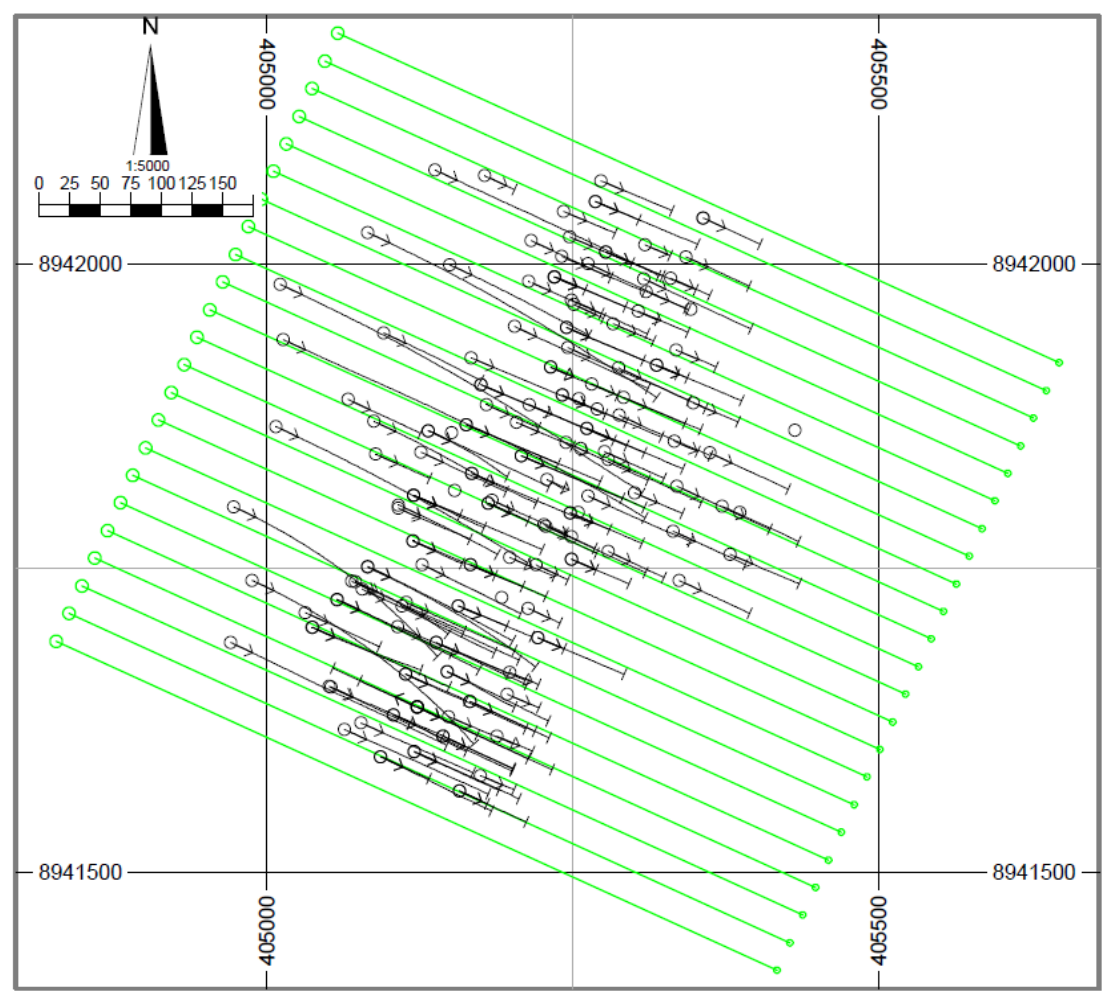

Figura 2.3 - Seções mestres utilizadas para a confecção das seções geológicas.

A partir do desenho das seções geológicas, os contatos em forma de linha são interligados por superfícies para que sejam gerados os sólidos, ou wireframes, que 
representam a limitação física dos domínios geológicos. A wireframe é a discretização da superfície de contato em triângulos, e é calculada no Leapfrog $^{\circledR}$ a partir de uma função de base radial definida como FastRBF ${ }^{\mathrm{TM}}$.

\subsubsection{Geoestatística}

Esta etapa se iniciou com a transformação das variáveis categóricas em variáveis indicadoras. A partir destas variáveis foi realizada a interpolação por indicadoras para definição de um modelo geológico interpolado e por fim foi realizada a simulação sequencial. O método de simulação utilizado foi a simulação sequencial de indicadoras, a partir da qual foram obtidas as diversas imagens e a variância do volume em cada domínio. Os resultados de variância da simulação foram, posteriormente, transferidos para os valores esperados nos modelos interpolado e interpretado. Tanto para a interpolação quanto para a simulação sequencial de indicadoras, o algoritmo utilizado para definição da litologia no ponto foi baseado no método de equações multiquádricas.

A análise de todos os cenários possíveis, com a definição em cada simulação do volume de cada domínio, resultou na quantificação da incerteza, que nada mais é do que a dispersão dos volumes obtidos ao redor dos volumes obtidos nos modelos interpretado e interpolado.

Foram utilizados os softwares StudioRM ${ }^{\circledR}$ e ModGeo ${ }^{\circledR}$, este último desenvolvido pelo Prof. Dr. Jorge Kazuo Yamamoto. 


\section{REVISÃO BIBLIOGRÁFICA}

Um dos primeiros passos para uma análise confiável de recursos e reservas minerais é um entendimento completo do contexto regional e local em que se inserem determinadas mineralizações. Desta forma é possível compreender as relações geométricas, anomalias de variáveis, bem como facilitar na definição de domínios homogêneos quando do cálculo probabilístico destes mesmos domínios. Também é necessário dominar os conceitos que envolvem a aplicação da geoestatística e simulação estocástica. Portanto, este capítulo tratará do contexto regional e local da geologia do depósito de Surubim, bem como dos conceitos de geoestatística utilizados.

A Província Cuprífera do Vale do Rio Curaçá concentra um importante conjunto de mineralizações que abrangem uma área de aproximadamente $1700 \mathrm{~km}^{2}$, ao norte do estado da Bahia, região de Jaguarari (TEIXEIRA et al., 2010).

É nesta região que se encontra o depósito de Surubim, depósito de cobre associado a rochas máficas e ultramáficas intrusivas e que possui uma gênese ainda bastante discutida devido a suas características peculiares, que o distingue de depósitos análogos (LINDENMAYER, 1982; BÜHN, 2013; OLIVEIRA e CHOUDHURI, 1993; MAIER e BARNES, 1996, 1999; TOWNNEND et al., 1980; OLIVEIRA; TARNEY, 1995; CHEN, 2008).

O conhecimento da gênese das ocorrências litológicas no depósito, ou seja, sua metalogênese, é de fundamental importância para a compreensão da geometria dos corpos mineralizados e para o direcionamento de futuras pesquisas. Neste contexto esta revisão se insere, para dar luz aos estudos realizados na região e levantar as possíveis teorias para a gênese do depósito. 
O depósito de Surubim está inserido no Orógeno Itabuna-Salvador-Curaçá, que consiste em um cinturão de rochas gnáissico-granulíticas arqueanas e paleoproterozoicas intensamente deformadas e que se estende por cerca de $800 \mathrm{~km}$, na borda leste do Cráton do São Francisco, desde o sul até a porção norte do Estado da Bahia (TEIXEIRA et al., 2010).

A mineralização tem forte controle estrutural e está associada aos corpos de rochas máficas-ultramáficas encaixadas em gabros gnaissificados. Os minerais de minério são majoritariamente bornita e calcopirita (REIS et al., 2013).

\subsection{Geologia Regional}

Segundo Barbosa et al. (2003) o Orógeno Itabuna-Salvador-Curaçá - OISC foi formado em um intervalo de tempo de cerca de 200-300 milhões de anos, durante o Paleoproterozoico, quando o Bloco do mesmo nome foi imprensado por outros Blocos de idade Arqueana (Blocos Gavião, Jequié e Serrinha) levando à formação de importante cadeia de montanhas. Atualmente este Orógeno está completamente arrasado na parte central, exibindo rochas metamórficas de alto grau das suas raízes. Estas rochas constituem uma das mais importantes províncias de granulitos aflorantes no mundo (BARBOSA, 1986).

O OISC, como definido por Barbosa (1990), Padilha e Melo (1991) e Barbosa et al.(1996), consiste em um cinturão de rochas gnáissico-granulíticas arqueanas e paleoproterozóicas intensamente deformadas e que se estende por cerca de $800 \mathrm{~km}$, na borda leste do Cráton do São Francisco, desde o sul até a porção norte do Estado da Bahia. Trata-se de uma faixa orogênica de idade riaciana, que evoluiu em decorrência da colisão de vários blocos arqueanos, no intervalo de 2,1-2,0Ga. (SABATÉ et al., 1990). A Figura 3.1 contém um mapa geológico esquemático do OISC. 
Na porção norte deste orógeno, identificada no retângulo destacado da Figura 3.1, localiza-se o Cinturão Salvador-Curaçá - CSC, intercalado entre os blocos arqueanos de Gavião a oeste e de Serrinha a leste. O CSC é caracterizado por apresentar lentes de diferentes rochas tectonicamente imbricadas, em decorrência de episódios de deformação cisalhante dúctil, inicialmente de caráter tangencial, que evoluiram para um regime transcorrente (Kosin et al., 2003).

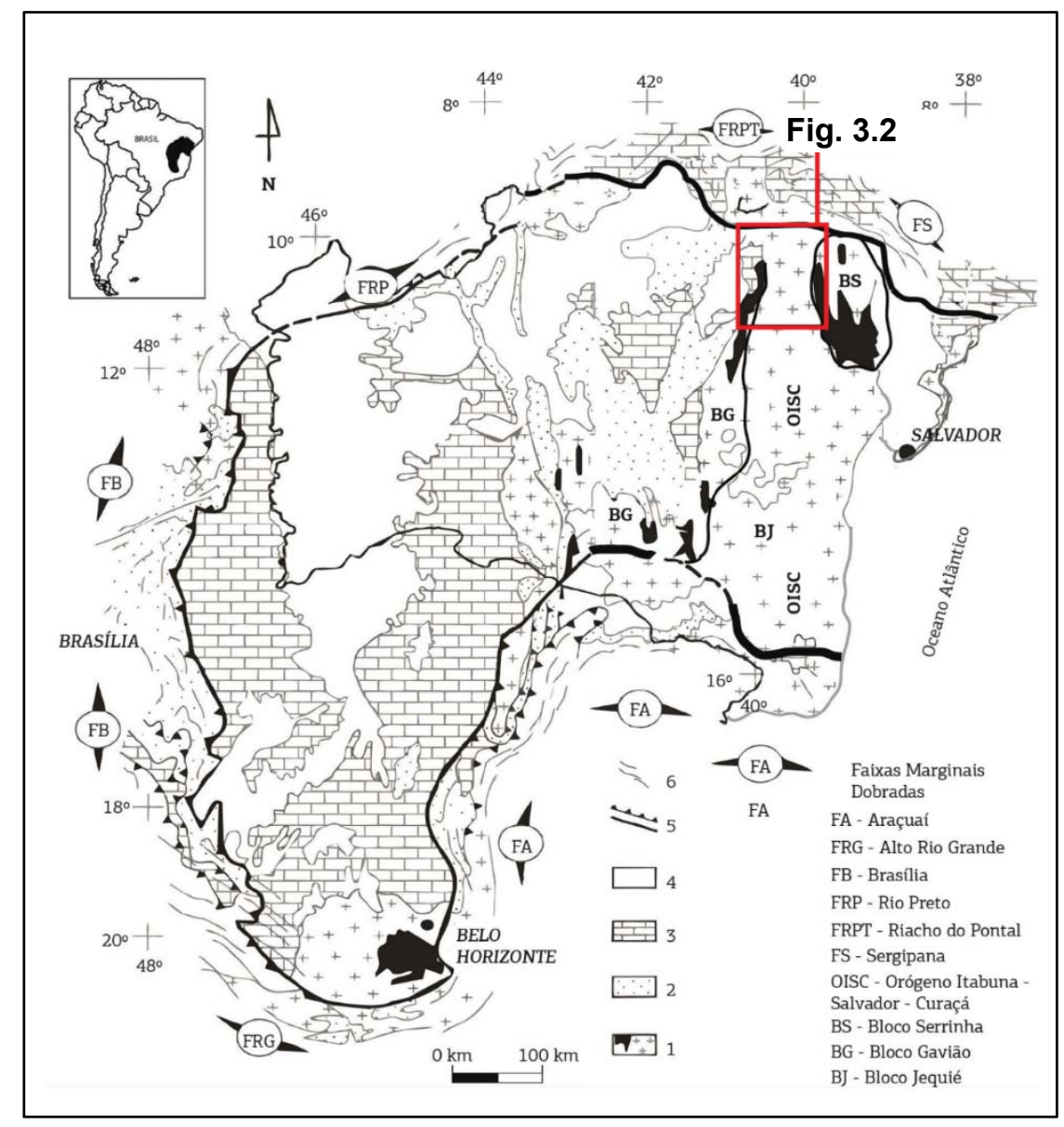

Figura 3.1 - Mapa geológico esquemático do Cráton São Francisco, com destaque para o (OISC). 0 retângulo corresponde ao segmento norte desse orógeno. Modificado de Barbosa et al. (2003).

A presença de mineralizações, com destaque para cromita no Vale do Rio Jacurici, despertou a atenção de geólogos e de pesquisadores para a região norte do OISC. Ladeira e Brockes Jr (1969) seguidos por Delgado e Souza (1975), foram os pioneiros no estudo detalhado das rochas hospedeiras de cobre do Vale do Rio Curaçá. 
Posteriormente, em função do potencial metalogenético, vários trabalhos foram desenvolvidos na região, tais como Figueiredo (1976), Lindenmayer (1981), Jardim de Sá et al. (1982), Conceição (1992), Oliveira (1990), Teixeira (1997) e Leite (2002).

Estudos específicos da evolução geoquímica e de geologia isotópica dos terrenos de alto grau do Vale do Curaçá foram realizados por Figueiredo (1980), Sabaté et al. (1994), Oliveira e Tarney (1995) e Silva et al. (1997). Trabalhos de síntese da evolução do conhecimento sobre o Cinturão Salvador-Curaçá, incluindo o Bloco Serrinha e o Cinturão Saúde-Itapicuru-Jacobina foram preparados por Kosin et al. (1999, 2001, 2003), Souza et al. (2000) e Oliveira et al. (2004).

Considerando que o presente capítulo trata apenas das mineralizações de cobre do CSC, que ocorrem no Vale do Rio Curaçá, serão discutidos a seguir aspectos relativos exclusivamente à geologia e metalogênese dessa porção do orógeno. Uma breve descrição da geologia do Complexo Jacurici será retratada para compreensão da extensão das mineralizações na região.

Nestes terrenos foram cartografadas as unidades Complexo Caraíba, Complexo Jacurici, Tanque Novo-Ipirá, os corpos máfico-ultramáficos portadores das mineralizações de cobre e diversas gerações de granitoides paleoproterozoicos, intrusivos (SEIXAS et al., 1975; LOUREIRO, 1991; MELO, 1991; SAMPAIO, 1992; MELO et al., 1995). A Figura 3.2 contém o mapa geológico esquemático com as unidades cartografadas.

\subsubsection{Síntese da Geologia do Vale do Rio Curaçá}

Os terrenos do vale do Rio Curaçá compõem uma estreita faixa de direção N-S situada na porção noroeste do CSC. A distribuição regional das ocorrências de cobre está circunscrita a essa faixa, embora existam alguns registros que transcendem a área do vale na direção sudeste (TEIXEIRA et al., 2010). 


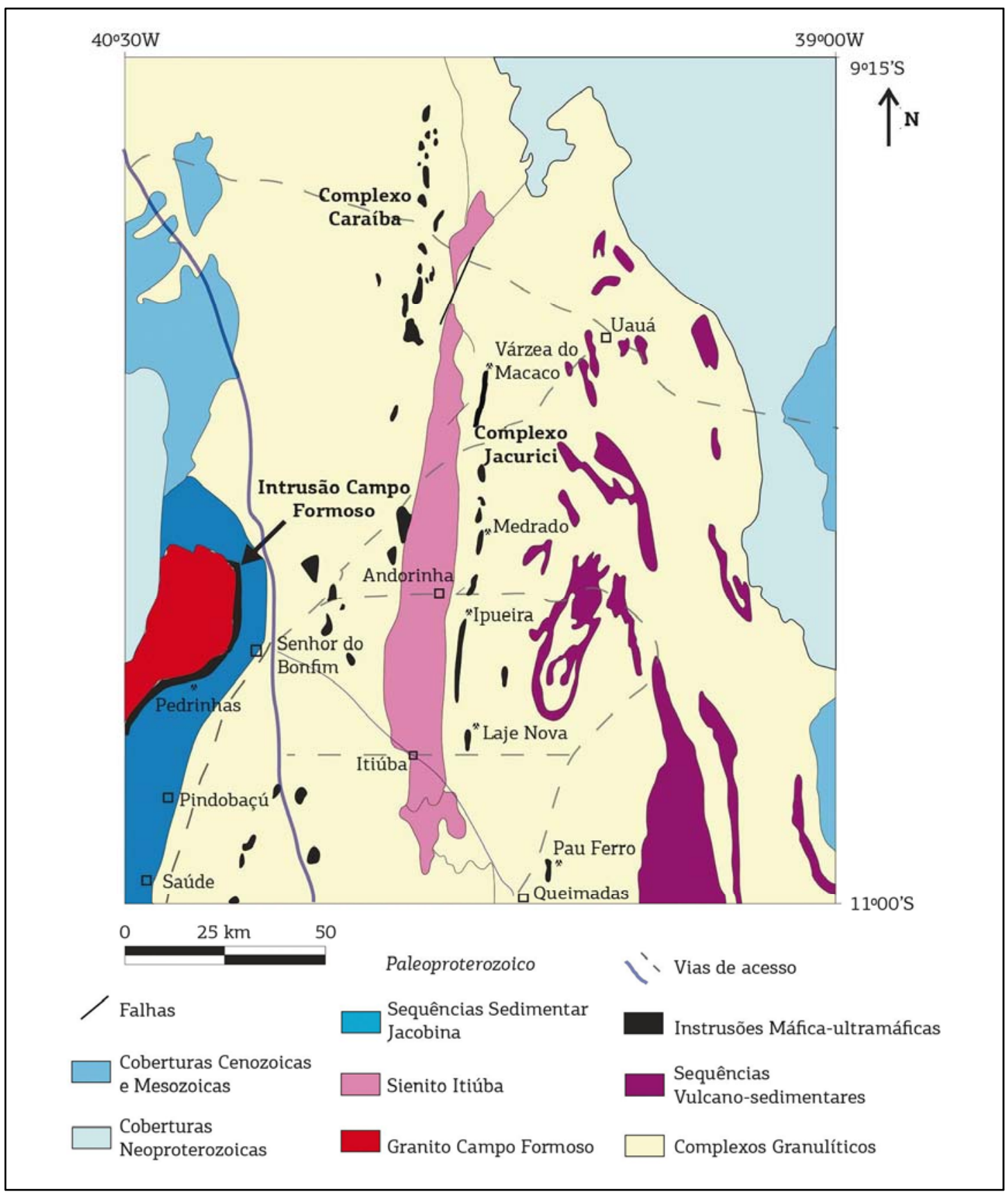

Figura 3.2 - Mapa geológico do segmento norte do OISC, modificado de Marques et al. (2005).

\subsubsection{Complexo Jacurici}

Segundo Dias et al. (2014) a relação entre os corpos do Complexo Jacurici ainda está em estudo, e suas encaixantes são pouco estudadas, mas consideradas como uma sequência de paragnaisses e ortognaisses granulitizados. O maior corpo do complexo e também o melhor estudado denomina-se sill Ipueira-Medrado. Esse corpo 
está dividido em dois segmentos (Ipueira e Medrado), que ocorrem em uma área de aproximadamente $7 \mathrm{~km}$ x 500 metros com 300 metros de espessura, e hospedam a maior parte do depósito de cromita do complexo em uma camada maciça de cromitito de até 8 metros de espessura.

Ainda segundo Dias et al. (2014) a formação de uma camada tão espessa de cromitito é difícil de explicar por um único mecanismo considerando os modelos atuais. Por isso, Marques e Ferreira Filho (2003) e Marques et al. (2003) definiram que a formação da camada de cromitito principal é caracterizada pela troca de regime magmático e por um aumento na quantidade de anfibólio durante e após a referida camada. Essas informações, com dados de química mineral e dados isotópicos de Nd e Os, forneceram evidências de que o cromitito possa ter se formado a partir da contaminação crustal de um magma primitivo, rico em Mg e Cr. Dados de geoquímica de elementos-traço mostraram que tanto a Unidade Ultramáfica Inferior quanto a Unidade Ultramáfica Superior cristalizaram a partir de magmas parentais similares.

\subsubsection{Complexo Caraíba}

Para Oliveira et al. (2004), a grande exposição deste complexo faz com que sua compreensão genética seja de grande importância para a compreensão da porção norte do Orógeno como um todo. Ele é a unidade litoestratigráfica de maior representatividade no Cinturão Salvador-Curaçá (LOUREIRO, 1991; MELO, 1991; PEREIRA, 1992; SAMPAIO, 1992; MELO et al. 1995), que ocorre desde o meridiano de Salvador, ao sul, até Curaçá, ao norte, numa faixa de aproximadamente $500 \mathrm{~km}$ de extensão. Esta unidade é composta por ortognaisse granulítico petrograficamente classificado como hiperstênio-gnaisse-tonalito, hiperstênio-gnaisse-diorito, hiperstênio-gnaisse-trondhjemito, gnaisses monzodiorítico e quartzo diorítico (TEIXEIRA, 1997). 
Segundo Melo (1991) as paragêneses minerais apontam para condições de metamorfismo na transição entre as fácies anfibolito alto e granulito, portanto um ambiente de favorabilidade para fenômenos de fusão parcial, que explicaria as frequentes estruturas migmatíticas do tipo nebulítico, schilieren e schöllen, cujas fases leucossomáticas são sieno-granítica e monzonítica. São ainda descritas estruturas migmatíticas decorrentes da injeção de granitoides, que teriam contaminado e transformado parcialmente os ortognaisses encaixantes em suas zonas de borda (KOSIN et al., 2003).

\subsubsection{Complexo Tanque Novo-Ipirá}

O Complexo Tanque Novo-Ipirá, tal como definido por Kosin et al. (1999), consiste em um conjunto de rochas supracrustais de natureza vulcanossedimentar, metamorfisadas nas fácies anfibolito a granulito. Nesta unidade, os autores supracitados descrevem biotita-gnaisse aluminoso, rochas calcissilicáticas, metacalcário, quartzito, formações ferríferas, gnaisse kinzigítico, gnaisse granatífero, gnaisse bandado e xisto grafitoso, além de rochas metamáficas e metaultramáficas.

\subsubsection{Corpos Máfico-Ultramáficos}

De acordo com Silva et al. (2014), ocorrem intrudidos, nos complexos Caraíba e Tanque Novo-Ipirá, vários corpos máfico-ultramáficos de dimensões variadas. Alguns corpos, em especial os distribuídos no Vale do Rio Curaçá, contêm mineralizações econômicas sulfetadas de cobre, principalmente sob a forma de bornita e calcopirita.

Ainda de acordo com os autores, o conjunto desses corpos mineralizados constitui a Província Cuprífera do Vale do Rio Curaçá, a qual abrange uma área de cerca de $1700 \mathrm{~km}^{2}$, englobando parcialmente os municípios de Juazeiro, Jaguarari e Curaçá. Os corpos máfico-ultramáficos são compostos de cumulatos ultramáficos e 
cumulatos máficos, além de leuconorito, norito e gabronorito. Essas rochas foram objeto de uma série de estudos realizados por diferentes autores, que lhes atribuíram diversas hipóteses petrogenéticas.

Em decorrência disto, constituiu-se um valioso acervo de dados cartográficos, estruturais, geofísicos, petrográficos, geoquímicos, isotópicos, geocronológicos, dentre outros, resultantes dos trabalhos históricos efetuados na área pela CPRM, Docegeo, Mineração Caraíba, Codelco, além de trabalhos de pesquisadores acadêmicos.

Os estudos realizados por Lindenmayer (1982) nos corpos máfico-ultramáficos, permitiram o reconhecimento de rochas de composição hiperstenítica-norítica, às quais estão associadas as principais mineralizações de cobre da área, associações de corpos noríticos e gabroicos com anortositos subordinados, que são pobres em sulfetos de $\mathrm{Cu}$, e lentes de gabro e gabronoritos estéreis.

A presença de intrusões mineralizadas sempre em contato direto com sedimentos carbonáticos, aliada à existência de sulfetos associados a grafita, bem como a existência, na jazida de Caraíba, de sedimentos carbonáticos portadores de níveis de anidrita e de prováveis níveis de evaporitos arqueanos, de acordo com Leake et al. (1979), em íntima associação com as rochas mineralizadas são fortes indícios de que a assimilação de enxofre das encaixantes tenha tido papel importante na formação desses depósitos. Lindenmayer (1982) propôs que os corpos máficoultramáficos representam soleiras diferenciadas, originados a partir de um magma basáltico toleítico. Trabalhos posteriores, realizados por Lindenmayer et al. (1984), D'el-Rey Silva $(1984,1985)$ e D'el-Rey Silva et al. (1988, 1994, 1996) convergiram para esta proposição de soleiras diferenciadas, intrusivas no embasamento do Cinturão Salvador-Curaçá. Para os autores citados, as intrusões teriam ocorrido antes 
dos três eventos deformacionais que atingiram a região. Isso explicaria, segundo eles, a complexa geometria apresentada pelos corpos mineralizados e suas encaixantes e a dificuldade encontrada em se estabelecer uma sequência litoestratigráfica coerente para os mesmos.

Para Mandetta (1982) os corpos mineralizados a cobre teriam sido gerados a partir de um magma toleítico e os corpos máficos estéreis, com destaque para as rochas mais ricas em olivina, teriam tido como fonte um magma rico em magnésio. 0 autor propôs que o conjunto de corpos represente uma intrusão máfico-ultramáfica diferenciada, com os membros ultramáficos na base, seguidos de rochas máficas e as rochas mais ricas em plagioclásio no topo.

Uma nova proposta surgiu para a petrogênese destes corpos em decorrência dos trabalhos desenvolvidos por Oliveira (1990) na Mina Caraíba. Para o autor, os corpos máfico-ultramáficos seriam representados por múltiplas intrusões de diques, além de brechas ígneas de composição hiperstenítica, norítica e anortosítica de afinidade toleítica. Os peridotitos e gabros, ainda segundo Oliveira (1990), seriam xenólitos trazidos pelo magma toleítico que deu origem aos diques e teriam uma assinatura geoquímica cálcico-alcalina. Embora discordantes, as propostas até então apresentadas convergem no sentido de que todas propõem uma origem magmática convencional para os corpos máfico-ultramáficos. A Figura 3.3 ilustra as ocorrências dos corpos máfico-ultramáficos cartografados na região de estudo.

Em total discordância em relação a esta linha de pensamento, Maier e Barnes (1999) propuseram que os piroxenitos e glimeritos mineralizados de Caraíba representariam restitos de um processo de fusão parcial de um protólito diorítico rico em sulfetos de cobre, pobre em sulfetos de níquel e rico em magnetita, flogopita, apatita e zircão. 
Fenômenos de anatexia, segundo esses autores, teriam ocorrido durante o pico do metamorfismo granulítico, relacionado à deformação D2.

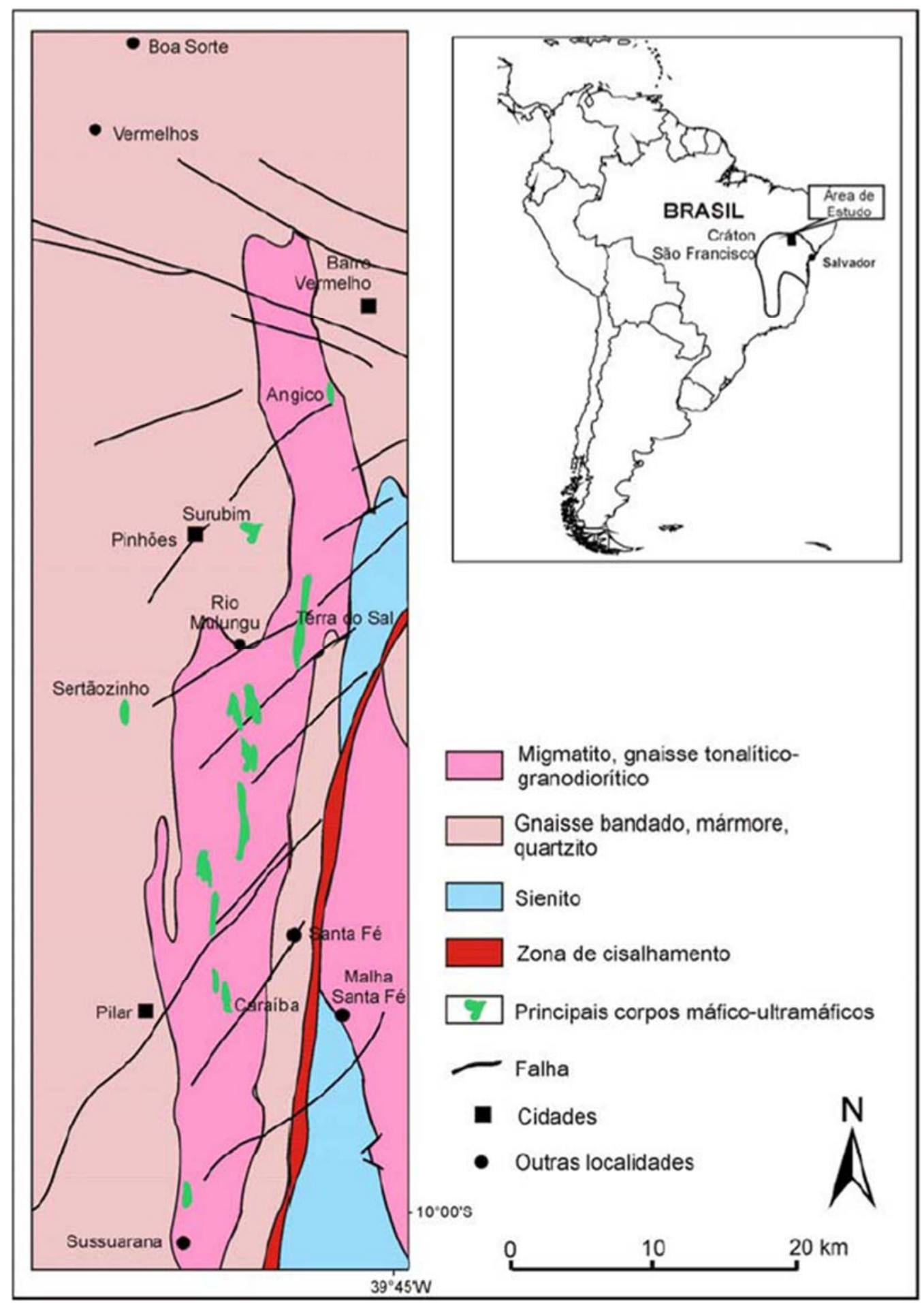

Figura 3.3 - Mapa geológico simplificado do vale do Rio Curaçá, mostrando as áreas de ocorrência de corpos máfico-ultramáficos. Modificado de Delgado e Souza (1981). 


\subsubsection{Granito e Sienito Paleoproterozoicos}

No Vale do Curaçá, a Suíte São José do Jacuípe é descrita como intrusões de granitoides paleoproterozoicos sin-, tardi- e pós-tectônicos, de acordo com Melo et al. (1995).

Ainda segundo estes autores, a geração de granitoides sintectônicos compreende corpos metaluminosos, subalcalinos, cujo representante mais expressivo é o granitoide Riacho da Onça. Trata-se de um corpo composto por augen gnaisses quartzo monzoníticos, monzoníticos e graníticos, colocados sintranscorrência, contendo xenólitos do Complexo Caraíba.

Além do granitoide de Riacho da Onça, são ainda descritos no âmbito do CSC outros corpos sintranscorrentes, de composição granodiorítica a granítica, derivados de magmas cálcico-alcalinos (origem mantélica), e também corpos peraluminosos, derivados de fusão crustal (KOSIN et al., 2003).

\subsubsection{Deformação e Metamorfismo}

Barbosa e Sabaté $(2002,2004)$ definiram o CSC como um orógeno colisional paleoproterozoico envolvendo diferentes terrenos presentes nos blocos arqueanos de Gavião e Serrinha. As deformações decorrentes desse evento colisional parecem ter ocorrido em dois estágios principais, ambos associados com intrusões graníticas, de acordo com vários autores, a exemplo de Alves da Silva et al. (1993), Sabaté (1996), Chauvet et al. (1997) e Leite (2002).

Segundo Alves da Silva et al. (1993) a deformação mais antiga (estágio D1), de natureza compressiva, teria sido dominada por empurrões e dobras com vergência para sudeste. Para Sabaté (1996) e Leite (2002) essa deformação D1 é caracterizada 
pela geração de um bandamento composicional e por dobras relíquias, isoclinais a deitadas.

Posteriormente, ainda de acordo com Alves da Silva et al. (1993), a tectônica compressiva teria mudado para direcional, com a formação de várias zonas de cisalhamento norte-sul e forte foliação. De acordo com Leite (2002), o estágio D2, resultante da tectônica de transpressão estabelecida pela colisão oblíqua, retrabalhou as deformações geradas no estágio D1 e teve seu padrão geométrico repartido em domínios de dobramentos e de cisalhamento, com foliação orientada NNW. Os dobramentos possuem planos axiais subverticalizados e dobras do tipo en echelon, enquanto os domínios de cisalhamento são constituídos por uma foliação milonítica verticalizada, cujas feições cinemáticas apontam para cisalhamento variando de simples a puro.

As condições de P-T durante a evolução do orógeno de caráter regional, realizados por Barbosa e Sabaté (2002, 2004), indicaram que as condições prevalecentes de metamorfismo foram de alto grau, com pressões que atingiram $7 \mathrm{~kb}$ e temperaturas em torno de $850^{\circ} \mathrm{C}$.

\subsubsection{Modelo Metalogenético}

Lindenmayer (1982) propôs uma origem magmática para os sulfetos, os quais teriam se formado por saturação do magma toleítico em enxofre, com ocorrência posterior do fenômeno de imiscibilidade de líquido. Na opinião da autora, o enxofre proviria de rochas ricas em anidrita, presentes na sequência metavulcanossedimentar encaixante dos corpos máfico-ultramáficos. Tal hipótese não explicaria a ausência de níquel na mineralização e nem as elevadas razões Se/S observadas.

Resultados de razões isotópicas nos sulfetos calcopirita e bornita em trabalho de Bühn (2013) mostram que os valores de $\delta 34 S$ (\%o VCDT) distribuem-se de +1,98 a - 
2,34, com valor médio de $-0,95$. Estes valores têm um espectro mais amplo de distribuição que os obtidos por Oliveira e Choudhuri (1993), situados na faixa de 1,495 a $+0,643$. Observa-se que os valores mais baixos, próximos de zero, estão relacionados aos sulfetos intersticiais, enquanto os valores afastados de zero, positivos e negativos, relacionam-se aos sulfetos condicionados a estruturas tectonocontroladas.

Ainda segundo os trabalhos de Bühn (2013) isto corrobora com a premissa da existência de um evento mineralizante primário, ortomagmático, que teria originado os sulfetos disseminados, intersticiais, e um segundo evento, hidrotermal, responsável pela mineralização tectono-controlado. Os valores isotópicos dos minerais de minério intersticial apontam para uma origem predominantemente magmática, mantélica, do S. Na mineralização tectono-controlado os valores de $\delta 34 \mathrm{~S}$ parecem indicar um S de origem igualmente mantélica, ou reciclado de fonte mantélica com baixo fracionamento, com discreta participação de enxofre crustal, mais pesado, oriundo das rochas encaixantes regionais dos corpos máfico-ultramáficos.

De maneira geral, a mineralização de Surubim e dos demais alvos mineralizados a cobre do Vale do Rio Curaçá, a exemplo de Caraíba e Vermelhos, apresenta características incomuns quando comparados a outros depósitos de cobre associados a rochas máfico-ultramáficas. Algumas destas características são destacadas por Maier e Barnes (1996, 1999): (i) as elevadas razões Cu/Ni (a presença de sulfetos de Ni é reduzida na mineralização); (ii) as altas razões Se/S, em média $1200 \times 10^{6}$, mas de até $4500 \times 10^{6}$, enquanto a razão no manto superior é da ordem de 230 a $350 \times 10^{6}$; (iii) o elevado percentual de magnetita associada aos sulfetos; (iv) a presença, por vezes dominante, de flogopita nos ortopiroxenitos; e (v) concentrações anômalas de apatita e zircão. 
A maior parte destas características foi também descrita nos depósitos de cobre de Koperberg, distrito cuprífero de Okiep, África do Sul, motivo pelo qual os depósitos do Vale do Curaçá têm sido historicamente comparados a Okiep (TOWNEND et al., 1980; OLIVEIRA; TARNEY, 1995). No caso do depósito de Okiep, Cawthorn e Meyer (1993) e Boer et al. (1994), postularam a existência de uma mineralização primária magmática, constituído por calcopirita e pirrotita, submetido a processos de oxidação e dessulfurização face ao metamorfismo de alto grau, resultando na associação calcopirita, bornita e magnetita pura. Para Maier e Barnes (1996), a gênese da mineralização de Caraíba poderia ser explicada à luz dessa hipótese.

Considerando que as altas razões Se/S não decorrem necessariamente da perda de enxofre pelo magma e que o modelo de dessulfurização não explicaria as elevadas razões $\mathrm{Cu} / \mathrm{Ni}$ da mineralização, Maier e Barnes (1999) reavaliaram a hipótese genética anteriormente proposta. Na reformulação da hipótese os autores citados propuseram uma origem crustal para a mineralização de cobre do Vale do Curaçá.

De acordo com esta proposta, os ortopiroxenitos representariam restitos da fusão parcial de um protólito diorítico que continha sulfetos ricos em Cu e Se (e pobres em Ni), magnetita, flogopita e apatita. Nesse modelo, os sulfetos teriam sofrido fusão, porém devido à sua alta densidade teriam permanecido no restito. Os autores prosseguiram sugerindo que bornita e calcopirita foram as principais fases cristalizadas a partir desse líquido sulfetado, com posterior redistribuição nas charneiras das dobras durante o último evento de deformação da área. Embora Maier e Barnes (1999) descartem a alternativa de modelo hidrotermal para a mineralização de Caraíba, Chen (2008) considera a possibilidade do depósito de Okiep, análogo aos do Vale do Curaçá, pertencer aos do tipo OFCO - Óxido Ferro-Cobre-Ouro. 
A natureza tectono-controlada da mineralização de cobre do Vale do Curaçá, somada à abundante presença de flogopita e magnetita, além de apatita e zircão, enriquecimento em ETRL, ausência de níquel, presença de ouro, dentre outras características, permite que se considere a possibilidade do depósito tratar-se de uma associação Cu-Fe-Au do tipo OFCO. Há que se considerar que a associação flogopita + magnetita pode eventualmente resultar de processo metassomático ferro-potássico. Ressalte-se que a flogopita dos glimmeritos tem idade $\mathrm{Ar}-\mathrm{Ar}$ em torno de $2 \mathrm{Ga}$ (MAIER; BARNES, 1999).

\subsection{Geologia Local}

Os tipos litológicos cartografados na área do entorno do depósito Surubim foram Biotita Gnaisse, Calcissilicática, Formação Ferrífera, as Rochas máfico-ultramáficas, Norito, Serpentinito, Gabronorito, Anfibolito e Aluvião, descritos a seguir, de acordo com Reis et al. (2013). Estes litotipos são apresentados na Figura 3.4.

\subsubsection{Biotita gnaisse}

Rocha félsica de cor cinza-claro e que ocorre ao longo de todo o entorno do depósito Surubim. É constituída basicamente por quartzo, feldspato e biotita. As formações ferríferas e as rochas calcissilicáticas ocorrem intercaladas ao longo do bandamento gnáissico, formando uma unidade estratigráfica, a nível regional, denominada de Gnaisse Bom Despacho.

\subsubsection{Gabronorito}

Rocha esverdeada, comumente alterada e não magnética é constituída por minerais de orto e clinopiroxênio. Os gabronoritos estão situados na parte sudoeste, em relação ao depósito Surubim, intercalado nas rochas calcissilicáticas. 


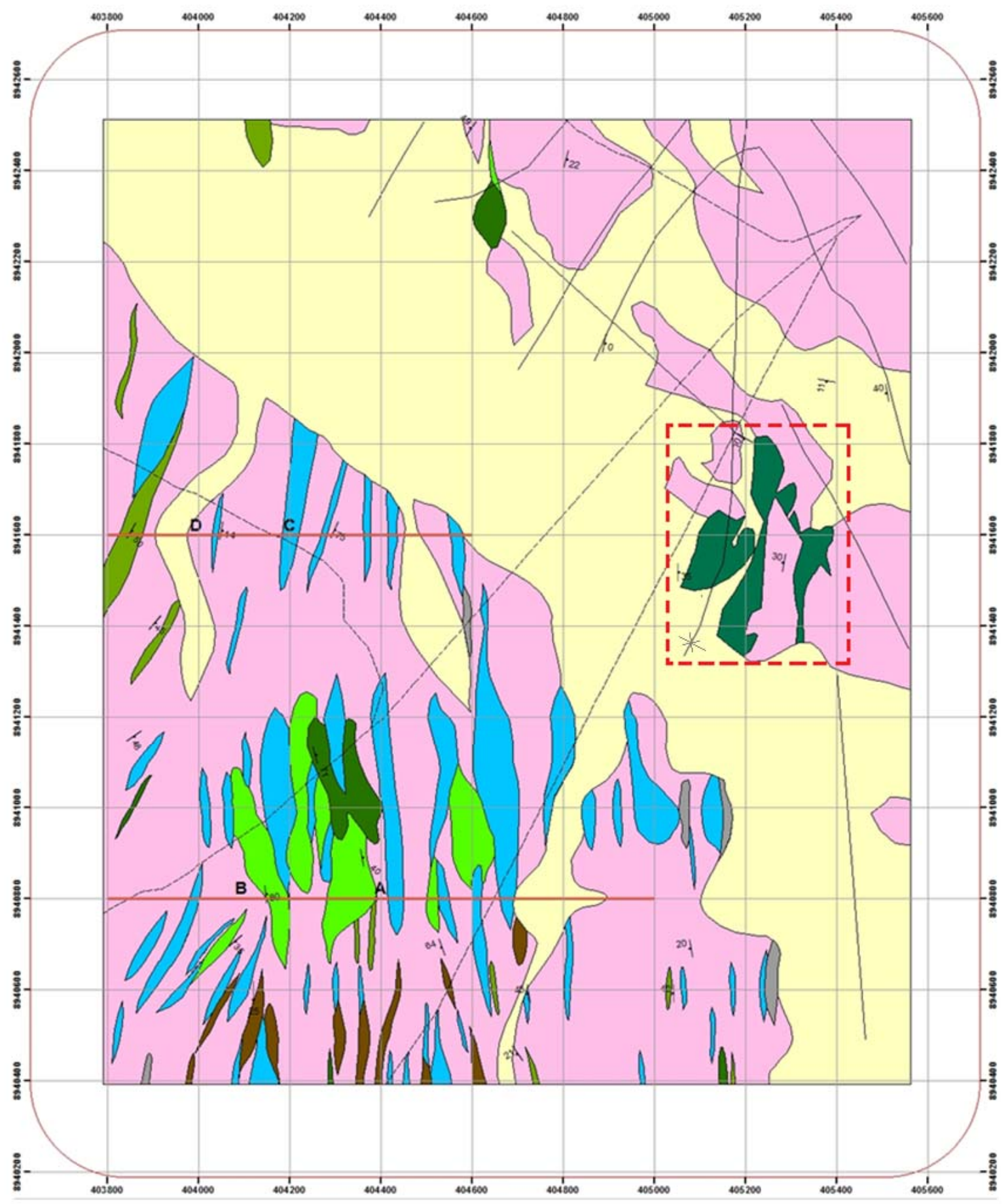

LEGENDA
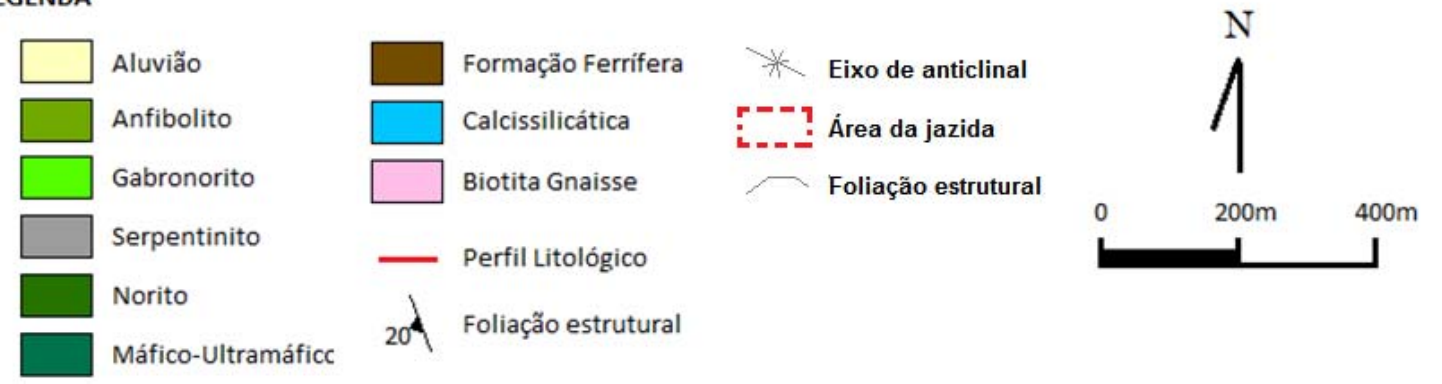

Figura 3.4 - Mapa geológico local no entorno do depósito Surubim, demarcado no quadrado pontilhado em vermelho. (Modificado de Reis et al., 2013). 


\subsubsection{Calcissilicática}

Rocha escura de cor cinza a esverdeada, granular a microgranular, disposta entre os bandamentos da biotita gnaisse e que ocorre na porção central e oeste na Figura 3.4. É constituída por plagioclásio cálcico alterado e quartzo, que aparenta estar nos interstícios da trama da rocha. Formada por diopsiditos esverdeados alterados. Seus corpos estão distribuídos de forma alongada na direção N-S.

\subsubsection{Norito}

Corpos máficos de coloração preta que, em fragmentos, apresentam formato arredondado. Constituído por ortopiroxênio, plagioclásio e biotita/flogopita, com teores subordinados de magnetita. Observados apenas na parte sudoeste e um corpo na parte norte em relação ao depósito de Surubim. É uma rocha fracamente magnética.

\subsubsection{Formação Ferrífera}

Rocha de cor marrom-escuro a avermelhado, com presença de bandamentos internos. Estes bandamentos são representados pela alternância de níveis de quartzo e níveis de óxido de ferro. Existem várias ocorrências na região a sudoeste do depósito, distribuídas de forma alongada e que ocorrem intercaladas lateralmente com as rochas calcissilicáticas.

\subsubsection{Aluvião}

Terreno tércio-quartenário localizado na beira de rios e drenagens. Constituem as planícies aluvionares comumente arenosas e constituídas por quartzo e feldspato, em menor proporção. Localiza-se em toda a região do entorno do depósito Surubim, cortando a área de noroeste a sudeste e encobrindo os litotipos situados abaixo dele. 


\subsubsection{Serpentinito}

De cor preta a esverdeada, granulometria muito fina e magnética situada na porção sudeste do entorno do depósito. Ocorre associado às rochas calcissilicáticas.

\subsubsection{Geologia Estrutural}

De acordo com Reis et al. (2013) os litotipos localizados a oeste possuem orientação NE-SW com caimento para E. Na direção leste o trend vai muda, ficando alinhado na direção N-S e NW-SE com caimento subvertical e, logo depois, para oeste evidenciado mais na porção sul da área. Camadas sub-horizontais foram mapeadas a sul da área, representadas na seção geológica A-B, Figura 3.5, como uma dobra sinforme. Provavelmente se trata do fechamento da estrutura, onde se percebe claramente o caimento das camadas no sentido da linha de charneira. Conforme a seção C-D, que fica na porção norte da Figura 3.4, as camadas rochosas possuem caimento para leste. Na seção $A-B$, as rochas a oeste da seção possuem caimento leste, e as rochas a leste da seção possuem um caimento para oeste formando uma sinforme. Esta sinforme parece ser a mesma que se estende até o nordeste do alvo onde está situada o depósito Surubim, se situando no flanco leste da estrutura.
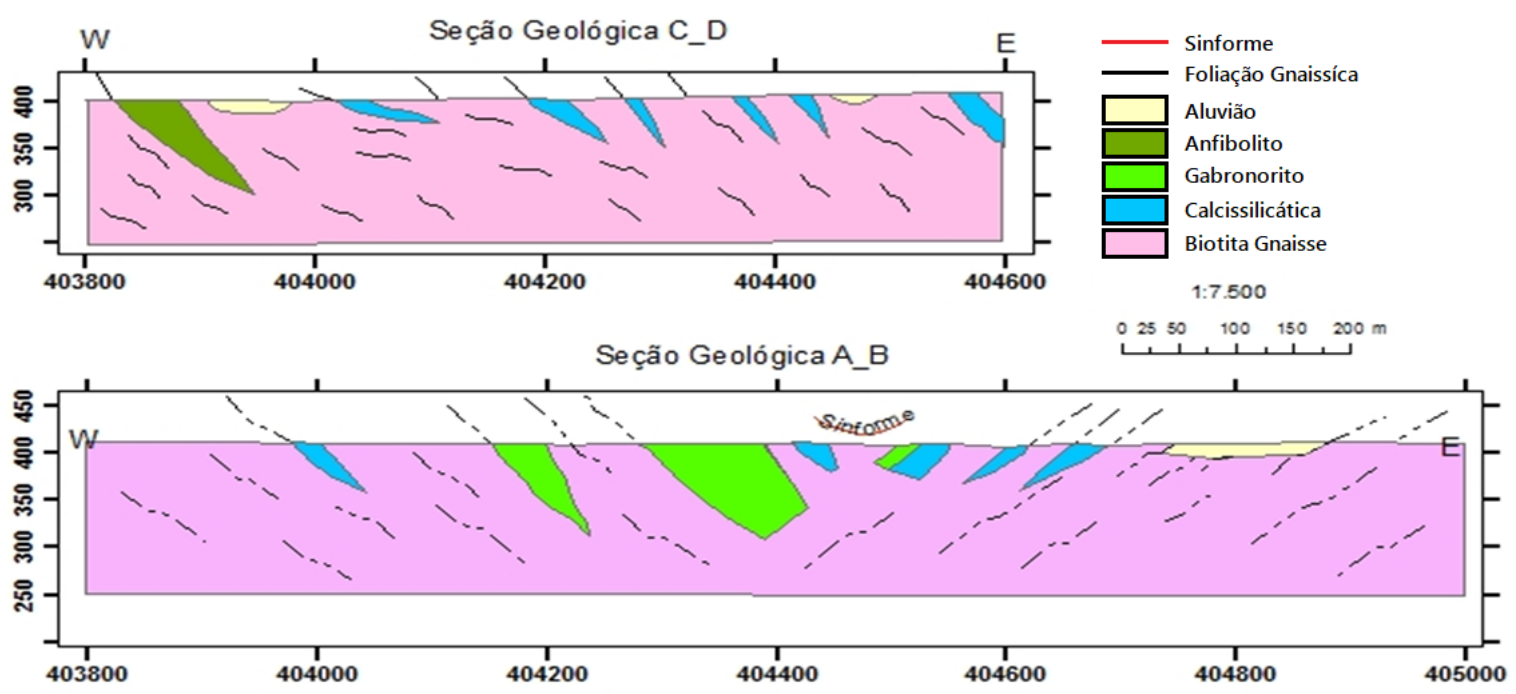

Figura 3.5 - Seções esquemáticas com a geologia no entorno do depósito Surubim. (Reis et al., 2013) 


\subsection{Geoestatística}

A geoestatística surgiu da necessidade de se estimar valores de uma variável de interesse em um ponto não amostrado a partir de amostras próximas. Nas décadas de 50 e 60 o engenheiro de minas sul africano Daniel Gerhardus Krige, percebendo a necessidade de conhecer previamente os teores de ouro que iria lavrar, desenvolveu os primeiros esboços de um método de estimativa linear que considerava a correlação espacial entre amostras. Futuramente este método seria formalizado por Matheron em Traité de géostatistique appliquée (MATHERON, 1963), onde as ferramentas básicas da geoestatística são definidas: a variografia, a estimativa e dispersão da variância e a própria krigagem, nome dado em homenagem ao engenheiro sulafricano.

Com o avanço dos recursos computacionais e com a difusão de seus usos e aplicações, a geoestatística se prolifera ao redor do mundo e em diversas áreas do conhecimento. Dados que tenham relação espacial ou temporal passam a ser tratados utilizando-se os conceitos das variáveis regionalizadas.

As definições de geoestatística são variadas, mas sempre se baseiam na análise de correlação espacial entre variáveis distribuídas no espaço ou tempo.

Segundo Yamamoto e Landim (2013), a geoestatística tem por objetivo a caracterização espacial de uma variável de interesse por meio do estudo de sua distribuição e variabilidade espacial, com determinação das incertezas associadas. Chilès e Delfiner (2012) afirmam que a geoestatística tem como objetivo prover uma quantificação das variáveis naturais distribuídas no espaço ou no espaço e tempo. Esta definição também é proposta por Olea (1991). Para Deutsch (2011), a geoestatística permite uma abordagem probabilística para a predição espacial. 
Em outras palavras a geoestatística analisa a relação espacial entre amostras, reconhecendo sua localização espacial e, desta forma, quantificando as similaridades entre estas.

Diversos métodos e técnicas da estatística e conceitos da geoestatística foram utilizados neste trabalho, os itens a seguir irão abordar os conceitos dos principais a serem utilizados.

\subsubsection{Variável Regionalizada e Função Aleatória}

O termo variáveis regionalizadas, definido por Matheron (1963, 1965), foi empregado para definir uma função numérica $Z(x)$ que depende de sua posição $x$ e apresenta um aspecto aleatório, que reflete as irregularidades locais em pequena escala e um aspecto estruturado, que reflete as tendência em escalas maiores.

Para a autora Armstrong (1998), os modelos estatísticos comuns, incluindo as superfícies de tendência, colocam toda a aleatoriedade dentro do termo de erro, enquanto toda a estruturação é colocada no termo determinístico, o que não condiz com a natureza dos dados geológicos. A melhor forma de lidar com este problema, segundo a autora, é acrescentar a aleatoriedade como flutuações ao redor de uma superfície fixa, que Matheron (1969) definiu como drift e que pode ser definida pela Equação 3.1, denominada por ele de modelo universal de variação espacial

$$
Z(x)=m(x)+\varepsilon^{\prime}(x)+\varepsilon^{\prime \prime}
$$

onde $\mathrm{m}(\mathrm{x})$ é referente à natureza estruturada da variável e portanto determinística, $\varepsilon^{\prime}(x)$ é a parte estocástica da natureza do dado e $\varepsilon^{\prime \prime}$ é o ruído referente à ruídos e erro que não podem ser previstos durante os estudos dada a atual escala de trabalho e dados disponíveis. A Figura 3.6 mostra uma ilustração deste conceito. 


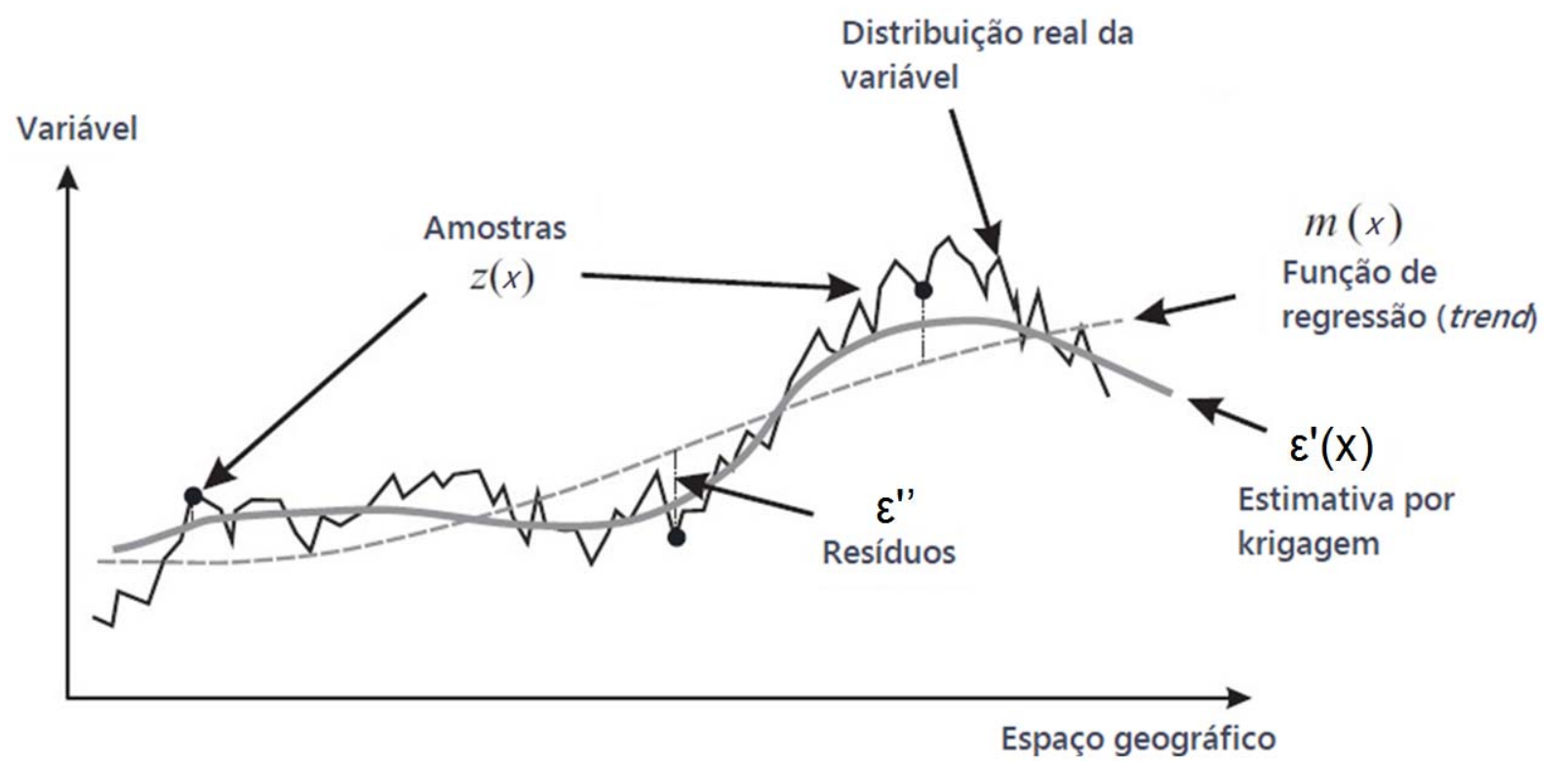

Figura 3.6 - Exemplo esquemático do modelo universal de variação espacial (modificado de Hengl, 2009)

Segundo Yamamoto e Landim (2013) o formalismo geoestatístico é baseado no conceito da dependência espacial e no entendimento de que cada ponto no espaço não apresenta um único valor, mas sim uma distribuição de probabilidade de ocorrência de valores. Desta forma, de acordo com Journel e Rossi (1989), a variável aleatória $Z$ é uma variável que pode assumir uma série de realizações $\left(z_{i}, i=1, \ldots, N\right)$ com uma dada probabilidade de ocorrência $\left(p_{i}, i=1, \ldots, N\right)$.

O conjunto das variáveis aleatórias constitui uma função aleatória e o conjunto dos valores reais de $\mathbf{Z}(\mathbf{x})$, que inclui a realização da função aleatória, é conhecido como variável regionalizada. Este conceito é bem diferente do tradicional, que considera cada observação pontual como o resultado independente de uma variável casual. Uma variável regionalizada é entendida, porém, como uma única realização de uma função casual, possuindo dependência espacial ou temporal. Desse modo, seu entendimento pode descrever melhor o padrão espacial do fenômeno em estudo (YAMAMOTO; LANDIM, 2013). 


\subsubsection{Análise Estatística}

A análise estatística dos dados é uma etapa fundamental antes do início dos tratamentos e modelagem destes. A verificação da consistência e qualidade dos dados é essencial para que se haja confiança nos resultados obtidos.

Segundo Sinclair e Blackwell (2004), os objetivos da análise inicial dos dados são principalmente: 1) reconhecer e corrigir erros; 2) compreender a estatística e características espaciais de todas as variáveis de interesse; 3) documentar e compreender as relações entre as variáveis de interesse; 4) reconhecer qualquer variação espacial sistemática; 5) reconhecer e definir distintos domínios geológicos que necessitem ser avaliados separadamente; 6) identificar e compreender valores anômalos; e 7) avaliar similaridades/dissimilaridades dos dados entre si a partir da malha de amostragem.

Os itens descritos a seguir se referem às medidas de estatística descritiva que foram utilizadas neste trabalho, tanto na etapa de modelagem quanto na validação e análise dos resultados, sendo utilizadas medidas de tendência central e de dispersão.

\subsubsection{Estatística descritiva}

Medidas de tendência central são essenciais para a avaliação do comportamento de um conjunto de dados. A média, ou esperança, é a medida mais utilizada para cálculo de tendência central e descreve o valor central a partir do qual os dados se dispersam. Em uma distribuição de probabilidades, a esperança de determinada variável aleatória é calculada como:

$$
E[X]=\sum_{i=1}^{n} x_{i} p\left(x_{i}\right)=\frac{1}{n} \sum_{i=1}^{n} x_{i}
$$


sendo $n$ o número de amostras analisadas, $x_{i}$ o iésimo termo da amostra e $p\left(x_{i}\right)$ a probabilidade de ocorrência do iésimo termo da amostra.

Dada a característica discreta da variável domínio geológico, o resultado mais provável da simulação sequencial indicadora será obtido a partir da moda de todas as realizações em cada bloco. A moda nada mais é do que a definição do valor mais frequente em uma distribuição de dados quando os dados são discretos, ou a média de um intervalo de maior frequência, quando os dados são contínuos.

Para cálculo das medidas de incerteza para cada domínio e para cada realização será calculada a variância dos volumes obtidos a partir das $L$ realizações. A variância mede quanto os dados se dispersam em relação à sua média, e é definida como:

$$
\operatorname{Var}[X]=\frac{1}{n-1} \sum_{i=1}^{n}\left(x_{i}-\bar{x}\right)^{2}
$$

em que $\bar{x}$ é a média das amostras.

Uma das propriedades associadas à variância, segundo Fonseca e Martins (1982), é a de que a variância de uma variável aleatória multiplicada por uma constante é igual à variância da variável aleatória multiplicada pelo quadrado dessa constante, segundo a Equação:

$$
\operatorname{Var}[K X]=K^{2} \operatorname{Var}[X]
$$

Esta equação permite transferir a variância de variáveis aleatórias para variáveis com magnitudes distintas relativas a uma constante $\mathrm{K}$. 
Um dos métodos utilizados para a análise de variabilidade de depósitos minerais é o coeficiente de variação. O coeficiente de variação $(C V)$ é dado pela razão entre o desvio padrão e a média das amostras, conforme segue:

$$
C V=\frac{s}{\bar{x}}
$$

em que $\bar{x}$ é a média da variável de interesse no depósito e $s$ é o desvio padrão da média. O coeficiente de variação reflete a dispersão geral da variável de interesse no depósito (teor, espessura, densidade etc.) (YAMAMOTO; ROCHA, 2001).

Foram utilizados métodos gráficos para o suporte desta atividade, como a apresentação e análise de histogramas, boxplots e função de distribuição acumulada.

\subsubsection{Função Indicadora}

Variáveis aleatórias podem ser basicamente de dois tipos, contínua e discreta. Segundo Yamamoto e Landim (2013), a variável regionalizada pode ser definida a partir de uma função de distribuição de probabilidades. Quando a variável aleatória é do tipo discreta, ou categórica, podendo receber qualquer realização de K (sendo $\mathrm{k}=1, \ldots, \mathrm{K})$, a seguinte notação é utilizada:

$$
F(x ; k \mid(n))=\operatorname{Prob}\{Z(x)=k \mid(n)\}
$$

Para que seja possível o manuseio e interpolação de variáveis categóricas nas técnicas geoestatísticas, é necessário que as variáveis sejam transformadas em variáveis indicadoras, de acordo com a seguinte equação, segundo Soares (2006),

$$
I(x, k)=\left\{\begin{array}{l}
0, \text { se } Z(s) \neq \text { tipo } k \\
1, \text { se } Z(s)=\text { tipo } k
\end{array}\right.
$$

Este tipo de variável é mutuamente exclusiva, como discutido por Journel e Hüijbregts (1978), pois quando a variável categórica K toma para sim um valor de k, esta variável receberá o valor um e todas as outras receberão valor zero. 
De acordo com Yamamoto et al. (2014) a média de uma variável indicadora pode ser escrita como:

$$
E[I(x ; k)]=\frac{f k}{N}=p_{k}
$$

em que pké a proporção do tipo $\mathrm{k} \mathrm{e} \mathrm{N}=\sum_{k} f_{k}$ é a totalidade do domínio.

A média, portanto, é a proporção de determinada variável no domínio.

Uma variável indicadora pode assumir apenas dois valores, zero ou um, indicando ausência ou presença, respectivamente. Isto a caracteriza, portanto, como uma distribuição de Bernoulli (KADER; PERRY, 2007) e desta forma tem sua variância calculada como a probabilidade de ocorrência de determinada categoria multiplicada pela probabilidade de não ocorrência desta categoria, como segue na equação a seguir:

$$
\operatorname{Var}[I(x ; k)]=p_{k}\left(1-p_{k}\right)
$$

A Tabela 3.1, contém um exemplo de como ficaria um conjunto de dados de 10 pontos que contém, 01 ponto classificado como classe $A, 02$ pontos como classe B, 03 pontos como classe C, 01 ponto como classe D e 03 pontos como classe E. Notar que são classes mutuamente exclusivas, ou seja, a presença de uma anula a presença de outras.

Tabela 3.1 - Exemplo de codificação binária de pontos hipotéticos.

\begin{tabular}{cccccc}
\hline \multirow{2}{*}{ Ponto } & \multicolumn{5}{c}{ Classe } \\
& A & B & C & D & E \\
\hline 1 & 1 & 0 & 0 & 0 & 0 \\
2 & 0 & 1 & 0 & 0 & 0 \\
3 & 0 & 1 & 0 & 0 & 0 \\
4 & 0 & 0 & 1 & 0 & 0 \\
5 & 0 & 0 & 1 & 0 & 0 \\
6 & 0 & 0 & 1 & 0 & 0 \\
7 & 0 & 0 & 0 & 1 & 0 \\
8 & 0 & 0 & 0 & 0 & 1 \\
9 & 0 & 0 & 0 & 0 & 1 \\
10 & 0 & 0 & 0 & 0 & 1 \\
\hline Proporção & 0,10 & 0,20 & 0,30 & 0,10 & 0,30 \\
Variância & 0,09 & 0,16 & 0,21 & 0,09 & 0,21 \\
\hline
\end{tabular}




\subsection{Interpolação multiquádrica}

Um método amplamente utilizado para a interpolação de variáveis categóricas é a krigagem de indicadoras, que tem como vantagem a capacidade de trabalhar com dados de natureza qualitativa, mas apresenta como desvantagem a necessidade de se modelar K variogramas (LEUANGTHONG et al., 2008), sendo $\mathrm{K}$ igual ao número de categorias definidas na modelagem. Esta desvantagem dificulta a execução da interpolação por krigagem uma vez que a modelagem dos variogramas fica comprometida pelo número de variogramas e pela proporção de cada categoria, que reflete na variabilidade entre os pontos. Yamamoto et al. (2012) propuseram, então, utilizar as equações multiquádricas apresentadas em Hardy (1971) para a interpolação de pontos não amostrados. Desta forma, a construção da função de distribuição acumulada condicional para cada nó não amostrado não será dada a partir da krigagem indicadora mas sim pelo uso de equações multiquádricas.

Volumes de domínios são obtidos através da modelagem dos contatos geológicos destes domínios ou pela interpolação de pontos em uma malha tridimensional, que representam centroides de voxels. Técnicas de modelagem de superfície são estudadas desde a década de 70 , sendo as equações multiquádricas uma destas técnicas de interpolação. A metodologia aqui utilizada será a metodologia proposta por Hardy (1971), que foi aperfeiçoada para interpolações locais e generalizadas como funções da base radial por diversos autores (BUHMANN, 2000; WANG; LIU, 2002; YAMAMOTO, 2002).

Segundo Silva (2010), a reconstrução de uma superfície de um conjunto de dados é simples no conceito, mas complicada quando analisada em detalhe. Uma vez que o mundo real é constituído por superfícies contínuas, e não por dados discretos, busca-se sempre criar uma superfície contínua utilizando esses mesmos dados. Os 
métodos sem malha, tais como as funções de base radial, têm possibilitado progressos notáveis nesta área. A reconstrução de superfícies ou estimativa de dados é um problema de interpolação ou aproximação, e consiste na construção de uma função contínua de duas ou mais variáveis independentes que estima os valores de dados conhecidos em quaisquer pontos.

Alfield (1989) mostrou que as aplicações de problemas de aproximação que utilizam dados, dispostos uniformemente ou não, são um dos problemas fundamentais da teoria de aproximação e modelagem em geral. A utilização de funções de base radial permite que tais questões sejam abordadas conjuntamente, de forma simples e de fácil implementação. As funções de base radial têm a seguinte forma em duas dimensões:

$$
Z^{*}\left(x_{0}\right)=\sum_{i=1}^{n} \alpha_{i} \varphi\left(\left\|x_{i}-x_{0}\right\|\right)
$$

onde $\alpha_{i}$ são os coeficientes da função de base radial, $x_{i}$ são os pontos de controle ou amostras, $\left\|x_{i}-x_{0}\right\|$ é a norma euclidiana entre os pontos $x_{i}$ e $x_{0}$ e $\varphi$ a função de base radial. Os coeficientes $\alpha_{i}$ são escolhidos de forma que as condições de aproximação sejam satisfeitas. Estas, são ajustadas segundo a resolução de um sistema de equações lineares, (YAMAMOTO; LANDIM, 2013):

$$
\left[\begin{array}{ccc}
q_{11} & \cdots & q_{1 n} \\
\vdots & \ddots & \vdots \\
q_{n 1} & \cdots & q_{n n}
\end{array}\right] \cdot\left[\begin{array}{c}
\alpha_{1} \\
\vdots \\
\alpha_{n}
\end{array}\right]=\left[\begin{array}{c}
Z\left(x_{1}\right) \\
\vdots \\
Z\left(x_{n}\right)
\end{array}\right]
$$

em que $\left.q_{i j}=\left[\left(x_{i}-x_{j}\right)^{2}+\left(y_{i}-y_{j}\right)^{2}\right]+C^{2}\right]^{1 / 2}$

A função $\varphi$ é univariada e radialmente simétrica com respeito à norma, no sentido que tem simetria em $\mathbb{R}^{n}$ (ALFIELD,1989). Segundo Yamamoto (2002) as funções de base radial mais utilizadas são apresentadas na Tabela 3.2. 
Tabela 3.2 - Funções de base radial mais utilizadas

\begin{tabular}{ll}
\hline Tipo & Função \\
\hline Linear & $\varphi(x)=|x|$ \\
Cúbica & $\varphi(x)=|x|^{3}$ \\
Multiquádrica generalizada & $\varphi(x)=\left(c+|x|^{2}\right)^{(2 k+1) / 2}$ para $k=-1,0, \ldots$ \\
Splines & $\varphi(x)=|x|^{2} \log |x|$ \\
Gaussiana & $\varphi(x)=\exp \left(-c|x|^{2}\right)$ \\
\hline
\end{tabular}

Yamamoto (2002) demonstrou que a Equação 3.10, pode ser reescrita, considerando-se todas as condições de restrição impostas, como:

$$
Z^{*}\left(x_{0}\right)=\sum_{i=1}^{n} W_{i} Z\left(x_{i}\right)
$$

em que $W_{i}$ da i-ésima amostra e $Z\left(x_{i}\right)$ é a amostra no ponto $x_{i}$.

Considerando-se a Equação 3.7 que transforma os dados para uma função indicadora, a equação ainda pode ser escrita, segundo Yamamoto et al. (2012), através da seguinte função:

$$
I^{*}\left(x_{0} ; k\right)=\sum_{i=1}^{n} w_{i} I\left(x_{i} ; k\right)
$$

com a condição de restrição de $\sum_{i=1}^{n} w_{i}=1$.

Ainda segundo Yamamoto et al. (2012) os pesos da Equação 3.13 são calculados a partir da solução do seguinte sistema de equações lineares:

$$
\left\{\begin{array}{l}
\sum_{j=1}^{n} w_{j} \varphi\left(x_{j}-x_{i}\right)+\mu=\varphi\left(x_{0}-x_{i}\right) \text { para } i=1, n \\
\sum_{j=1}^{n} w_{j}=1
\end{array}\right.
$$

em que $\mu$ é o parâmetro adicional para incluir-se a condição de não viés no sistema de equações multiquádricas. 
A variância para a interpolação obtida na Equação 3.13 pode ser obtida a partir da seguinte equação (YAMAMOTO et al., 2012):

$$
S_{0}^{2}\left(x_{0} ; k\right)=\sum_{i=1}^{n} w_{i}\left[i\left(x_{i} ; k\right)-i_{M Q}^{*}\left(x_{0} ; k\right)\right]^{2}
$$

em que $i$ é a iésima indicadora no ponto $x_{i}$ e $i_{M Q}^{*}$ é a indicadora interpolada no ponto $x_{0}$. A função radial usada neste trabalho será a multiquádrica generalizada para $\mathrm{k}=0$ :

$$
\varphi(x)=\sqrt{|x|^{2}+C}
$$

em que $|x|$ é a norma de um vetor em $\mathbb{R}^{n}$ e $C$ uma constante positiva. Esta constante é conhecida como um parâmetro de forma e a acurácia da interpolação multiquádrica depende desta (BAYONA et al., 2011).

Assim como na krigagem de indicadoras, em cada ponto interpolado as equações multiquádricas retornarão a probabilidade de ocorrência de determinada categoria. A categoria mais provável no ponto xo será portanto aquela que apresentar o maior valor de probabilidade de ocorrência como definido em Teng e Koike (2007):

$$
I^{*}\left(x_{0} ; k_{\max }\right)=\max \left(I^{*}\left(x_{0} ; k\right), k=1, \ldots, K\right)
$$

e paralelamente a variância associada a litologia mais provável neste ponto será:

$$
S_{0}^{2}\left(x_{0} ; k_{\max }\right)=I^{*}\left(x_{0} ; k_{\max }\right)\left(1-I^{*}\left(x_{0} ; k_{\max }\right)\right)
$$




\subsection{Modelagem Geológica}

A base para praticamente todo cálculo de recursos e reservas minerais é o modelo geológico aplicado para a mineralização em questão. Recursos são ativos que estão abaixo da superfície e, desta forma, invisíveis. Suas características de forma, qualidade e quantidade exata são desconhecidas. A exploração geológica tem como objetivo determinar todas estas incertezas (SINCLAIR; BLACKWELL, 2004).

No início de todo projeto, informações topográficas e litológicas são coletadas, e um banco de dados com estas amostras é gerado. Profundidade, espessura, mudança de teores, estruturas sobrepostas, volume de mineralização, forma e extensões são determinadas por várias abordagens matemáticas a partir deste banco de dados. Todas as estimativas numéricas e visuais auxiliam na determinação de um modelo geológico (SINGER; MENZIE, 2010).

Devido ao elevado custo da obtenção de tais amostras e da impossibilidade de se conhecer a população como um todo, amostragens sistemáticas são necessárias para que se otimize a verificação da realidade em determinados pontos.

Segundo Rossi e Deutsch (2014), um importante passo para a modelagem geológica é definir as variáveis geológicas mais importantes e significativas em relação à mineralização, para que possam ser interpretadas e modeladas.

As variáveis obtidas na modelagem são aplicadas em voxels, que podem ser blocos, sendo estes a discretização das unidades de volume presentes no depósito.

De acordo com Deutsch (2002), existem três formas de se realizar a modelagem geológica tridimensional: (1) modelagem geoestatística baseada em células; (2) modelagem estocástica baseada em objetos; e (3) modelagem determinística. Ainda de acordo com este autor, o método de modelagem geoestatística baseada em células se justifica quando se tem um grande número de informações. 


\subsection{Simulação Estocástica}

A principal ferramenta para se realizar a análise e modelagem da incerteza relacionada a variáveis discretas é a simulação estocástica, segundo Deutsch (2011). Os modelos booleanos de geometria estocástica são processos probabilísticos para a distribuição de variáveis no espaço, desta forma não são considerados como fenômenos determinísticos. Os modelos booleanos de aplicação mais promissora às geociências são os modelos de objetos discretos, pois nestes modelos é adotada uma forma geométrica passível de ser parametrizada, em que cada locação a ser interpolada poderá ser ocupada por apenas uma variável discreta, litologia, tipo de mineralização, etc (POLETTO, 1996).

Simulações geoestatísticas nada mais são do que uma extensão espacial dos conceitos da simulação de Monte Carlo. Além de reproduzir o histograma dos dados, as simulações geoestatísticas também honram a variabilidade espacial, usualmente caracterizada por um modelo de variograma. Se a simulação honra os próprios dados utilizados na simulação, então ela é chamada de simulação condicional. O resultado gerado é uma série de imagens, ou realizações, em oposição às estimativas que têm como saída apenas um resultado. Estas realizações apresentam uma amplitude de plausíveis possibilidades sobre a distribuição espacial da variável analisada, e que são consistentes com o seu momento estatístico, variograma e histograma e, no caso das simulações condicionais, também aos próprios dados. É importante salientar que as simulações têm objetivos distintos aos das estimativas. Um dos objetivos é caracterizar e reproduzir a variância dos dados de entrada. Simulações providenciam apropriados meios para estudar problemas relacionados à variabilidade de uma forma que as estimativas não conseguem lidar (VANN et al., 2002). 
A krigagem indicadora possui diversas limitações práticas que tornam inviável a interpolação de variáveis categóricas, e a variância resultante não representa a incerteza, uma vez que ela é apenas um índice de configuração espacial dos pontos vizinhos próximos (JOURNEL; ROSSI, 1989). As vantagens da simulação estocástica de indicadoras em relação à krigagem indicadora foram definidas por Chambers et al. (2000) e são a possibilidade de: (1) reconhecimento da heterogeneidade; simulação de domínios, litologias, características das rochas ou todos; (3) integração de informações complexas; e (4) quantificação da incerteza.

Ainda segundo Chambers et al. (2000) a captura da heterogeneidade (1) se reflete em diversos modelos que permitem um melhor entendimento da relação entre diferentes zonas mineralizadas. Já a simulação de domínios e características categóricas das rochas (2) é uma importante vantagem deste processo, uma vez que estas informações podem ser agregadas ao modelo final, que represente não apenas variáveis contínuas, mas também as variáveis categóricas mais prováveis. O respeito a dados secundários (3) é outra característica importante de métodos estocásticos, já que podem ser facilmente incorporados na simulação onde não existirem dados primários disponíveis. Por fim (4) um dos mais importantes fatores quando se opta pela realização de simulação é a possibilidade da realização de diversos cenários equiprováveis. A presença de diversos cenários torna a análise volumétrica mais segura, uma vez que é possível analisar o melhor e o pior cenário, bem como todos os cenários intermediários e identificar regiões com baixa e alta confiança. A análise conjunta destes cenários contém importante informação, da qual podem ser retiradas a média, o desvio padrão e consequentemente as incertezas das realizações. A Figura 3.7 contém um exemplo de aplicação do cálculo de diferentes cenários para a quantificação de volume de uma determinada mineralização. 


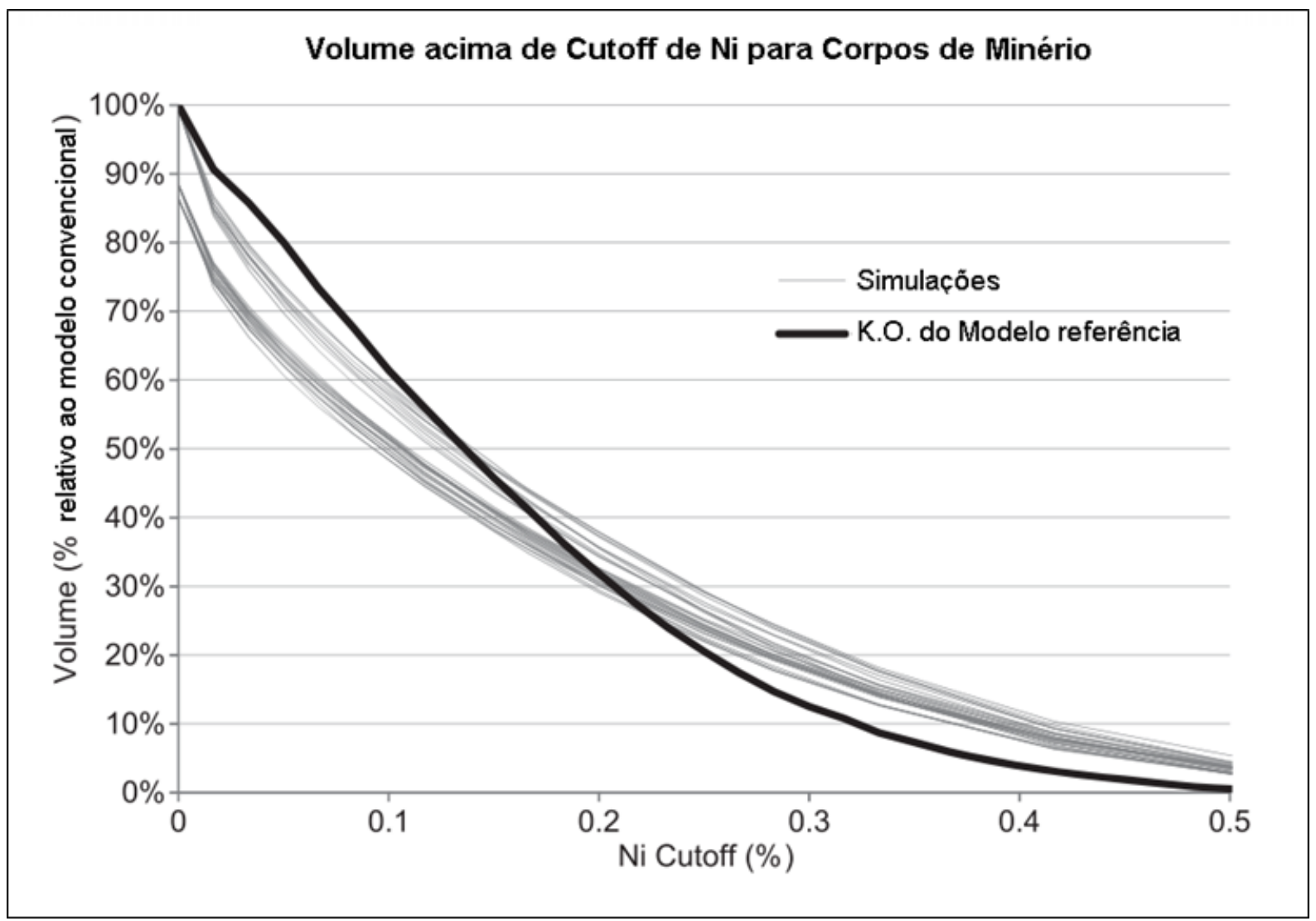

Figura 3.7 - Curvas de volume de mineralização acima de cutoff em simulação de diversos cenários equiprováveis. (Adaptado de Goodfellow et al., 2012).

Os modelos estocásticos podem ser divididos em dois grupos, modelos contínuos e discretos, segundo Damsleth et al. (1990). Os modelos contínuos são baseados em fenômenos que variam continuamente, dentro desta categoria podem ser incluídos, por exemplo, dados de teor e de densidade.

Os modelos discretos são aqueles baseados em informações categóricas, que precisam ser transformadas para que possam ser analisadas quanto à sua probabilidade de ocorrência. As transformações podem ser realizadas tanto em dados contínuos, com a definição de limiares, quanto em variáveis discretas, com a definição de inclusão. Este último tipo de transformação, para variável discreta, é mutuamente exclusivo, ou seja, um ponto no espaço pertence única e exclusivamente a um tipo de categoria, e a simulação estocástica definirá a probabilidade de ocorrência de 
determinada categoria em um ponto não amostrado. Exemplo de variáveis discretas, foco deste trabalho, são as descrições litológicas, tipo de mineralização, zonas alteradas e domínios litológicos.

Segundo Deutsch (2002), a simulação sequencial gaussiana é o método mais utilizado para modelagem devido à sua simplicidade, facilidade de manuseio e eficiência satisfatória. Dentre os métodos de simulação sequencial estão inclusos diversas formas de simulação, tais como a simulação sequencial indicadora (DEUTSCH; JOURNEL, 1998) e a simulação sequencial direta (SOARES, 2001).

\subsubsection{Métodos sequenciais de simulação}

Dentro do universo do uso de simulações os métodos sequenciais são os mais utilizados, como mencionado anteriormente, devido à facilidade de aplicação.

Segundo Deutsch e Journel (1992), seja $n$ uma distribuição de variáveis aleatórias, que pode ser representada por: nós de uma malha densa em que $Z_{i}$ é sua variável; atributos medidos em uma mesma localização; ou uma representação de diferentes atributos destes nós. Segundo Goovaerts (1997), a simulação sequencial nada mais é do que a geração das diversas possibilidades desta variável $Z_{i}$, nas $n$ localidades condicionadas às amostras:

$$
\left[\left\{z^{l}\left(x_{j}\right), j=1, N\right\}, l=1, L\right] \mid\left\{z\left(x_{\alpha}\right), \alpha=1, n\right\},
$$

sendo $L$ o número de realizações.

Devido ao fato de serem condicionadas, este tipo de simulação é classificado homonimamente de condicional. É importante salientar que este método sequencial, após simular um valor para determinado nó, iniciará aleatoriamente a simulação de outro ponto. Este novo ponto simulado utilizará os pontos amostrais existentes e 
também os pontos simulados previamente, gerando uma acumulação do banco de dados que alimenta a simulação (YAMAMOTO; LANDIM, 2013).

Cada nova realização atualiza a função de distribuição acumulada condicional, que pode ser resumida para $N$ variáveis como (GOOVAERTS, 1997):

$$
F_{N}\left(x_{1}, \ldots, x_{n} ; z_{1}, \ldots, z_{N} \mid(n)\right)=\operatorname{Pr}\left\{Z\left(x_{i}\right) \leq z_{i}, i=1, N \mid(n)\right\}
$$

A partir da nova função de distribuição acumulada, um valor é simulado aleatoriamente por Monte Carlo, e um novo valor do nó definido. Esta etapa é repetida até que todos os nós do domínio tenham sido simulados (YAMAMOTO; LANDIM, 2013).

\subsubsection{Simulação Sequencial Gaussiana - SSG}

A principal premissa da SSG é a de que a função de distribuição acumulada condicional local é uma distribuição normal padronizada. Se a distribuição dos dados originais, $Z(x)$, não for normal padronizada, ou até mesmo normal, é necessário uma transformação em $\mathrm{Y}(\mathrm{x})$, com uma distribuição normal padronizada. Isto pode ser feito a partir de uma associação dos percentis da distribuição acumulada de $Z(x)$ com os percentis correspondentes de uma distribuição normal padronizada. Isto é chamado de padronização ou anamorfose gaussiana e preserva a ordem das amostras. A simulação é então realizada em um espaço normalizado em que o valor aleatório da distribuição normal score é definido pontualmente a partir da seguinte equação:

$$
Y(x)=\mu_{k s}+\mathrm{r} \sigma_{k s}
$$

em que $\mu_{k s}$ é a média obtida pela krigagem simples, $\sigma_{k s}$ é a variância da krigagem simples e r é um valor aleatório em $[0,1]$. A realização é posteriormente transformada de volta para os valores originais (GOOVAERTS, 1997). 


\subsubsection{Simulação Sequencial Indicadora - SSI}

Assim como a SSG, a SSI também é um método sequencial. Este procedimento inclui todos os dados na região de vizinhança, incluindo os dados originais e os nós previamente simulados. Os métodos de simulação sequencial necessitam a interpolação prévia de uma função de distribuição em cada nó a ser simulado e é nisto que estas três técnicas sequenciais apresentadas se diferenciam.

A simulação gaussiana obtém esta função de distribuição através da média e da variância condicional da krigagem simples realizada para cada nó, a partir dos valores transformados para os escores da distribuição normal (YAMAMOTO; LANDIM, 2013).

No caso da simulação indicadora, o valor também é atribuído através de uma amostragem de Monte Carlo da função de distribuição acumulada condicional, com a diferença de que esta função é obtida através da resolução das multiquádricas. A maior vantagem da SSI é o fato de poder ser aplicada tanto a variáveis contínuas, com a aplicação de limiares, quanto a variáveis discretas, fato crucial para a escolha desta metodologia neste trabalho.

Deutsch e Journel (1992) mencionam que sua grande vantagem é atribuída ao fato de se poder avaliar diretamente as probabilidades condicionais, utilizadas pelos métodos sequenciais.

O primeiro passo para a obtenção da f.d.a.c. é a transformação dos dados em variáveis binárias. Quando as variáveis são contínuas é necessário discretiza-las em intervalos, como, por exemplo, faixas de teor. Desta forma, segundo Olea (1999), a transformação é representada da seguinte forma:

$$
\left\{\begin{array}{l}
I\left(x_{i} ; z_{k}\right)=1 \text { se } z\left(x_{i}\right) \leq z_{k} \\
I\left(x_{i} ; z_{k}\right)=0 \text { se } z\left(x_{i}\right)>z_{k}
\end{array}\right.
$$

em que $z_{k}$ é determinado teor de corte sendo $\mathrm{K}$ o conjunto de teores de corte. 
Já as variáveis categóricas são compostas por valores distribuídos em classes, e sua forma é representada da seguinte maneira:

$$
\left\{\begin{array}{l}
I\left(x_{i} ; k\right)=1 \text { se } x_{i} \in k \\
I\left(x_{i} ; k\right)=0 \text { se } x_{i} \notin k
\end{array}\right.
$$

A partir deste ponto, obtém-se $\mathrm{K}$ vetores binários que serão utilizados para a simulação dos nós a partir do método de equações multiquádricas. Deutsch (1996) e Leuangthong et al. (2008) ainda afirmam que funções indicadoras de variáveis aleatórias categóricas são mutuamente exclusivas, pois a probabilidade de que uma classe prevaleça sobre a outra é 1 ou opostamente de 0 , e são mutuamente exaustivas uma vez que: $\sum_{k}^{K} i(x ; k)=1$.

Após a codificação das variáveis em indicadoras, cada nó do domínio definido é visitado aleatoriamente $\left(x_{1}^{\prime}, x_{2}^{\prime}, \ldots, x_{n}^{\prime}\right)$. Em cada nó $\left(x_{m}^{\prime}\right)$, a partir das equações multiquádricas, será construída a função de distribuição acumulada condicional,

$$
F\left(x_{m}^{\prime} ; k \mid(n+m-1)\right)=\operatorname{Prob}\left\{z\left(x_{m}^{\prime}\right)=k \mid(n)\right\}
$$

em que $n$ são as amostras da vizinhança e $(m-1)$ os nós previamente simulados.

Após a construção da f.d.a.c. é retirado aleatoriamente um valor na distribuição, o nó receberá o valor correspondente à probabilidade do valor simulado $[0,1]$. O valor simulado anteriormente no nó $x_{m}^{\prime}, z_{S S I}^{*}\left(x_{m}^{\prime}\right)$, é adicionado ao banco de dados, que alimenta a Equação 3.26 que modelará a próxima f.d.a.c. do próximo nó, $x_{m+1}^{\prime}$. Os passos anteriores são repetidos até que todos os nós sejam visitados e simulados (JUANG, et al., 2004).

A Figura 3.8 contém o fluxograma do processo descrito. 


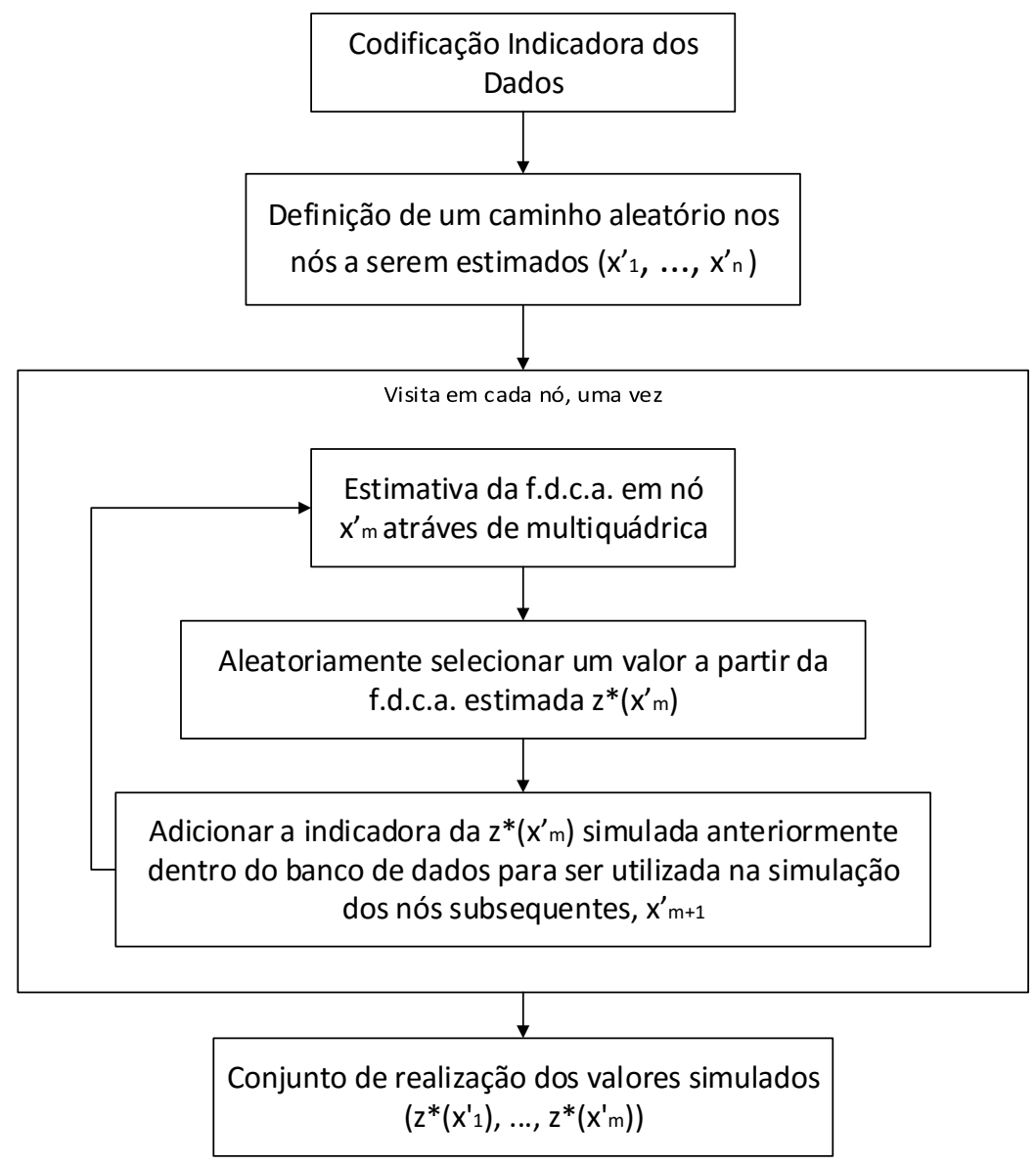

Figura 3.8 - Fluxograma para a realização da SSI (Modificado de Juang et al., 2004)

O resultado final da simulação é um conjunto de cenários equiprováveis e que podem ser utilizados para avaliar a incerteza de ocorrência de determinada categoria em um ponto. Esta análise deve ser realizada com cautela, uma vez que, segundo Deutsch (1996), a SSI para variáveis categóricas leva frequentemente a transições incontroladas e geologicamente irreais entre os tipos simulados. Se o objetivo da simulação for a reprodução de estruturas, outros métodos de simulação devem ser levados em consideração.

De qualquer forma a SSI apresenta características positivas que a fizeram ser considerada neste trabalho, tais como: estatísticas facilmente inferidas com base nos resultados amostrais; algoritmo robusto e de fácil aplicação; e transferência direta da incerteza das categóricas com base nos resultados numéricos (DEUTSCH, 1996).

A Figura 3.9 contém o passo-a-passo do uso da SSI com as multiquádricas. 
Passo 1:

Seleção aleatória de nó a ser simulado.
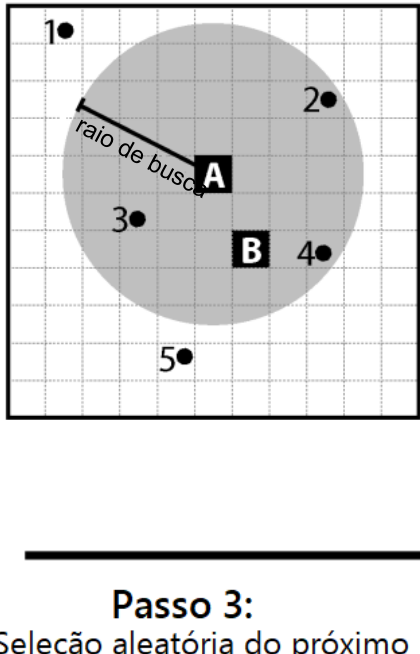

Seleção aleatória do próximo nó a ser simulado (B).

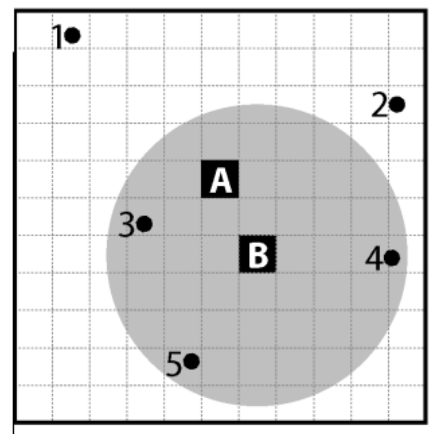

\section{Passo 2:}

03 amostras encontradas no raio de busca.

Resolução do sistema de equações multiquádricas.

$$
\left[\begin{array}{cccc}
\varphi_{22} & \varphi_{23} & \varphi_{24} & 1 \\
\varphi_{32} & \varphi_{33} & \varphi_{34} & 1 \\
\varphi_{42} & \varphi_{43} & \varphi_{44} & 1 \\
1 & 1 & 1 & 0
\end{array}\right] \cdot\left[\begin{array}{c}
w_{2} \\
w_{3} \\
w_{4} \\
\mu
\end{array}\right]=\left[\begin{array}{c}
\varphi_{A 2} \\
\varphi_{A 3} \\
\varphi_{A 4} \\
1
\end{array}\right]
$$

Como exemplo de resultado,

$i_{M Q}^{*}\left(x_{A} ; k_{1}\right)=0,346 \quad i_{M Q}^{*}\left(x_{A} ; k_{3}\right)=0,485$

$i_{M Q}^{*}\left(x_{A} ; k_{2}\right)=0,169 i_{M Q}^{*}\left(x_{A} ; k_{4}\right)=0$

Sortear um número aleatório $(0,68)$.

Obter o valor referente a probabilidade sorteada.

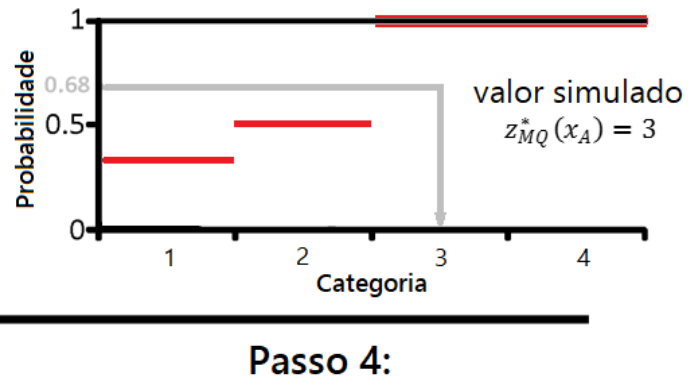

Encontrado 03 pontos e o nó previamente simulado $(A)$, dentro do raio de busca.

Resolução do sistema de equações multiquádricas.

$\left[\begin{array}{ccccc}\varphi_{33} & \varphi_{34} & \varphi_{35} & \varphi_{3 A} & 1 \\ \varphi_{43} & \varphi_{44} & \varphi_{45} & \varphi_{4 A} & 1 \\ \varphi_{53} & \varphi_{54} & \varphi_{55} & \varphi_{5 A} & 1 \\ \varphi_{A 3} & \varphi_{A 4} & \varphi_{A 5} & \varphi_{A A} & 1 \\ 1 & 1 & 1 & 1 & 0\end{array}\right]\left[\begin{array}{c}w_{3} \\ w_{4} \\ w_{5} \\ w_{A} \\ \mu\end{array}\right]=\left[\begin{array}{c}\varphi_{B 3} \\ \varphi_{B 4} \\ \varphi_{B 5} \\ \varphi_{B A} \\ 1\end{array}\right] \quad \begin{aligned} & \text { Nota: os nós previamente } \\ & \text { simulados são utilizados no } \\ & \text { cálculo de } z_{M Q}^{*}\left(x_{B}\right)\end{aligned}$

Como exemplo de resultado,

$$
\begin{array}{ll}
i_{M Q}^{*}\left(x_{B} ; k_{1}\right)=0,349 & i_{M Q}^{*}\left(x_{B} ; k_{3}\right)=0,424 \\
i_{M Q}^{*}\left(x_{B} ; k_{2}\right)=0 & i_{M Q}^{*}\left(x_{B} ; k_{4}\right)=0,227
\end{array}
$$

Sortear um número aleatório $(0,34)$.

Obter o valor referente a probabilidade sorteada.

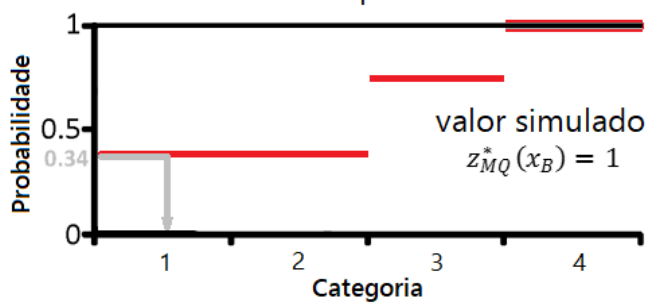

Figura 3.9 - Passos da SSI para $k$ categorias $(k=1, \ldots, 4)$, utilizando equações multiquádricas. MQ: Multiquádrica; $\mathbf{W}$ : pesos da multiquádricas; $\varphi$ : norma entre os pontos destacados; $\mu$ :variável adicional para condição de não viés. Passos 3 e 4 se repetem até que todos os nós do domínio tenham sido simulados. (Modificado de Emery, 2004) 


\subsubsection{Análise da incerteza}

Praticamente todos os dados geológicos estão sujeitos a diversas fontes de incerteza (MANN, 1993; DAVIS, 2002). Segundo Wellmann et al. (2010), entre elas, pode-se citar imprecisões nas medidas, hipóteses e conceitos incorretos, a necessidade de simplificações, heterogeneidade, limitação de amostragem, número insuficiente de amostras, aleatoriedade intrínseca ao fenômeno e muitas outras. Todos estes tipos de incerteza podem ser, de forma geral, agrupados em três categorias (COX, 1982; MANN, 1993; BÁRDOSSY; FODOR, 2001): (1) imprecisão e erro de medidas, (2) estocasticidade, e (3) conhecimento incompleto do fenômeno em estudo.

Estes três tipos de incertezas são resumidos por Wellmann et al. (2010) como:

- Tipo 1 (erro, viés e imprecisão): incerteza em todos os tipos de informação no banco de dados utilizado na modelagem, como posição do contato na sondagem ou orientação de uma estrutura;

- Tipo 2 (estocasticidade e aleatoriedade intrínseca): está normalmente presente na incerteza da interpolação (ou extrapolação) de pontos conhecidos. A Figura 3.10 contém um exemplo deste tipo de erro;

- Tipo 3 (limitação de conhecimento): aplicada ao conhecimento incompleto ou impreciso do fenômeno em estudo, ambiguidades nos conceitos gerais e na necessidade de generalização.

Este trabalho procurará quantificar as incertezas associadas ao Tipo 2 a partir das $L$ realizações da SSI. 


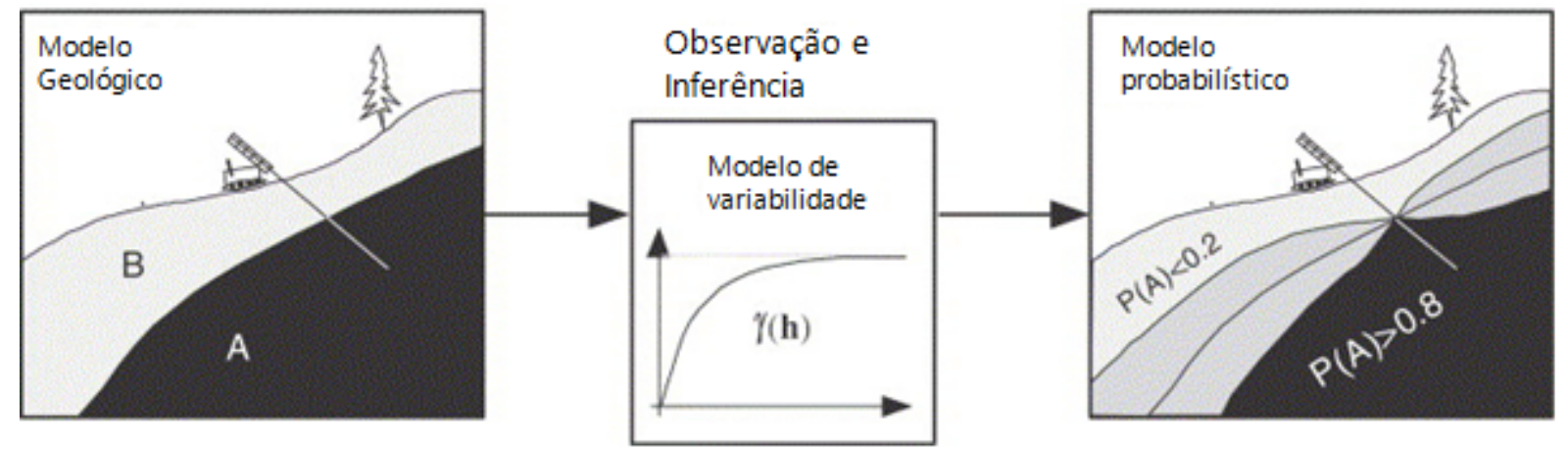

Figura 3.10 - Representação da incerteza tipo 2 e 3, à esquerda a definição de um contato entre dois domínios, A e B, a partir de uma amostra de sondagem. Dada variabilidade espacial, definida pelo variograma, a região de contato passa a ter uma probabilidade de ocorrência, imagem à direita, em que na região escura a probabilidade de ocorrência de $A$ é maior que 0,8 e na região rachurada é menor que 0,2. (POMIAN-SRZEDNICKI, 2002).

Para Yamamoto e Landim (2013), dadas $L$ realizações da simulação sequencial indicadora, são obtidas $L$ classes no conjunto $\{k=1, \ldots, K\}$ para cada célula no modelo. Se $L$ é determinado como um número ímpar então pode-se obter a classe mais provável somando-se todas as realizações:

$$
p\left(x_{0} ; k\right)=\frac{1}{L} \sum_{l=1}^{L} i^{(l)}\left(x_{0} ; k\right)
$$

A classe mais provável é associada com a máxima proporção $p\left(x_{0} ; k_{\max }\right)$ :

$$
p\left(x_{0} ; k_{\max }\right)=\max \left[p\left(x_{0} ; 1\right), p\left(x_{0} ; 2\right), \ldots, p\left(x_{0} ; K\right)\right]
$$

Cada realização $L$ terá $k$ categorias simuladas $\left(\mathrm{Z}^{*}\left(\mathrm{x}_{\mathrm{m} ; \mathrm{k}}\right), \mathrm{i}=1, \ldots, \mathrm{K}\right)$.

A discretização dos nós deste trabalho se dará da forma de voxels com volume definido. Desta forma, o volume absoluto de cada uma das $k$ categorias simuladas em cada $L$ realização poderá ter seu volume calculado a partir da seguinte equação:

$$
\{\mathrm{V}(\mathrm{k} ; \mathrm{l}), \mathrm{l}=1, \ldots, \mathrm{L}\}=\sum_{m=1}^{n} v\left(n\left(x_{m}\right)\right)
$$


em que $v$ é uma constante que representa o volume dos voxels e $n\left(x_{m}\right)$ são os nós referentes à determinada categoria $k$ no nó $x_{m}$.

Da mesma forma, cada realização $L$ terá o seu conjunto de $k$ categorias simuladas. A quantificação da esperança do volume relativo à probabilidade de ocorrência de determinada categoria $k$ é obtida então da seguinte forma:

$$
E\left[V\left(x_{0} ; k\right)\right]=\sum_{i=1}^{n} v_{i}\left(p\left(x_{0} ; k\right)\right)
$$

Segundo Myers (1997), os parâmetros de dispersão têm importante papel na gestão de erros. Eles representam o nível de incerteza associado a estimativas de diversos tipos. Quanto maior a dispersão, maior a incerteza. Esta incerteza pode ser medida através da variância, definida na Equação 3.3. Já a fórmula apresentada na Equação 3.4 pode ser utilizada para transferir a variância de uma escala de magnitude para outra.

Uma forma de análise de incerteza local é apresentada em Leonel (2015) através da comparação de gráfico de médias móveis e também será utilizada neste trabalho. 


\section{RESULTADOS}

\subsection{Validação e análise estatística dos dados}

A mineralização de cobre no depósito de Surubim ocorre em rochas ultramáficas e hidrotermais, que também contém anomalias de níquel. Estes dois elementos foram utilizados como marcadores para análise dos domínios definidos.

Esta análise consistiu basicamente no levantamento estatístico descritivo das amostras globalmente e por domínio litológico, nas variáveis contínuas para cobre e níquel e litologias como variáveis discretas.

O banco de dados é composto de 168 sondagens com 24.102 metros perfurados. A localização das sondagens utilizadas neste projeto encontra-se na Figura 4.1.
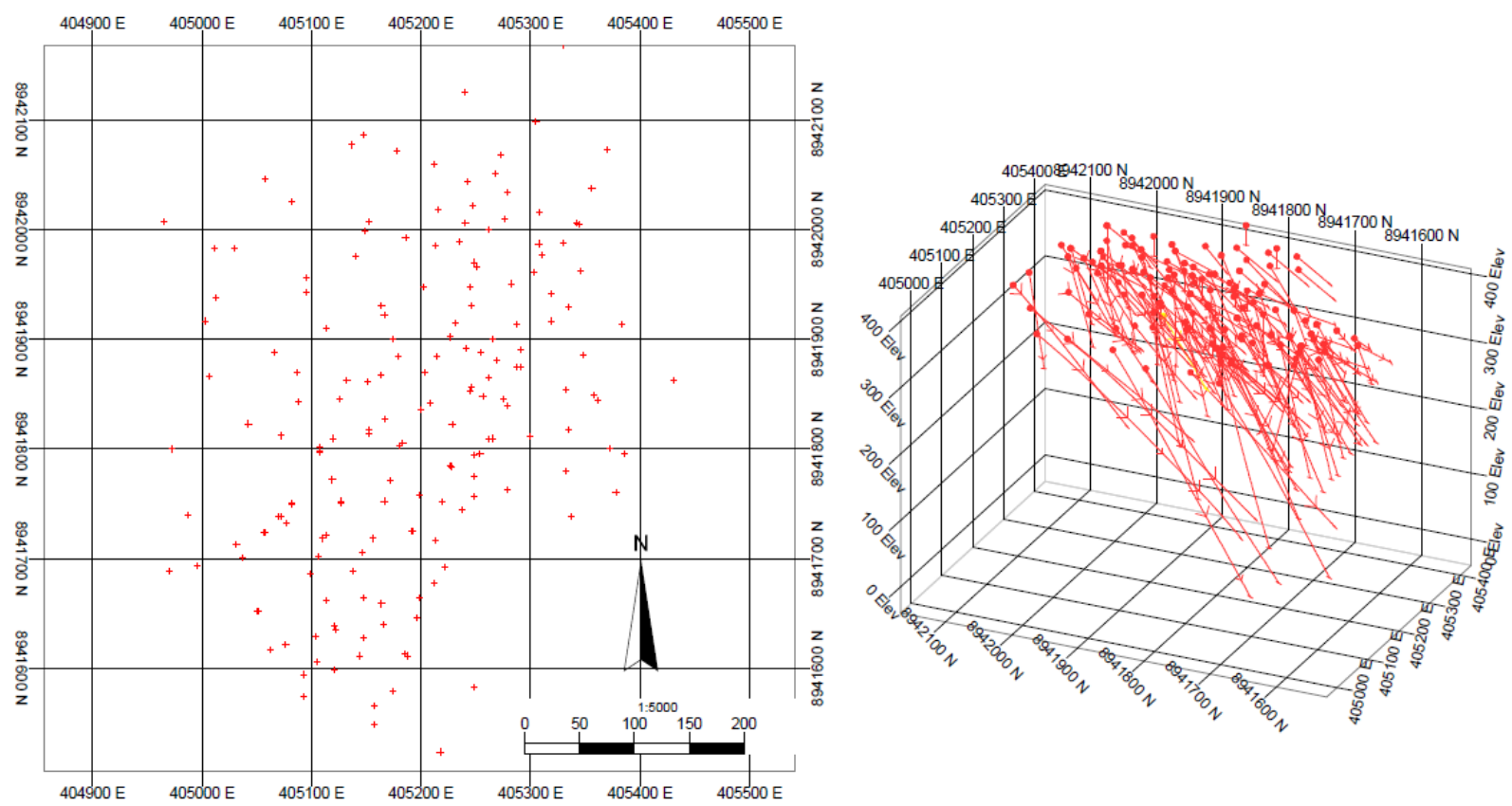

Figura 4.1 - Localização das sondagens em planta e em perspectiva. 
A malha de sondagem é composta majoritariamente por furos inclinados, com direção de perfuração para sudeste, ligeiramente perpendicular à estrutura da mineralização. A malha tem distribuição irregular e todas as sondagens foram realizadas a partir da cota topográfica.

A validação dos dados buscou identificar inconsistências de ordem geográfica, quantitativa nas análises químicas, e qualitativa nas descrições de campo. Erros de sobreposições, duplicações e inconsistências foram verificados e, se necessário, corrigidos.

Para efeito de validação da separação de diferentes domínios geológicos, foi utilizado o elemento $\mathrm{Cu}(\%)$.

As amostras possuem teor médio de $0,29 \%$ de Cu e $0,012 \%$ de Ni. A estatística descritiva global das amostras é apresentada na Tabela 4.1. Os histogramas para as variáveis $\mathrm{Cu}$ e $\mathrm{Ni}$, juntamente com os gráficos de probabilidade, são apresentados na Figura 4.2.

Tabela 4.1 - Estatística descritiva das amostras do depósito de Surubim

\begin{tabular}{ccccccccc}
\hline Varíavel & Dados & Média & Variância & Máximo & $\begin{array}{c}\text { Quartil } \\
\text { Superior }\end{array}$ & Mediana & $\begin{array}{c}\text { Quartil } \\
\text { Inferior }\end{array}$ & Mínimo \\
\hline $\mathrm{Cu}(\%)$ & 17438 & 0.290 & 0.3200 & 17.500 & 0.332 & 0.023 & 0.010 & 0 \\
$\mathrm{Ni}(\%)$ & 17432 & 0.012 & 0.0003 & 0.203 & 0.014 & 0.006 & 0.001 & 0 \\
\hline
\end{tabular}
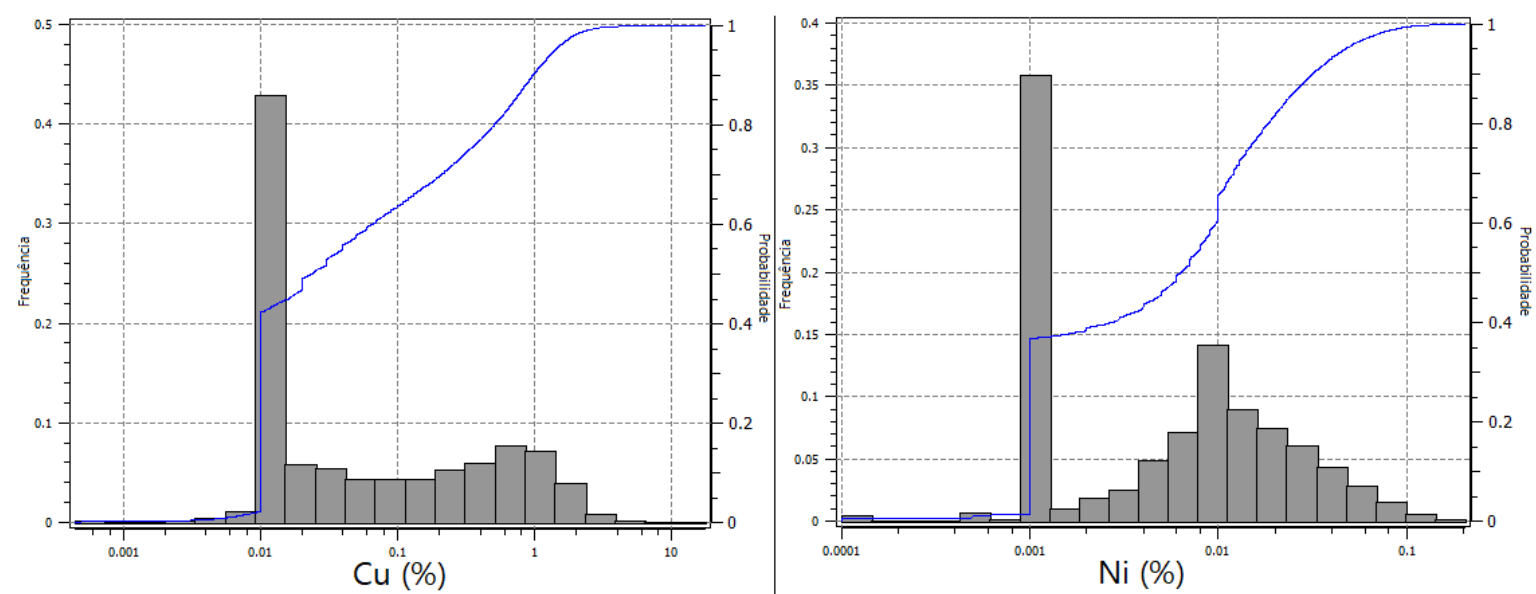

Figura 4.2 - Histogramas e gráficos P.P para as variáveis Cu e Ni de todos os domínios do depósito. 
É nítida a presença de quebras na distribuição de probabilidades nas duas variáveis. Isso se deve ao fato de haver diversas amostras com teores inferiores ao limite de detecção dos equipamentos de análise química à época das análises, equivalentes a $0,01 \%$ para $\mathrm{Cu}$ e $\mathrm{Ni}$ e $0,001 \%$ para $\mathrm{Ni}$. Inflexões de menor intensidade na curva de probabilidade podem representar misturas populacionais, fato já esperado, uma vez que elas representam todos os domínios do depósito de Surubim.

Para esta dissertação foram utilizadas 2845 amostras de descrição litológica, que foram agrupadas em domínios de acordo com sua afinidade genética-estrutural. Esta classificação reflete também em dissimilaridades nos teores de cobre e níquel uma vez que a mineralização do depósito tem forte controle estrutural e litológico.

O agrupamento inicial de litologias em domínios obteve um conjunto de 06 categorias, identificados a seguir como:

- Solo (I): Domínio das litologias intemperizadas. Incluem-se nesta categoria os litotipos descritos como solo, saprolito e rocha alterada;

- Indiferenciadas (II): Domínio de litologias pouco expressivas, tanto do ponto de vista de proporção quanto de interpretação geológica, devido à baixa continuidade. Incluem-se nesta categoria as rochas descritas como calcários calcíticos, dolomíticos, calcarenitos, grafita, pegmatóides e veios de quartzo;

- Rochas de Alteração Hidrotermal (III): Rochas de origem hidrotermal classificadas como hidrotermalitos, associadas à mineralização do depósito. Incluem-se neste domínio os litotipos biotitito, epidoto hidrotermalito, metassomatito, flogopititos e serpentinito;

- Granito-gnaisses (IV): Domínio das rochas encaixantes ácidas representadas no depósito pelos litotipos biotita gnaisse, cataclasito, 
brecha, calciossilicática, diopsidito, gnaisse gabro, gnaisse granítico, gnaisse tonalítico, granito, granada gnaisse, migmatito e milonito;

- Rochas Básica (V): Domínio das rochas encaixantes do depósito. Dentro desta classificação se encontram as rochas descritas como anfibolito, biotita gabro, gabro, gabronorito, granada norito, e norito;

- Ultramáficas (VI): Litotipo pertencente ao domínio das rochas ultramáficas que contém a mineralização no depósito, estão inclusos neste domínio os litotipos biotita norito, piroxenito e melanorito.

Os domínios definidos são mutuamente exclusivos. A Figura 4.3 contém a proporção dos domínios, no contexto das amostras descritas nos testemunhos de sondagem.

Proporção dos Domínios

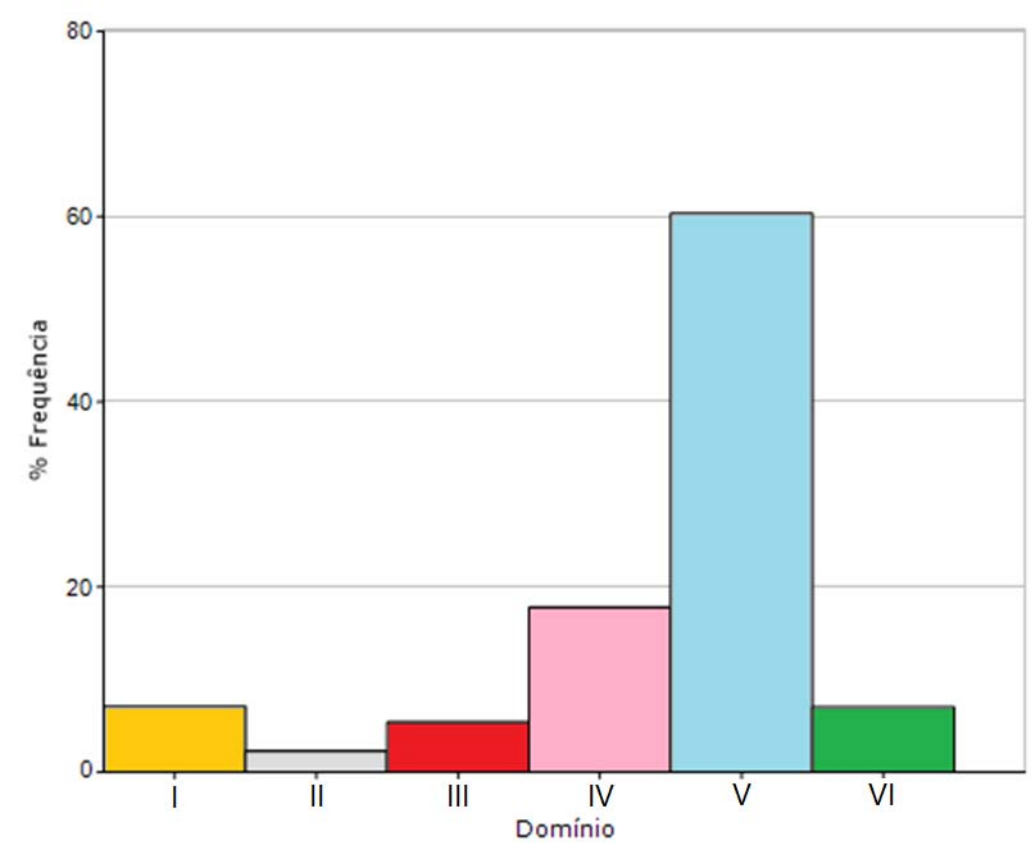

Figura 4.3 - Histograma com frequência relativa dos domínios descritos no depósito de Surubim.

A proporção das amostras para estes domínios é apresentada na Tabela 4.2. 
Tabela 4.2 - Proporção dos domínios a serem modelados e simulados.

\begin{tabular}{ccc}
\hline Domínio & Metragem & Porcentagem \\
\hline (I) & 1704.56 & 7.07 \\
(II) & 486.32 & 2.02 \\
(III) & 1268.13 & 5.26 \\
(IV) & 4276.36 & 17.74 \\
(V) & 14703.12 & 61.00 \\
(VI) & 1663.89 & 6.90 \\
\hline Total & $\mathbf{2 4 1 0 2 . 3 8}$ & $\mathbf{1 0 0}$ \\
\hline
\end{tabular}

Visando mostrar as características químicas de cada um destes domínios foi efetuada uma análise do comportamento dos teores de cobre e níquel. Esta análise avaliou a dispersão dos teores em forma de boxplots e por estatística descritiva, e é ilustrada a seguir nas Figuras 4.4 e 4.5 .

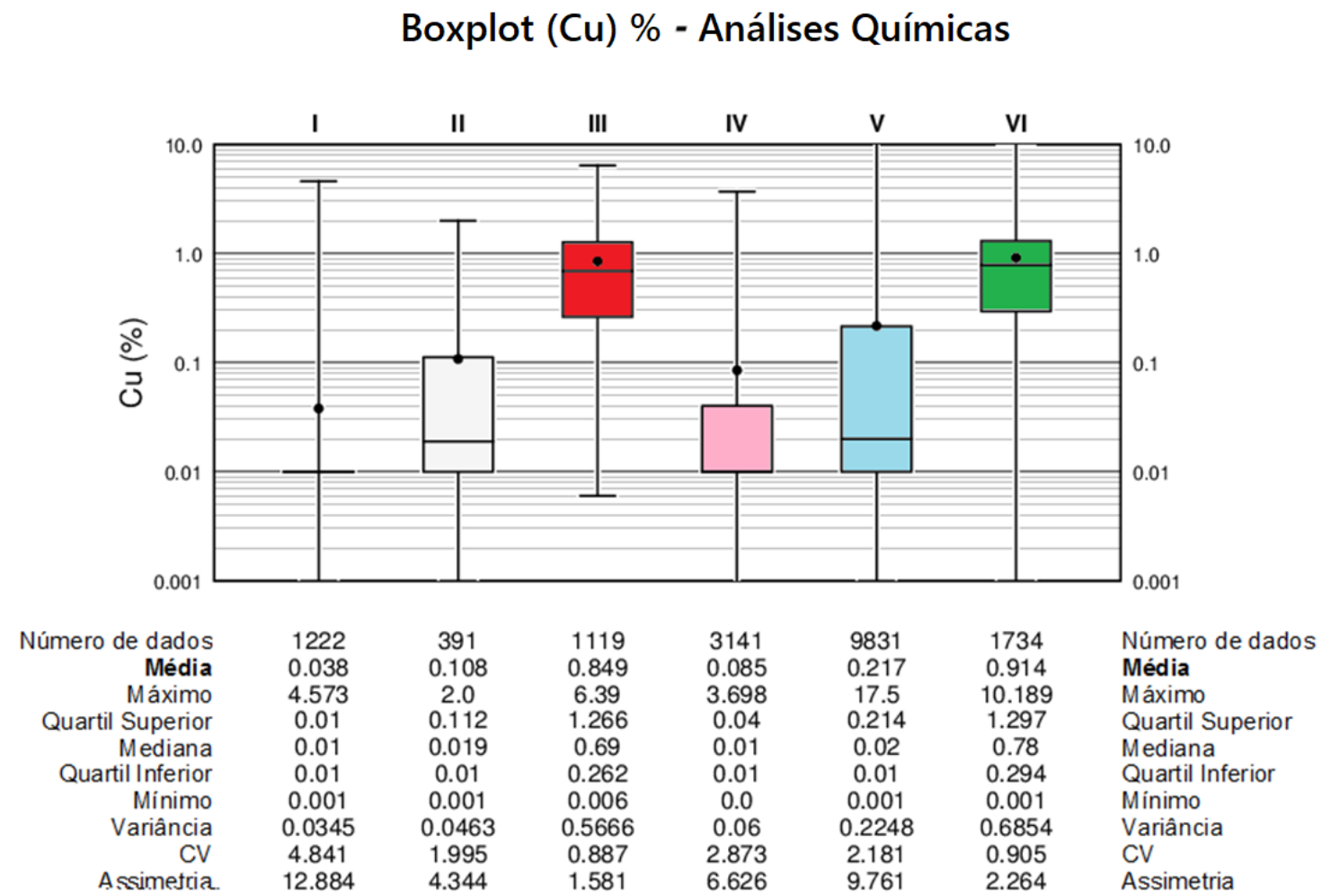

Figura 4.4 - Boxplot para o elemento cobre nos domínios geológicos. 


\section{Boxplot Ni (\%) - Análises Químicas}

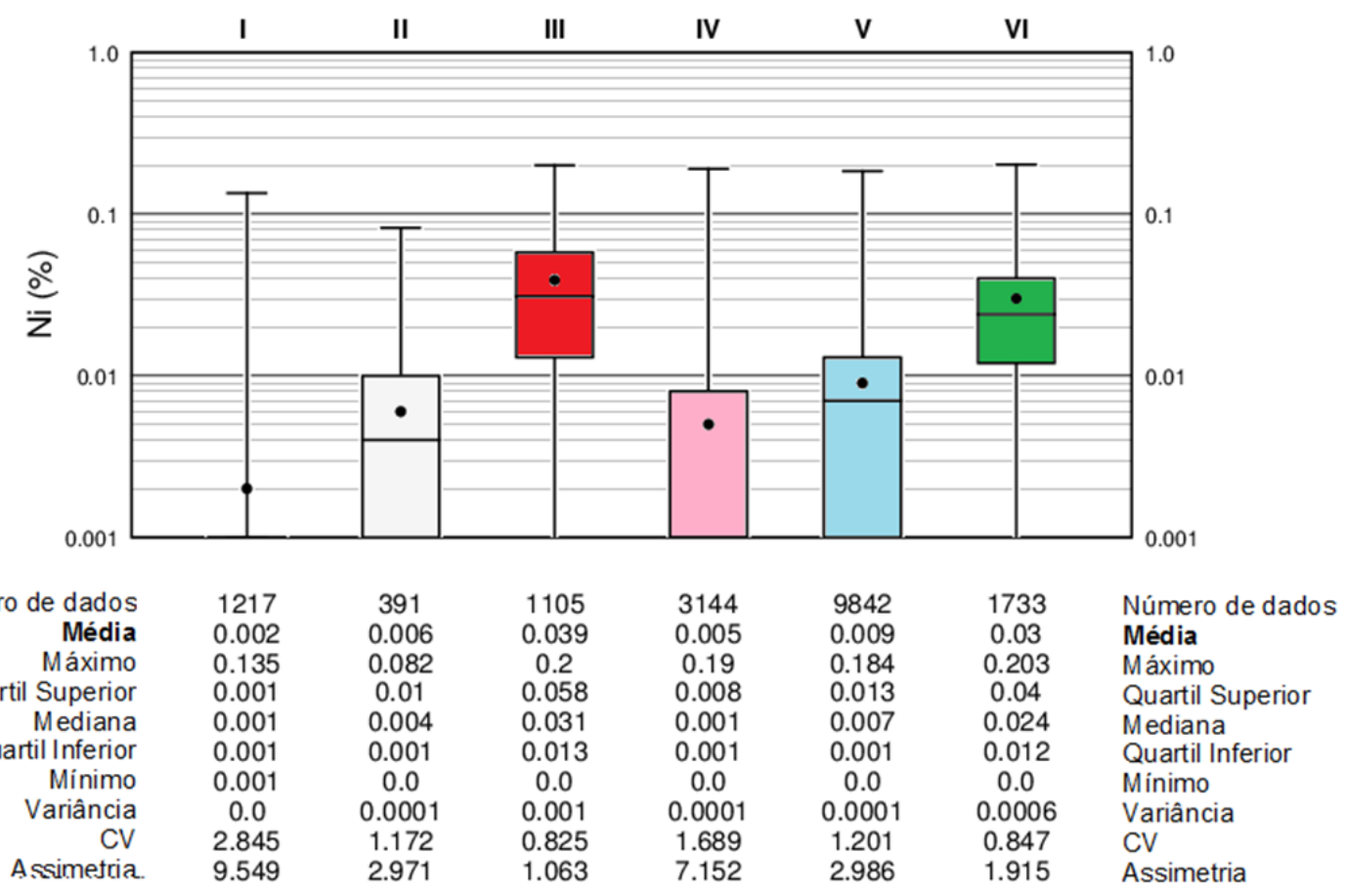

Figura 4.5 - Boxplot para o elemento níquel nos domínios geológicos.

A análise dos gráficos para $\mathrm{Cu}$ e $\mathrm{Ni}$ confirma que a mineralização tem forte controle litológico, uma vez que os teores de cobre e níquel variam entre os distintos domínios com destaque para os domínios mineralizados (III) e (VI) que apresentam os maiores valores de média, quartil e máximo. A análise do CV mostra um caráter de distribuição mais homogênea, quando comparado aos outros domínios, nos domínios mineralizados (III) e (VI). É importante ressaltar que estes dois domínios com maiores teores de $\mathrm{Cu}$ são considerados como minério pela equipe técnica de Surubim. As Figura 4.6 e 4.7 contêm os gráficos de probabilidade e histograma dos domínios (III) e $(\mathrm{VI})$, respectivamente. 

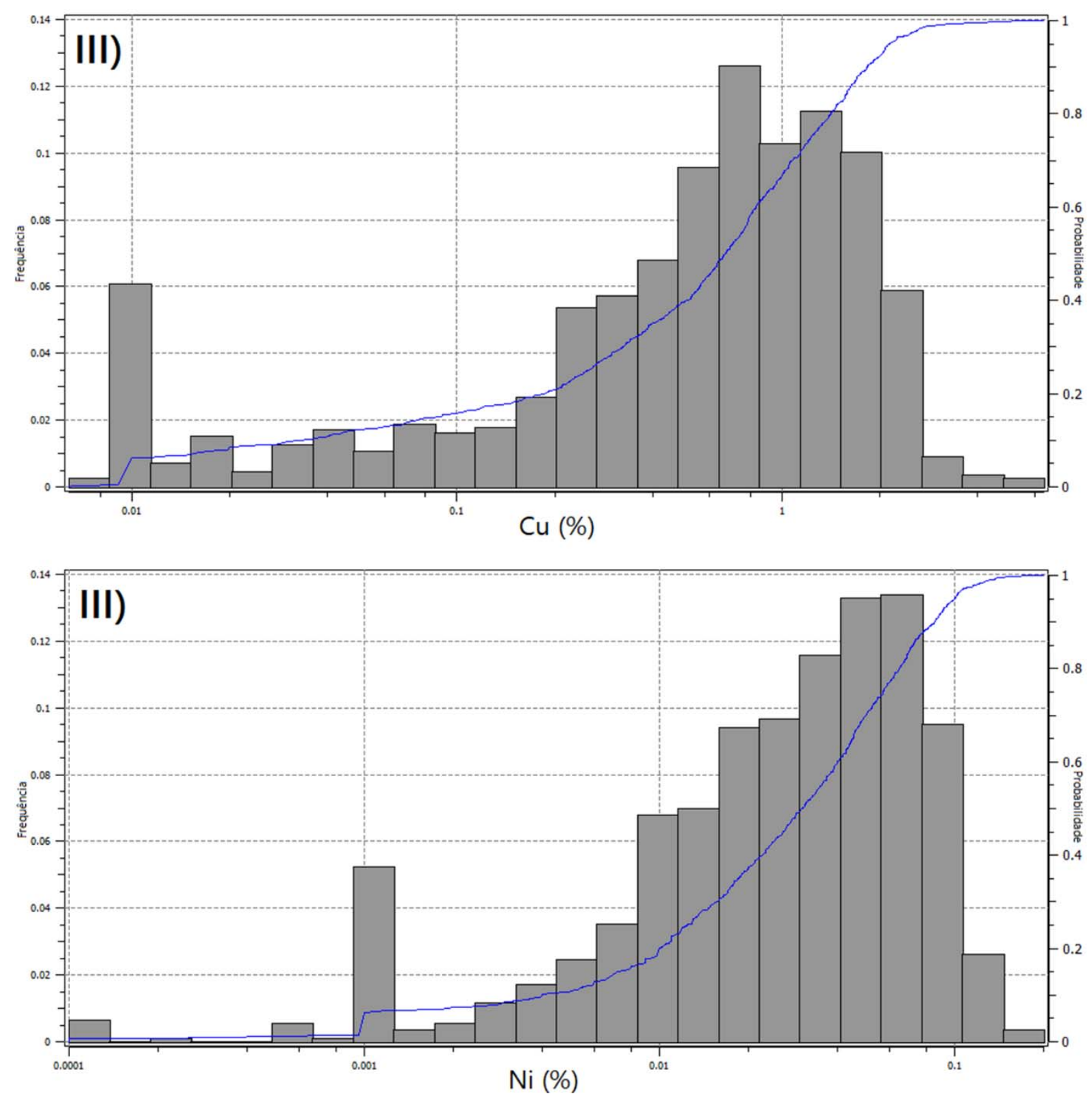

Figura 4.6 - Histogramas e frequência acumulada em escala logarítmica para as variáveis Cu e Ni no domínio (III).

A estatística dos domínios definidos, que também mostra a individualização do comportamento após a separação das amostras, com distinção dos teores em cada domínio, é apresentada na Tabela 4.3. 

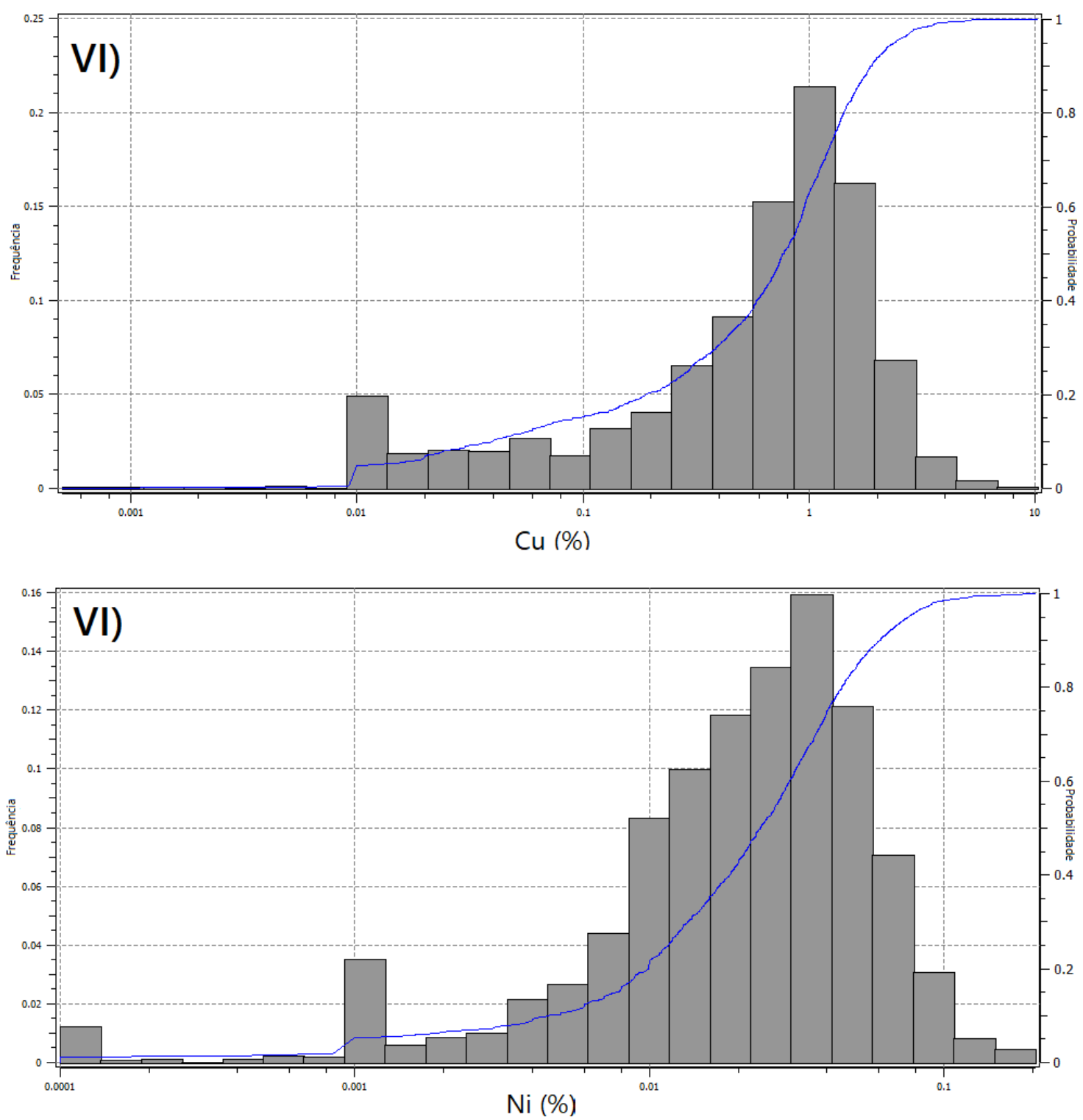

Figura 4.7 - Histogramas e frequência acumulada em escala logarítmica para as variáveis Cu e Ni no domínio (VI).

Tabela 4.3 - Estatística descritiva dos domínios previamente definidos, em destaque os domínios mineralizados III e VI.

\begin{tabular}{ccccccccc}
\hline Domínio & Dados & Média & Variância & Máximo & $\begin{array}{c}\text { Quartil } \\
\text { Superior }\end{array}$ & Mediana & $\begin{array}{c}\text { Quartil } \\
\text { Inferior }\end{array}$ & Mínimo \\
\hline I & 1222 & 0.043 & 0.044 & 4.573 & 0.010 & 0.010 & 0.010 & 0 \\
II & 391 & 0.113 & 0.054 & 2.000 & 0.108 & 0.197 & 0.010 & 0 \\
III & 1119 & 0.832 & 0.558 & 6.390 & 1.229 & 0.672 & 0.251 & 0 \\
IV & 3141 & 0.089 & 0.064 & 3.698 & 0.040 & 0.010 & 0.010 & 0 \\
V & 9831 & 0.222 & 0.228 & 17.500 & 0.223 & 0.022 & 0.010 & 0 \\
VI & 1734 & 0.909 & 0.680 & 10.189 & 1.290 & 0.776 & 0.290 & 0 \\
\hline
\end{tabular}


Com a separação dos domínios, nota-se a mudança de comportamento dos domínios em relação à distribuição de frequência para $\mathrm{Cu}$ e $\mathrm{Ni}$ das amostras globalmente. Enquanto a maioria dos domínios apresenta assimetria positiva (lognormal), figuras no ANEXO A, os domínios (III) e (VI) apresentam uma distribuição assimétrica positiva, dada a maior presença de valores altos na distribuição.

Após a subdivisão dos domínios foi realizada uma análise de contato para definição dos tipos de contatos. A análise de contato é uma comparação gráfica que opõe visualmente, a partir de uma distância preestabelecida entre dois domínios, os teores médios de cada um destes. Tem como função contribuir na definição do tipo de contato químico que existe entre duas categorias diferentes, que pode ser definido como contato transicional de teores ou contato brusco. Os gráficos gerados estão apresentados na Figura 4.8.

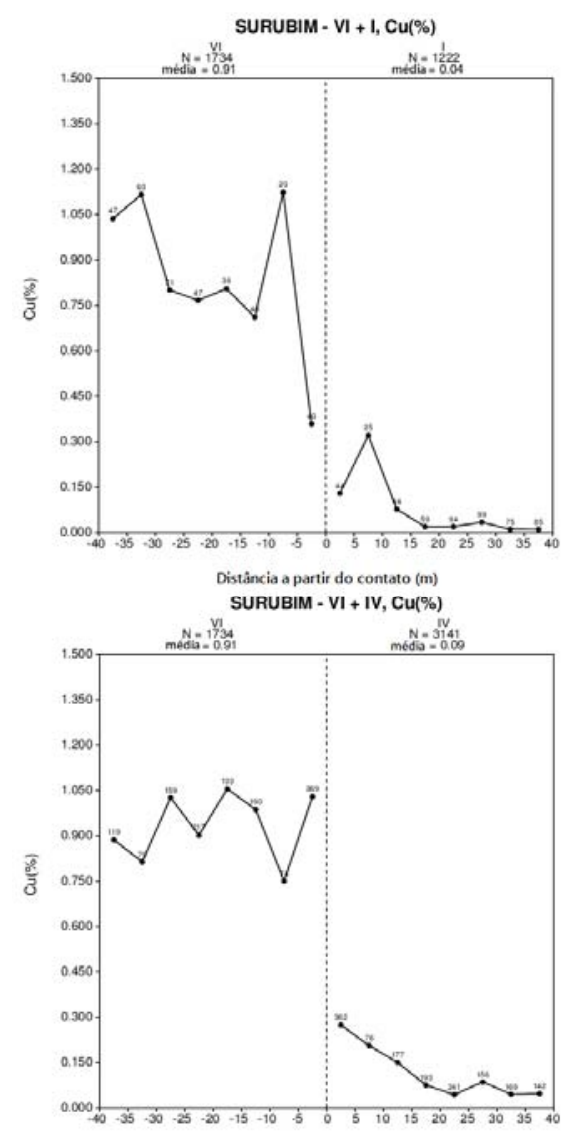

Distância a partir do contato $(\mathrm{m})$

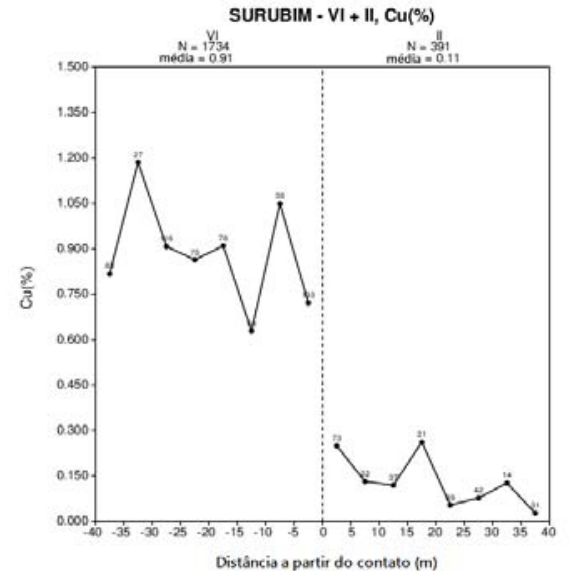

SURUBIM- $V I+v$, Cu

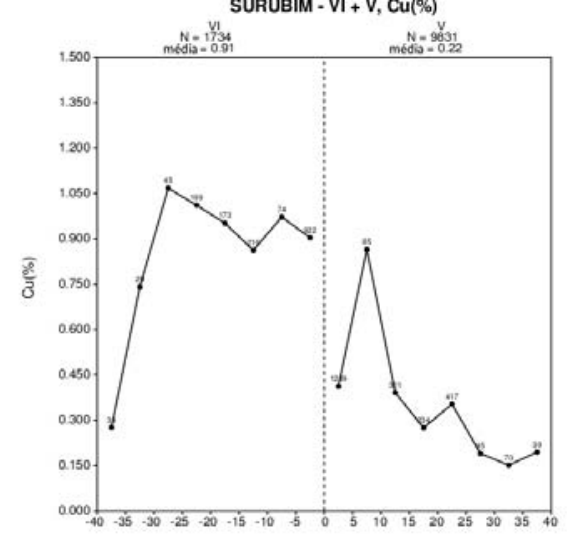

Diståncia a partir do contato (m)

Figura 4.8- Análise de Contato para os Domínios I, II, III, IV, V e VI. 

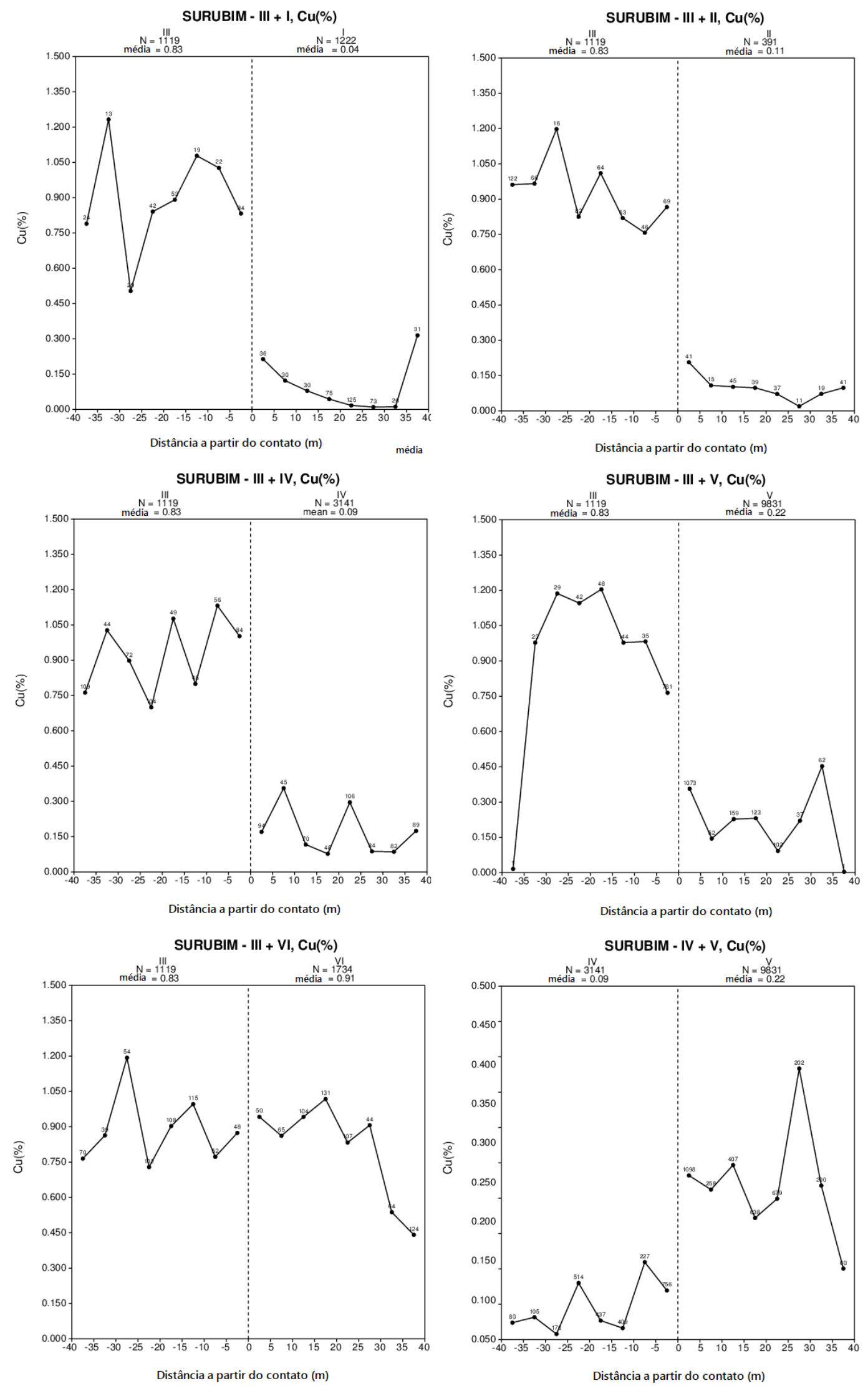

Figura 4.8 (cont.) - Análise de Contato para os Domínios I, II, III, IV, V e VI. 
Conhecendo-se os controles metalogenéticos do depósito e avaliando os gráficos apresentados, pode-se afirmar que a definição dos domínios é coerente com a ocorrência da mineralização no depósito.

A mineralização nos hidrotermalitos (III) apresenta contato brusco em relação a praticamente todos os domínios, com exceção das ultramáficas (VI) e das rochas básicas $(V)$, havendo uma transição gradual entre estes domínios.

Já as ultramáficas (VI) apresentam a variação de teores mais gradual em relação aos domínios, com exceção dos granito-gnaisses (IV). As básicas (V) e os granitognaisse (IV) apresentam contatos brusco em relação aos teores de $\mathrm{Cu}$.

Considerando que tanto o comportamento estatístico quanto de comportamento de teores no contato são distintos entre os domínios, pode-se afirmar que no geral a delimitação foi bem efetuada.

Desta forma, o próximo item apresentará o resultado da modelagem destes domínios, que serviram como controle para as simulações posteriores.

\subsection{Interpretação do Modelo Geológico}

Esta etapa das atividades é fruto da discretização inicial dos domínios geológicos obtida na análise dos dados. Dentro do contexto no depósito de Surubim, como mencionado anteriormente, os domínios (III) e (VI) contêm as litologias que hospedam a mineralização de Cu. A mineralização é controlada estruturalmente pela percolação de fluídos hidrotermais, e litologicamente quando relacionadas com as rochas ultramáficas. Ambos domínios mineralizados estão encaixados nos domínios (IV) e (V), que também apresentam estruturação condizente com o trend regional. Para fins de simplificação, o domínio (II) não foi modelado tridimensionalmente dada sua pequena expressão e continuidade lateral entre as sondagens. 
Os programas utilizados para a modelagem foram os softwares StudioRM e Leapfrog.

O método escolhido para interpretação dos corpos geológicos foi o método de seções que posteriormente são ligadas entre si por triângulos.

\subsubsection{Seções Geológicas}

O planejamento inicial das seções pode ser observado na Figura 2.2. Entretanto, visando respeitar a posição das amostras e detalhamento dos corpos em três dimensões, este planejamento sofreu algumas alterações. Desta forma, a Figura 4.9 apresenta a planta com o desenho de todas as seções interpretadas.

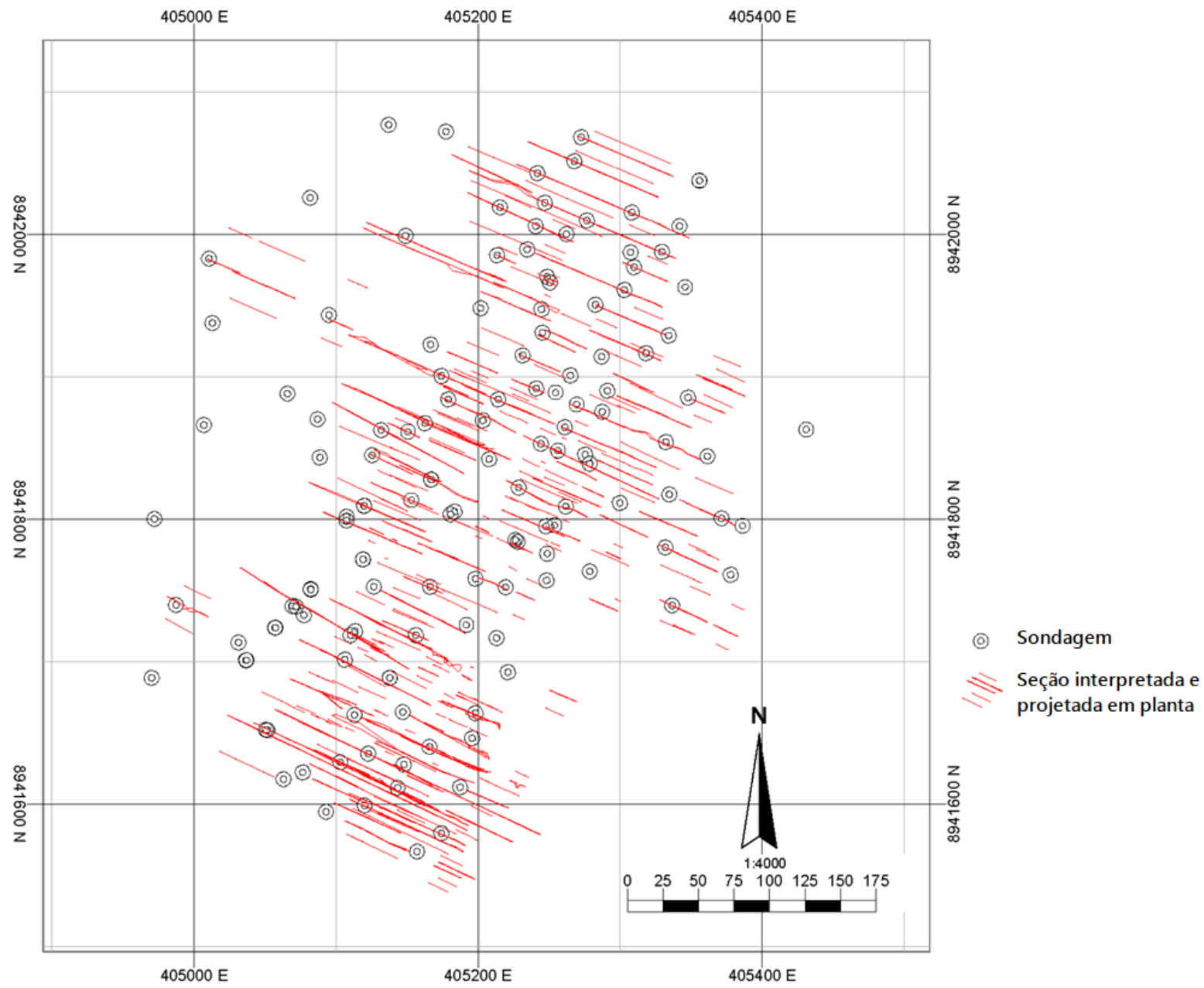

Figura 4.9 - Seções desenhadas a partir do banco de dados do depósito Surubim. 
Foi respeitada a descrição da geologia local nas amostras das sondagens. Os corpos têm geometria lenticular, com mergulho de aproximadamente $45^{\circ}$ para oeste. Os domínios são mutuamente exclusivos, e desta forma não se interceptam nas seções. A Figura 4.10 contém um exemplo da modelagem por seção.

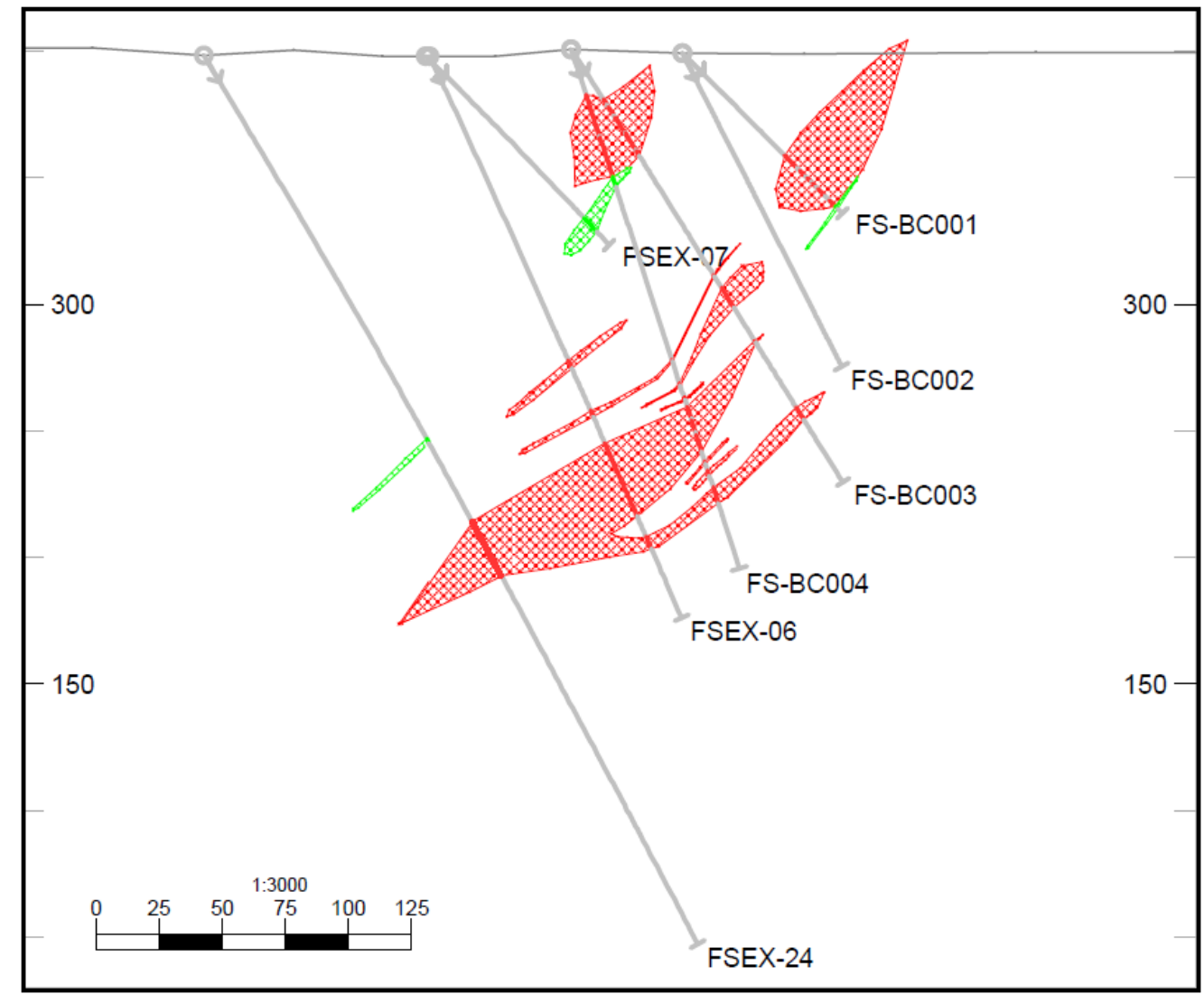

Figura 4.10 - Esquema de seção geológica interpretada para dois corpos. Em vermelho domínio dos hidrotermalitos (III) e em verde domínio das ultramáficas (VI).

O resultado de todas as seções delineadas permitiu a posterior interpretação tridimensional dos corpos. Durante o desenho, tanto a continuidade vertical quanto a horizontal foram respeitadas e utilizadas na interpretação. O fechamento dos corpos lenticularizados se deu através da técnica de meia-seção, que acunha o corpo a meia distância entre sondagens negativas e positivas. O resultado final das seções interpretadas para as rochas hidrotermais (III) e ultramáficas (VI) está apresentado na Figura 4.11. 


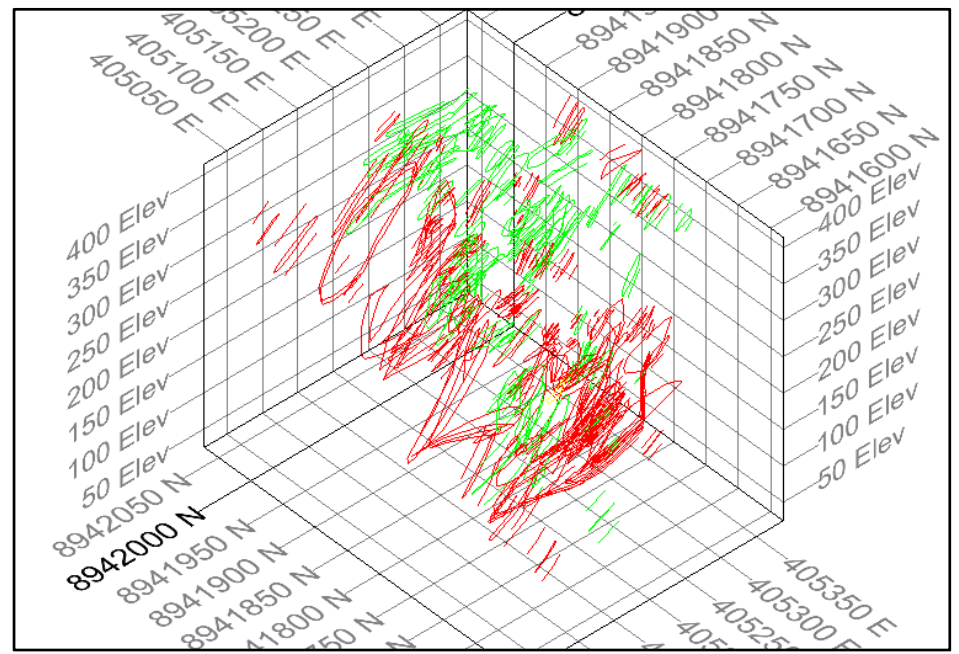

Figura 4.11 - Seções geológicas em perspectiva. Em vermelho os hidrotermalitos (III) e em verde as ultramáficas (VI).

\subsubsection{Triangularização do Modelo Geológico Interpretado}

Etapa final da modelagem 3D, tem como base a interpretação realizada nas seções geológicas previamente apresentadas. Os corpos delimitados são apresentados em forma de sólidos para os domínios III, IV, V e VI e de superfície para o domínio I. Como são mutuamente exclusivos ocorre apenas uma litologia em cada volume modelado. Esta etapa foi realizada no programa Leapfrog, com a definição de camadas e volumes a partir dos contatos dos domínios e das seções interpretadas. O resultado da modelagem pode ser observado na Figura 4.12.

Avaliando a geometria dos corpos obtidos na modelagem no contexto geológico regional em que o depósito está inserido, percebe-se uma estruturação preferencial na direção Norte, compatível com a geologia regional e com as estruturas observadas em campo na mina. Nota-se, também, a reprodutibilidade da estruturação em relação ao mergulho das camadas, mergulhando em torno de $45^{\circ}$ na direção oeste. Para avaliar com maior detalhe a estruturação dos domínios mineralizados, os domínios III e VI foram individualizados e podem ser analisados na Figura 4.13. 

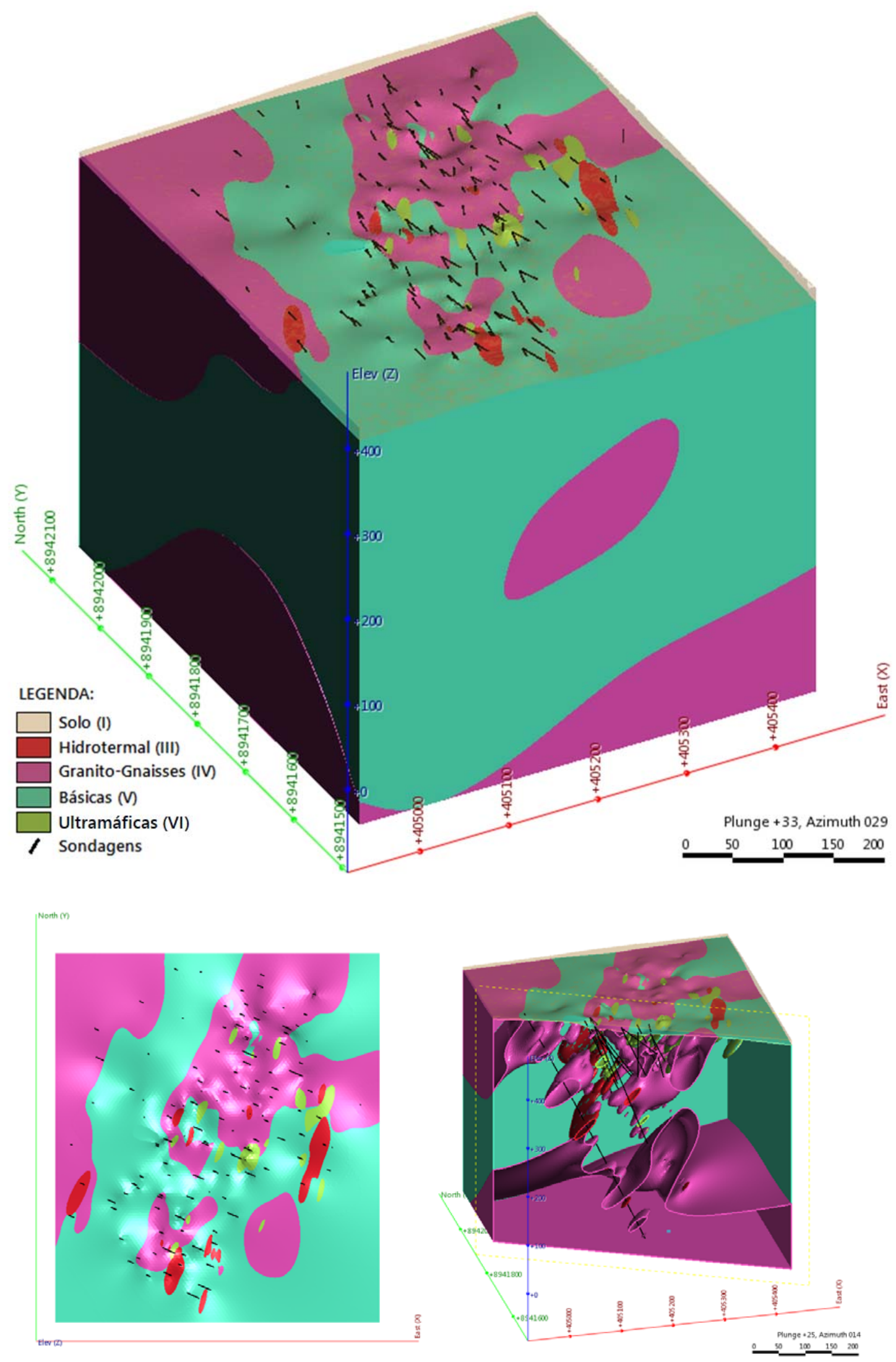

Figura 4.12 - Resultado da modelagem geológica para o depósito de Surubim, vista ortogonal (acima), planta (abaixo à esquerda) e em seção (abaixo à direita). 

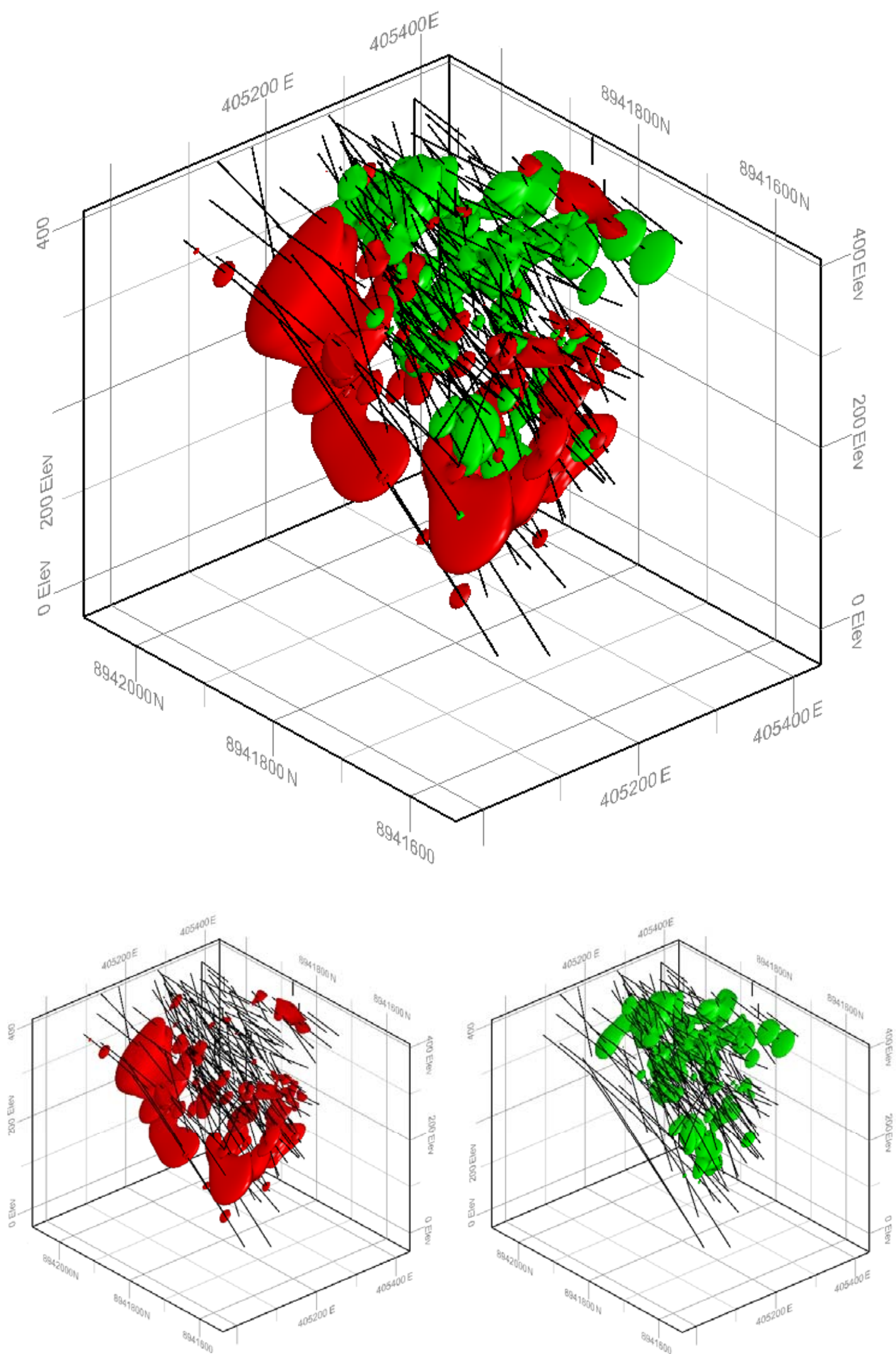

Figura 4.13 - Resultado da modelagem geológica para o depósito de Surubim, em vermelho o domínio dos hidrotermalitos (III) e em verde o domínio das ultramáficas (VI). 


\subsubsection{Volumes}

Após a obtenção dos sólidos tridimensionais dos domínios, foi realizada a quantificação dos volumes para os corpos apresentados. Os resultados dos volumes obtidos na modelagem serviram como referência para transferência da incerteza a partir dos resultados da simulação. A Tabela 4.4 apresenta a informação da quantificação destes volumes.

Tabela 4.4 - Volumes obtidos para os domínios modelados.

\begin{tabular}{crc}
\hline Domínio & Volume $\left(10^{3} \mathrm{~m}^{3}\right)$ & Porcentagem \\
\hline (I) & $1,234.50$ & 2.40 \\
(III) & $1,526.45$ & 2.97 \\
(IV) & $11,048.03$ & 21.51 \\
(V) & $36,676.41$ & 71.40 \\
(VI) & 883.61 & 1.72 \\
\hline Total & $\mathbf{5 1 , 3 6 9 . 0 0}$ & $\mathbf{1 0 0 . 0 0}$ \\
\hline
\end{tabular}

Estes valores foram utilizados como referência para avaliação da incerteza deste método de modelagem. A partir dos resultados da simulação foi possível identificar a incerteza desta modelagem geológica.

A diferença entre os valores de proporção nas amostras de sondagem e no modelo geológico obtido se deve principalmente ao viés amostral, que super amostra as regiões que contém as mineralizações, aumentando artificialmente sua proporção amostrada. Outro fator que contribui para a diminuição da proporção dos domínios (III) e (VI) é a exclusão da modelagem de corpos muito pequenos e descontínuos destes domínios, o que acaba por reduzir sua proporção quando comparada com as amostras do testemunho, que incluem estes dados na contagem. Há também de se mencionar que as diferenças de proporção são também oriundas de erros de interpretação durante o desenho, falta de conhecimento total das características do depósito quando da modelagem, limitações para o desenho de estruturas complexas, entre outros. 


\subsection{Interpolação multiquádrica de Indicadoras}

O método utilizado para interpolar os domínios neste projeto foram as equações multiquádricas. Todos os domínios foram interpolados, inclusive o domínio (II), que não foi modelado através da interpretação geológica.

Para esta interpolação, as variáveis foram previamente transformadas em indicadoras. Esta etapa foi realizada no software ModGeo. A interpolação foi realizada nos nós que representam o centro de um bloco de dimensões de $5 \mathrm{~m}$ nas direções $\mathrm{X}$, Y e Z. Esta dimensão de bloco foi definida a partir das distâncias das sondagens em planta e principalmente pela dimensão dos corpos mineralizados. Os atributos do modelo de blocos utilizado estão apresentados na Tabela 4.5.

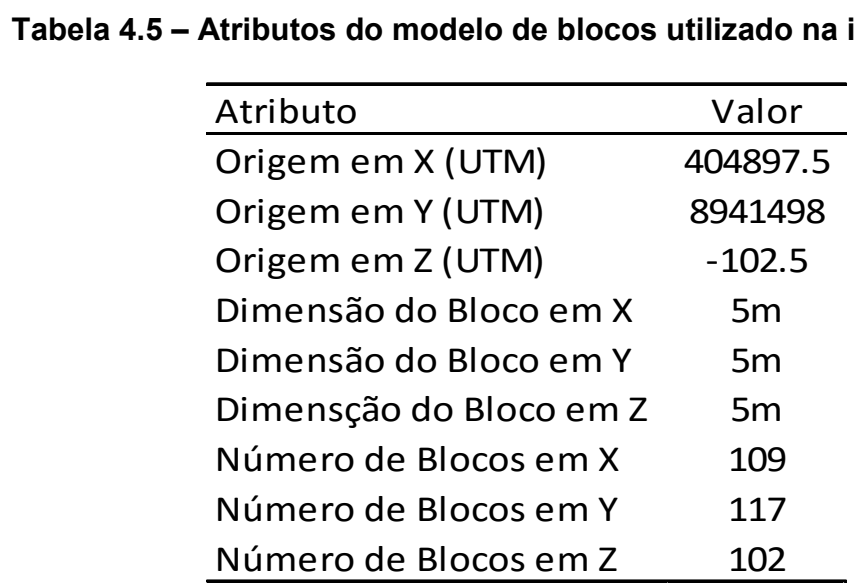

Ressalta-se que o modelo de blocos utilizado na interpolação tem as mesmas coordenadas e tamanhos dos modelos de blocos simulados, desta forma, todos os blocos puderam ser comparados com seus equivalentes em cada método.

Os parâmetros de busca utilizados para as multiquádricas são apresentados na Tabela 4.6. 
Tabela 4.6 - Parâmetros de busca utilizados

\begin{tabular}{lc}
\hline \multicolumn{2}{l}{ Parâmetros da equação multiquádrica } \\
\hline Distância máxima busca & $63 \mathrm{~m}$ \\
No de pontos/setor & 2 \\
Mínimo/bloco & 2 \\
Máximo/bloco & 16 \\
Lado & 9 \\
Distância vertical & 10 \\
Altura & 2 \\
\hline
\end{tabular}

Nestes parâmetros, a distância máxima é definida como a soma da diagonal de 9 blocos, identificada como lado na Tabela 4.6 e foi definida a partir da distância média entre as sondagens, sendo considerada uma distância com extrapolação adequada à geologia do depósito. Na mesma tabela, a distância vertical é definida com 10 metros, ou 2 blocos. Os parâmetros foram assim definidos a partir da malha amostral e para evitar extrapolações em regiões sem informação.

A interpolação multiquádrica constrói, para cada ponto interpolado, uma função de distribuição acumulada condicional, em que cada domínio tem sua probabilidade de ocorrência estimada. Desta forma, o resultado é a probabilidade, por ponto, de ocorrência de cada domínio. O domínio definido para o ponto é aquele que, dentre os domínios interpolados, apresentar o maior valor de probabilidade. Como referência, a função de distribuição acumulada para as amostras do depósito como um todo é apresentada na Figura 4.14. 

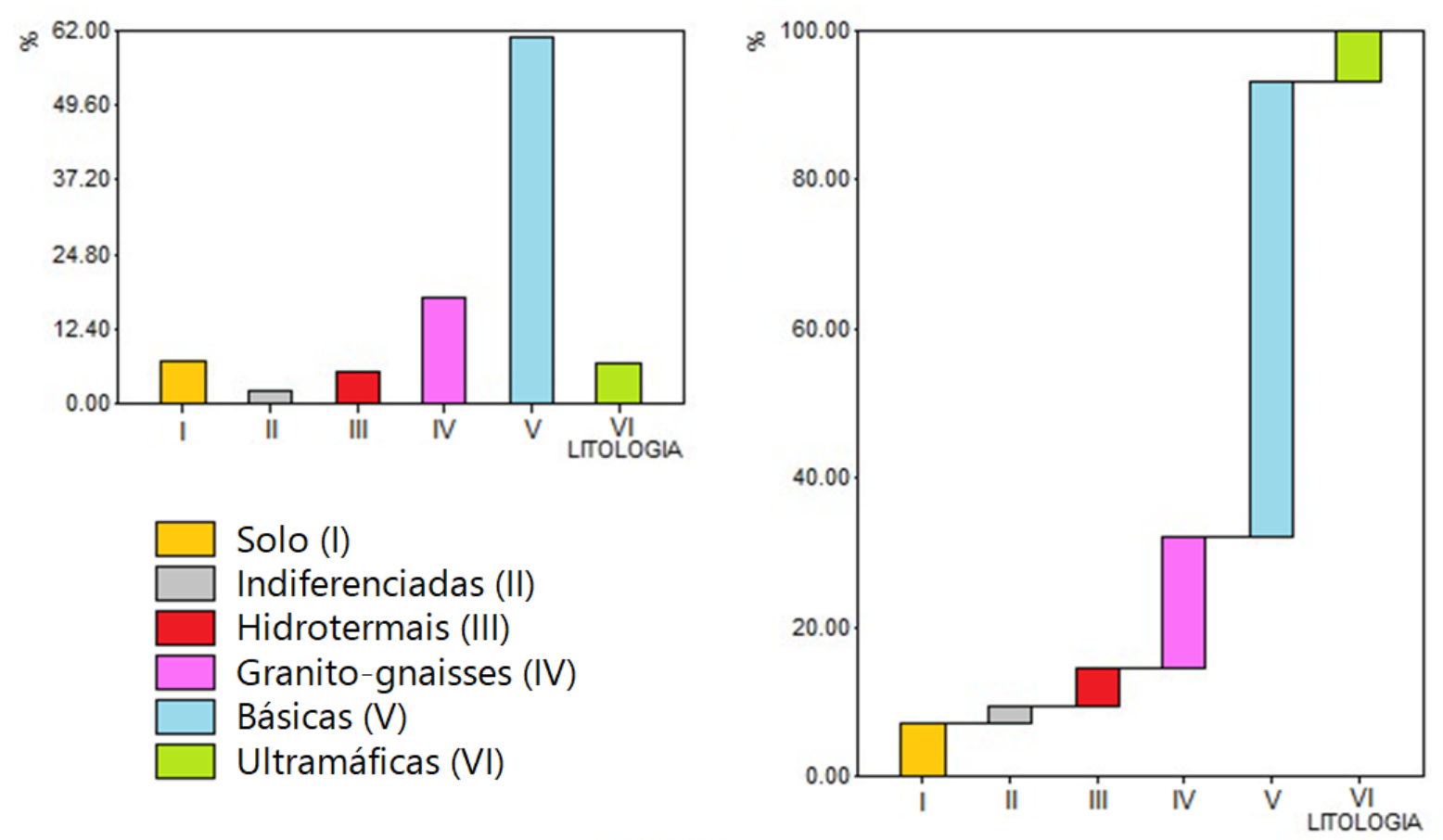

Figura 4.14 - Função de distribuição acumulada para a variável domínio, com 6 tipos

O resultado da interpolação multiquádrica é calculado a partir da resolução da equação multiquádrica generalizada, apresentada na Tabela 3.2 , para k=0 e c=0. Assim, cada ponto tem a função de distribuição acumulada construída a partir da Equação 3.13. Por fim, o resultado mais provável é definido a partir da Equação 3.17, resultado que pode ser observado na Figura 4.15. O resultado para os domínios (III) e (VI) estão apresentados na Figura 4.16. Nota-se que a estruturação do depósito foi respeitada no resultado da interpolação, mostrando camadas com direção e mergulho compatíveis com a geologia local e com a geologia modelada no item 4.2. 


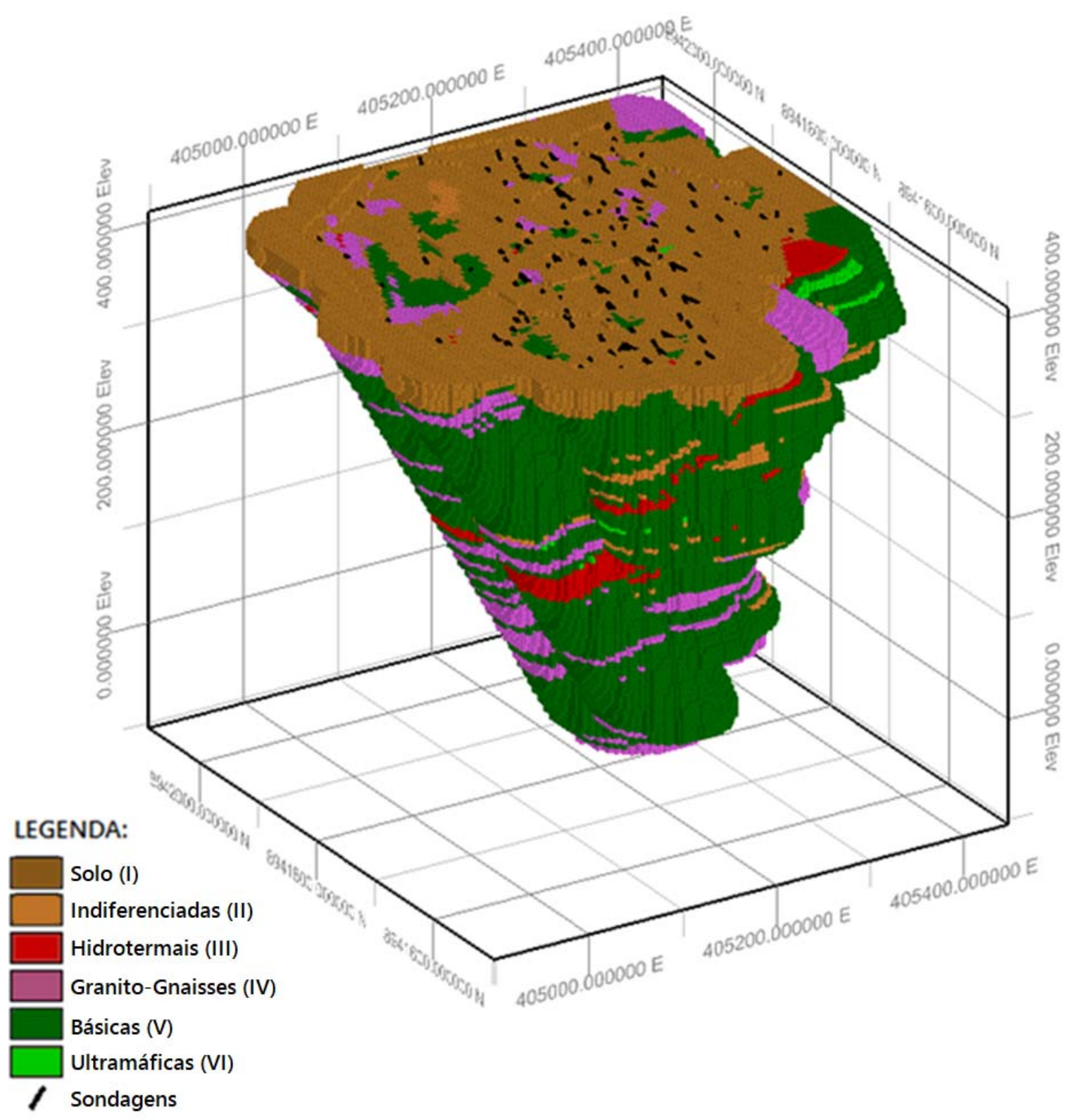

Figura 4.15 - Resultado da interpolação multiquádrica para os domínios de Surubim.

\subsubsection{Volumes}

Após a obtenção dos corpos dos domínios interpolados, foi realizada a quantificação dos volumes obtidos. Os resultados da interpolação serviram como referência para transferência da incerteza a partir dos resultados da simulação. A Tabela 4.7 contém a informação da quantificação destes volumes. Como mencionado anteriormente, o volume do domínio (II) foi computado, uma vez que seu cálculo é possível graças ao algoritmo das multiquádricas. 


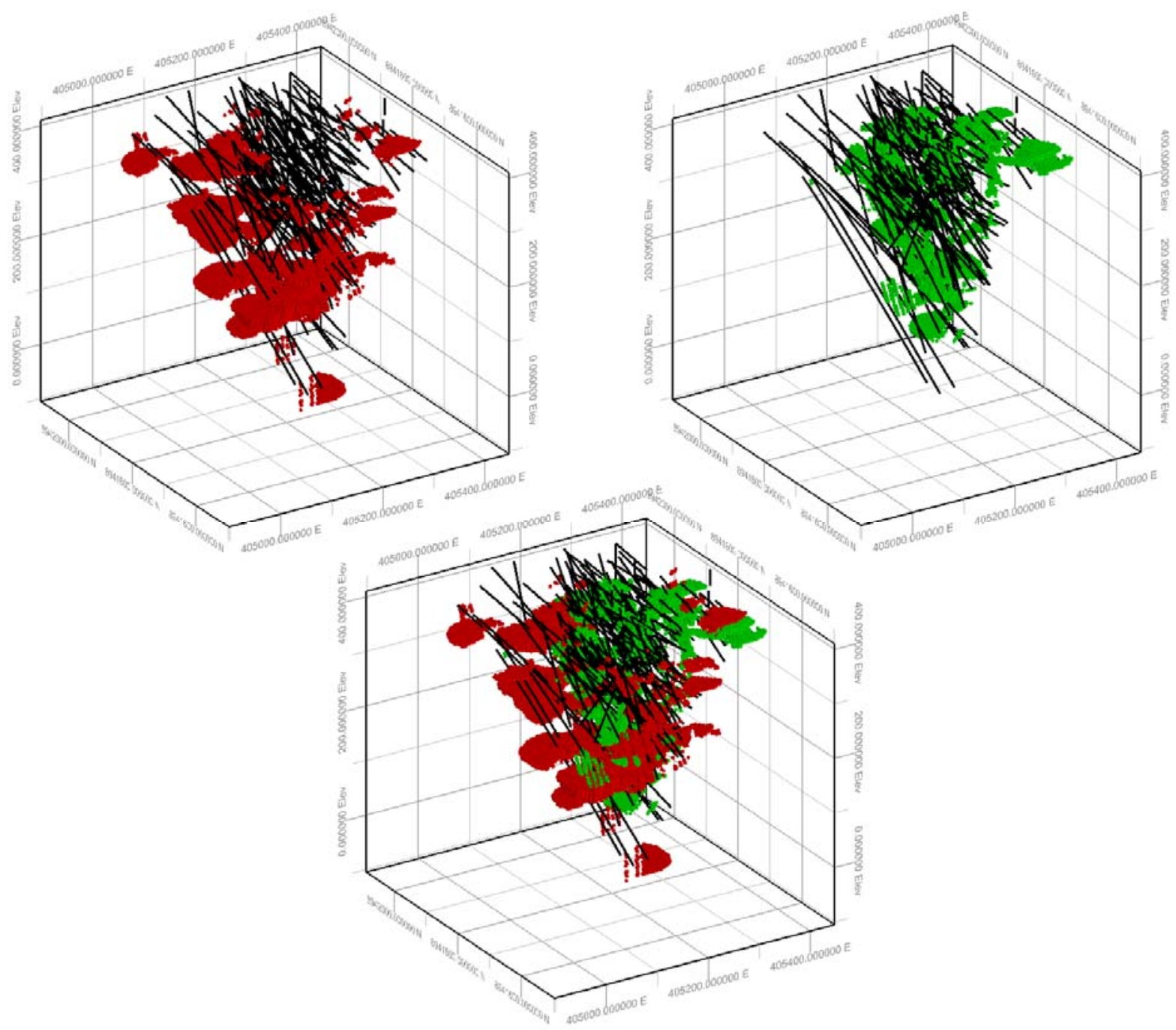

Figura 4.16 - Resultado da interpolação multiquádrica para os domínios mineralizados dos hidrotermalitos (III) em vermelho e ultramáficas (VI) em verde.

Tabela 4.7 - Volumes obtidos para os domínios interpolados.

\begin{tabular}{crc}
\hline Domínio & Volume $\left(10^{3} \mathrm{~m}^{3}\right)$ & Porcentagem \\
\hline (I) & $2,093.46$ & 4.08 \\
(II) & 675.72 & 1.32 \\
(III) & $1,741.50$ & 3.39 \\
(IV) & $9,878.91$ & 19.23 \\
(V) & $35,787.11$ & 69.67 \\
(VI) & $1,192.30$ & 2.32 \\
\hline Total & $\mathbf{5 1 , 3 6 9 . 0 0}$ & $\mathbf{1 0 0}$ \\
\hline
\end{tabular}




\subsection{Simulação Sequencial de Indicadoras}

O número de cenários escolhido para a execução da simulação de indicadoras foi 101 realizações. A simulação indicadora foi baseada nas equações multiquádricas para construção da função de distribuição acumulada condicional. Esta etapa também foi realizada no software ModGeo.

A simulação se deu nos nós que têm a coordenada coincidente com os atributos do modelo de blocos apresentado na Tabela 4.5, e teve como função permitir a comparação pontual entre os blocos simulados e interpolados.

A simulação, assim como a interpolação, foi realizada para os 6 domínios do depósito. O resultado para a simulação pode ser observado na Figura 4.17. A figura apresenta o resultado de duas simulações (34 e 67) para exemplificar o resultado obtido, e a média das simulações. A média das simulações é o resultado da sobreposição de todas as realizações em que o valor mais frequente é definido como o mais provável no ponto, como definido na Equação 3.28.

A Tabela 4.8 contém os volumes médios obtidos para cada domínio, como também os volumes para mínimo, máximo e mediana de volumes absolutos em todas as simulações. A Figura 4.18 apresenta as proporções dos domínios de duas simulações, para ilustrar a manutenção das proporções das amostras originais.

A Figura 4.19 ilustra a realização média com os domínios (III) e (VI) individualizados para melhor visualização.

Já a Figura 4.20 mostra os histogramas com a distribuição de frequência para todos os domínios nos 101 cenários. 


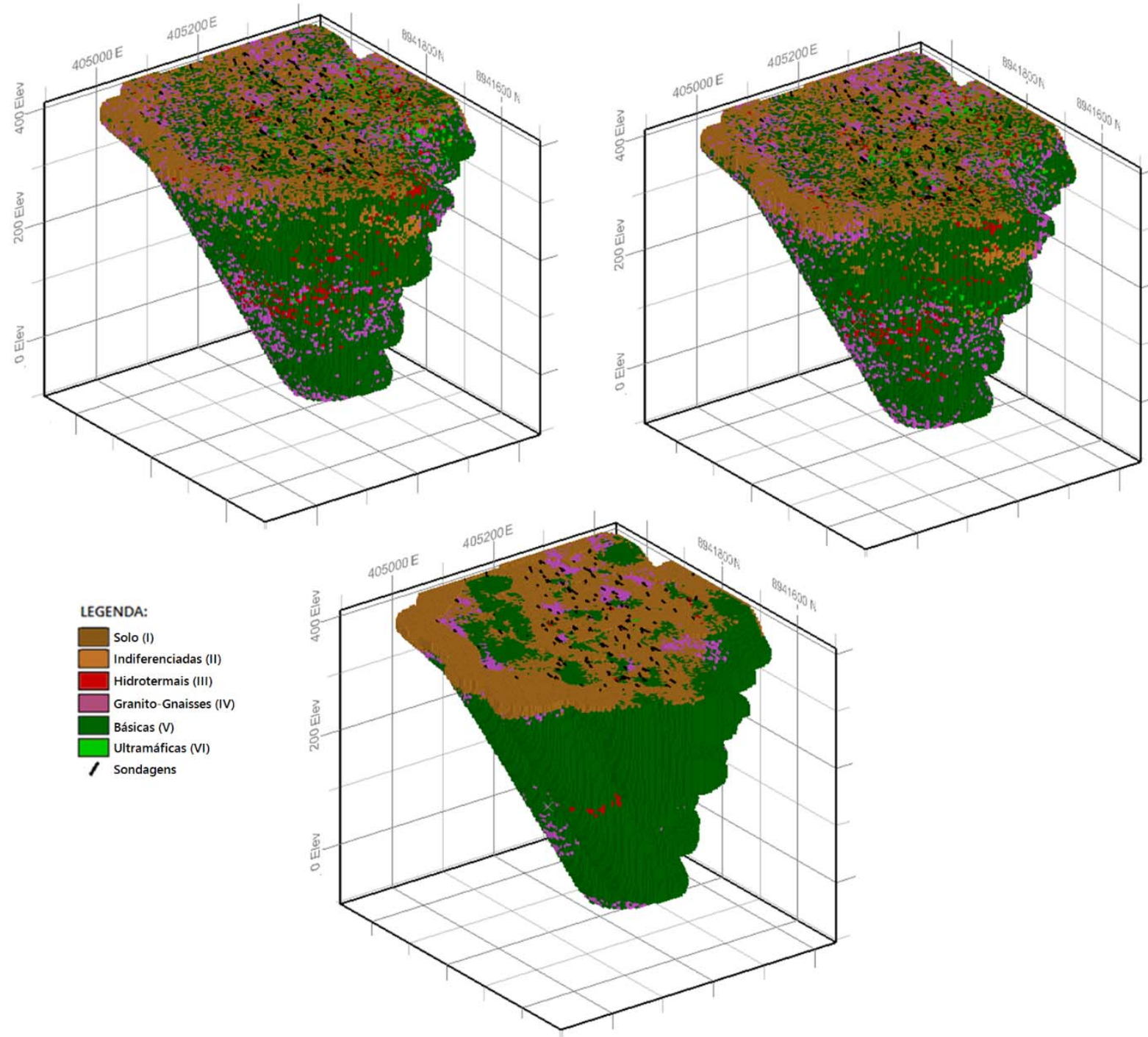

Figura 4.17 - Resultado da simulação de indicadoras por multiquádricas para o depósito de Surubim.

Tabela 4.8 - Volumes obtidos para os domínios simulados no cenário mais provável e nos cenários de mínimo, máximo e de mediana para os domínios

\begin{tabular}{lrrrrrr}
\hline \multirow{2}{*}{ Cenários } & \multicolumn{7}{c}{ Domínios $\left(\mathrm{m}^{3}\right)$} \\
& \multicolumn{1}{c}{$(\mathrm{I})$} & $(\mathrm{II})$ & \multicolumn{1}{c}{$(\mathrm{III})$} & \multicolumn{1}{c}{$(\mathrm{IV})$} & \multicolumn{1}{c}{$(\mathrm{V})$} & \multicolumn{1}{c}{$(\mathrm{VI})$} \\
\hline Mínimo & $1,472.92$ & 917.55 & $2,336.06$ & $11,150.52$ & $33,108.09$ & $1,624.52$ \\
Mediana & $1,525.95$ & 997.47 & $2,441.42$ & $11,347.02$ & $33,348.58$ & $1,687.88$ \\
Média & $1,529.12$ & 995.23 & $2,444.01$ & $11,354.74$ & $33,356.27$ & $1,689.63$ \\
Máximo & $1,599.56$ & $1,055.22$ & $2,551.39$ & $11,546.52$ & $33,569.67$ & $1,761.55$ \\
Desvio Padrão & 25.68 & 29.77 & 42.74 & 73.24 & 91.11 & 26.23 \\
\hline
\end{tabular}



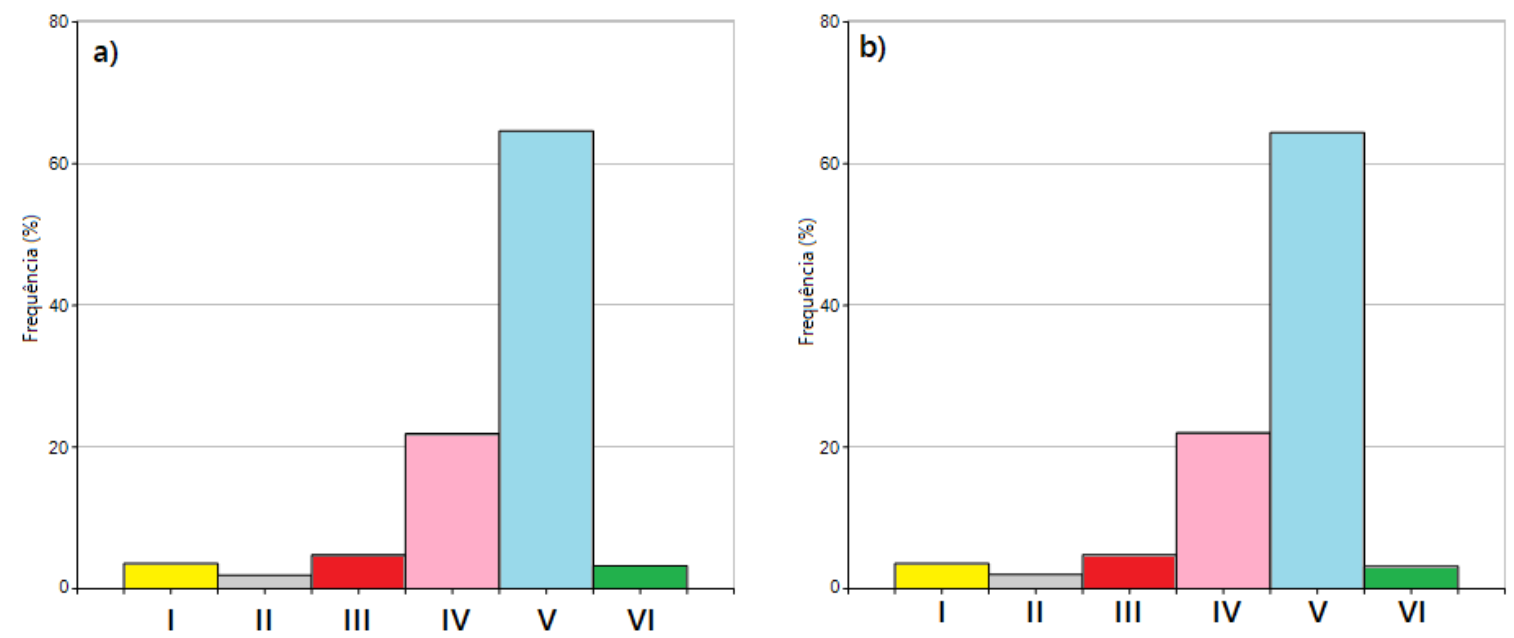

Figura 4.18 - Proporção dos domínios simulados nas realizações número 11 (a) e número 56 (b).

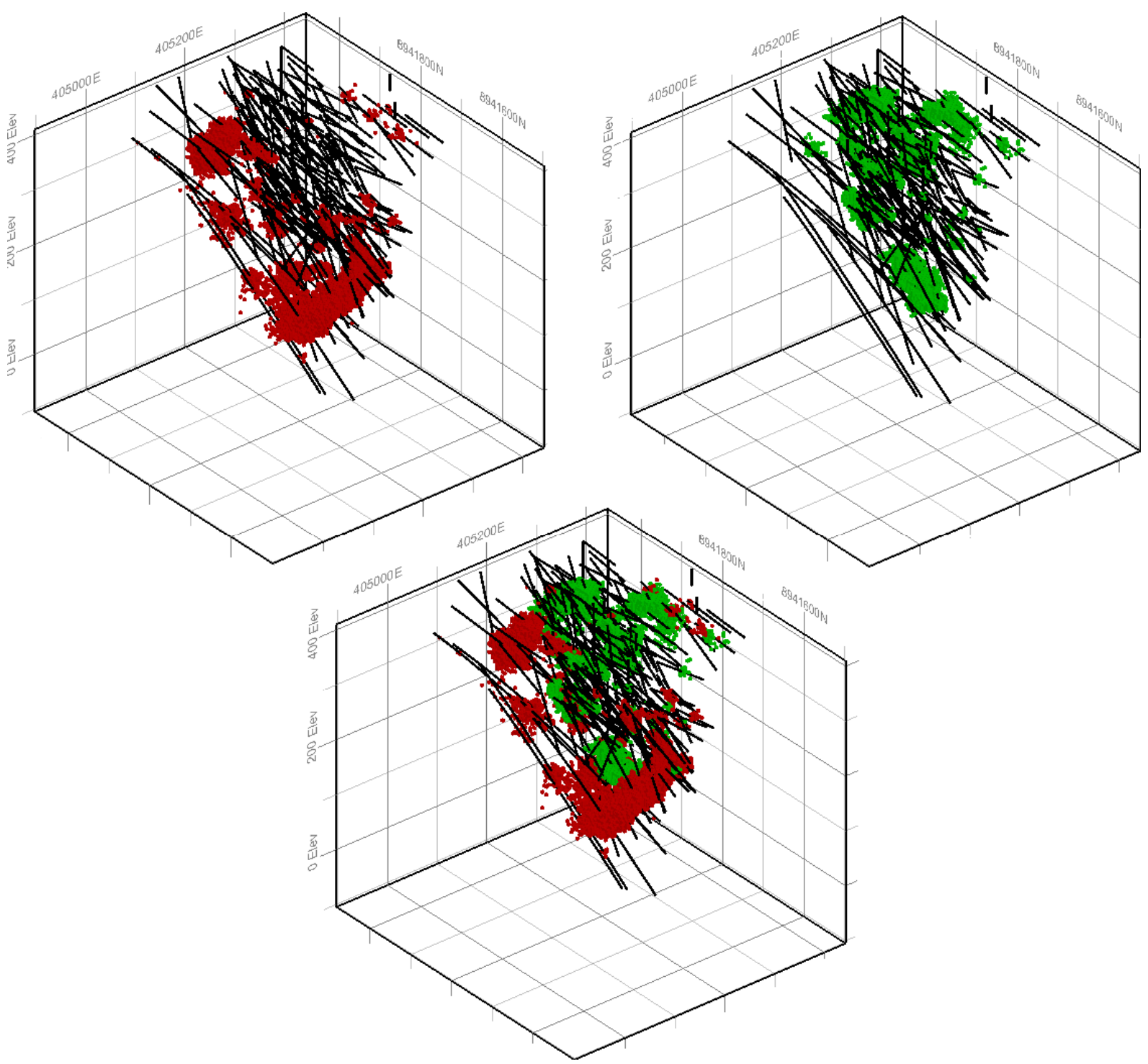

Figura 4.19 - Resultado da litologia mais provável por bloco para os domínios mineralizados dos hidrotermalitos (III) em vermelho e ultramáficas (VI) em verde. 

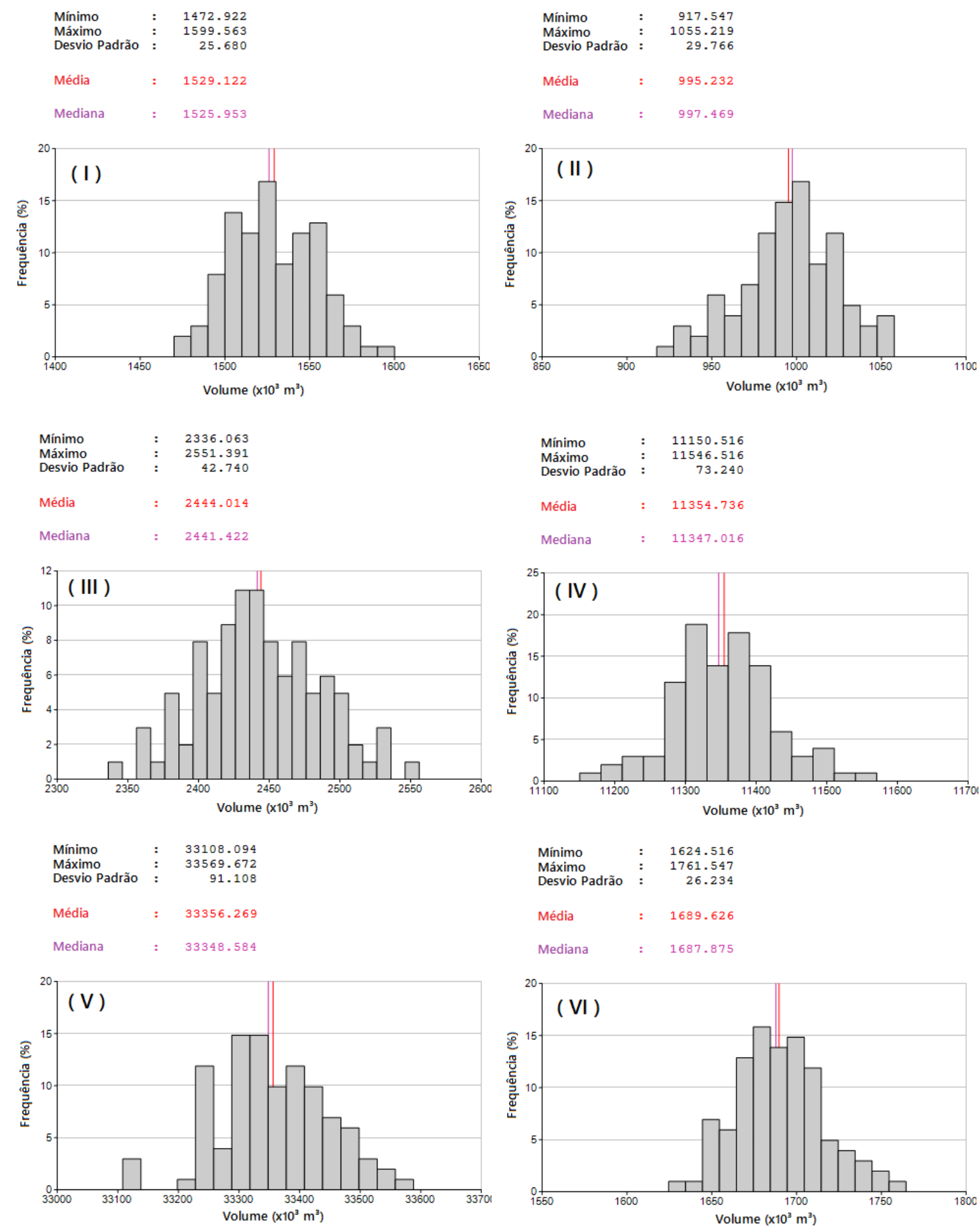

Figura 4.20 - Volumes nas 101 realizações, para os domínios I, II, III, IV, V e VI.

O resultado de todos os volumes simulados, para cada domínio e em cada realização é apresentado no ANEXO B. 


\section{DISCUSSÃO DOS RESULTADOS}

Este capítulo trata da análise e quantificação da incerteza associada aos volumes dos domínios no depósito de Surubim, em especial em relação aos domínios mineralizados. Os três métodos utilizados forneceram os volumes para todos os domínios definidos, com exceção do modelo interpretado, no qual não foi modelado o domínio (II).

Neste capítulo, as comparações foram realizadas entre os domínios (III) e (VI) dos métodos utilizados, sendo estes: modelo interpretado; modelo interpolado e modelos simulados. A análise será realizada globalmente e localmente, a partir das proporções entre os volumes e do valor esperado destes.

\subsection{Análise da Incerteza}

A incerteza foi quantificada de duas formas: através das probabilidades de ocorrência dos domínios, a partir do processamento em cada bloco dos resultados obtidos nas 101 realizações da SIS e consequente obtenção da distribuição de probabilidades; e pela distribuição de frequências dos volumes dos domínios a partir da avaliação da variância das 101 realizações.

Para melhor caracterização da incerteza, a avaliação da variação de volume entre os métodos também se deu localmente a partir do diagrama de médias móveis, ou swath-plot, que é um diagrama que mostra o valor médio do volume contido em um dado painel de direção leste-oeste e com largura de 50 metros.

A quantificação do volume se deu através do volume esperado, como definido na Equação 3.30. Em cada bloco dos domínios em estudo há a probabilidade de ocorrência de determinado domínio, obtida a partir das simulações. Em cada bloco também há a geologia definida por métodos distintos, interpretação e interpolação. $O$ 
resultado do volume esperado foi definido pela multiplicação do volume do bloco pela probabilidade de ocorrência deste domínio.

Sendo assim, o resultado final é um modelo que apresenta por bloco, a litologia definida pela interpretação, a litologia definida pela interpolação, a geologia definida pelo mais provável das simulações, o volume esperado em cada método e, por fim, a incerteza dos modelos a partir do desvio padrão das simulações.

\subsubsection{Análise Local}

A Figura 5.1 contém a localização dos painéis utilizados para o cálculo dos swath-plots. Os volumes foram avaliados para os modelos obtidos pela interpretação, interpolação multiquádrica e para os cenários de mínimo e máximo para a simulação. As Figuras 5.2 e 5.3 apresentam os resultados da análise local para os domínios (III) e $(\mathrm{VI})$, respectivamente. A direção dos painéis foi escolhida por ser a direção perpendicular às principais estruturas do depósito.

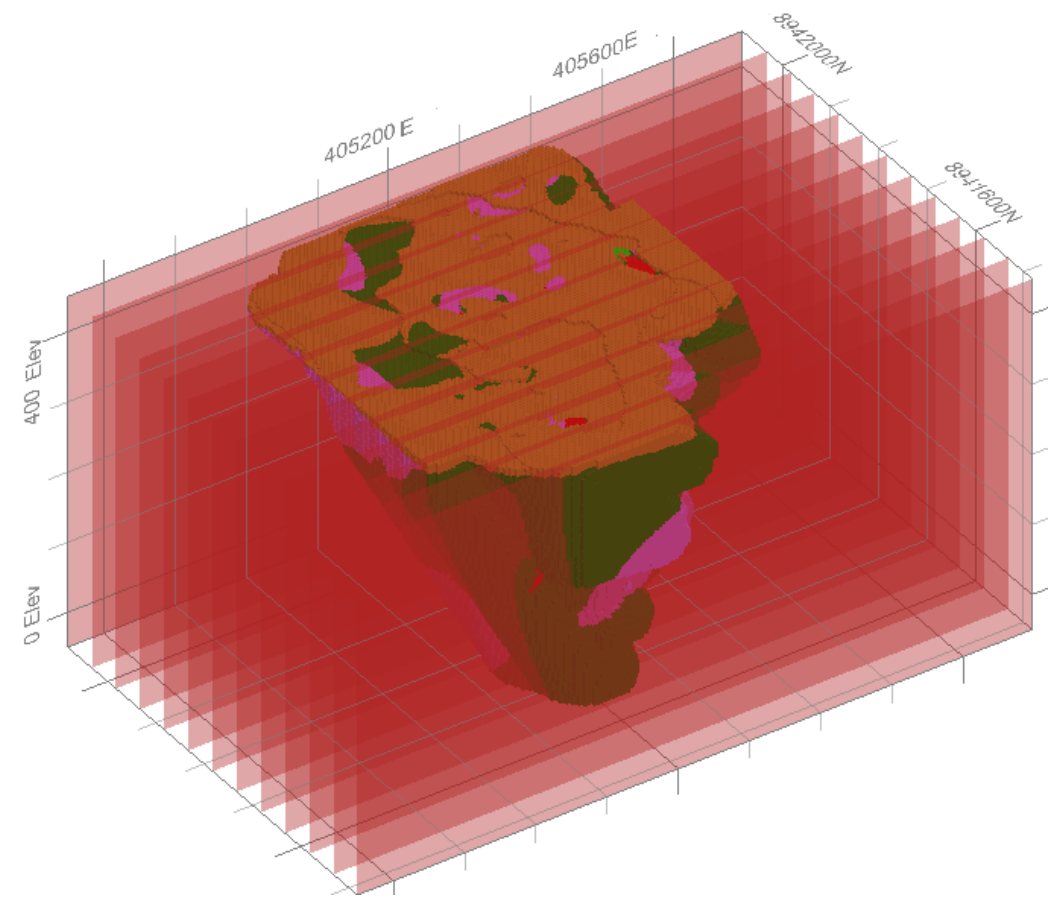

Figura 5.1 - Painéis utilizados para o cálculo dos swath-plots nos 03 modelos gerados. 
Os resultados dos volumes na análise local mostram uma coerência em relação à tendência nos domínios modelados, com diferença apenas em relação aos valores obtidos para cada modelo. As regiões que apresentam as maiores diferenças nos dois domínios podem ser consideradas com maior incerteza para quantificação do volume.

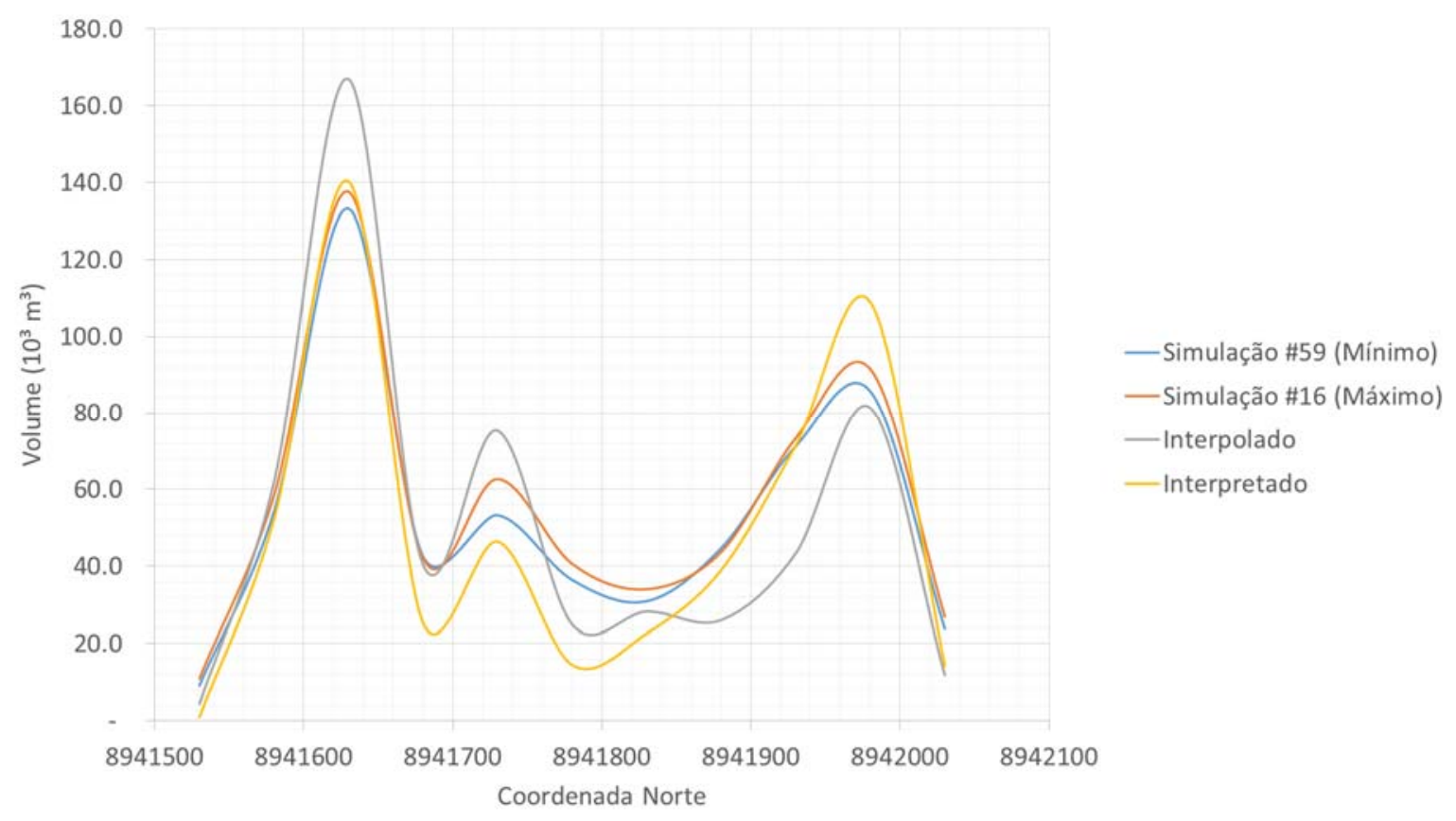

Figura 5.2 - Swath-plot para os volumes esperados nos modelos geológicos para o domínio (III)

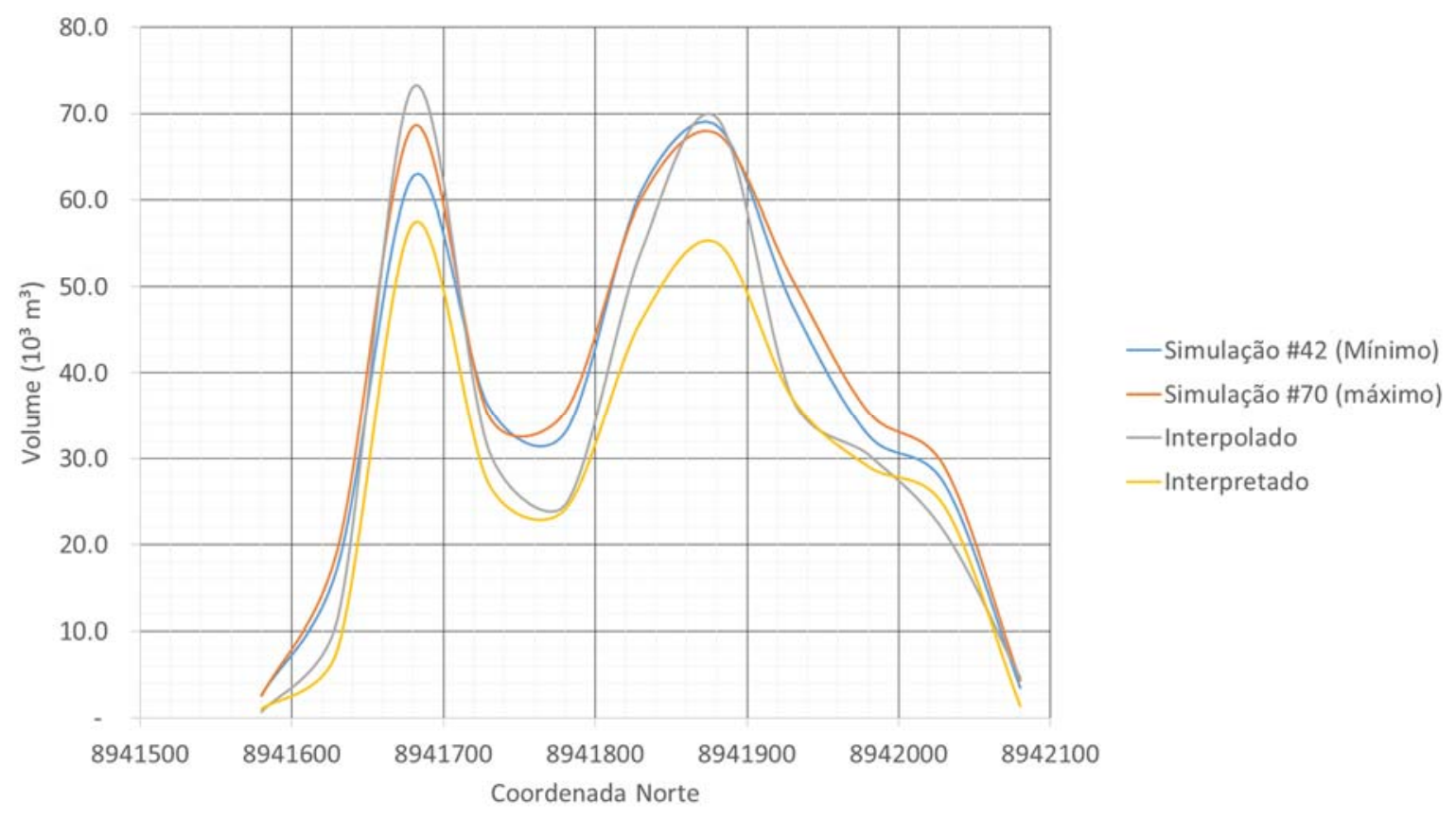

Figura 5.3 - Swath-plot para os volumes esperados nos modelos geológicos para o domínio (VI) 
Para o domínio (III), os modelos interpolado e interpretado apresentam 4 e 3 regiões, respectivamente, com diferenças acima de $40 \%$ em relação ao modelo simulado. Já o domínio (VI) apresenta 1 e 3 regiões para os modelos interpolado e interpretado, respectivamente, com diferença acima de $40 \%$ de volume em relação ao modelo simulado. A Tabela 5.1 contém as diferenças relativas em cada banda apresentada do swath-plot, para o domínio (III).

Tabela 5.1 - Diferença relativa dos volumes obtidos para os volumes do modelo geológico interpretado e interpolado em relação ao cenário de mínimo no domínio (III)

\begin{tabular}{ccc}
\hline Banda & $\begin{array}{c}\text { Diferença - } \\
\text { Interpolado e } \\
\text { Cenário de Mínimo }\end{array}$ & $\begin{array}{c}\text { Diferença - } \\
\text { Interpretado e } \\
\text { Cenário de Mínimo }\end{array}$ \\
\hline 8941530 & -52.60 & -75.29 \\
8941580 & 14.16 & -3.37 \\
8941630 & 25.31 & 5.13 \\
8941680 & -4.99 & -40.96 \\
8941730 & 41.32 & -10.93 \\
8941780 & -31.56 & -54.04 \\
8941830 & -8.56 & -24.53 \\
8941880 & -41.79 & -13.06 \\
8941930 & -39.15 & 0.27 \\
8941980 & -5.07 & 25.43 \\
8942030 & -50.10 & -35.24 \\
\hline Total & -3.83 & -8.27 \\
\hline
\end{tabular}

Fica claro nos resultados que em praticamente todas as regiões do depósito o volume obtido nos dois métodos, interpretado e interpolado, são menores que os valores obtidos no cenário de menor volume das simulações. Uma das explicações para os valores consistentemente menores para o modelo interpretado é a presença de pequenos intervalos nas amostras de sondagem, com baixa continuidade lateral, que não foram modelados no modelo geológico, porém são utilizadas na modelagem probabilística da interpolação e da simulação. O fato da simulação ter maior liberdade de atribuir domínios nos blocos, independentemente da sua localização no espaço, 
enquanto a interpretação e a interpolação são condicionadas pelas amostras observadas, também pode ter afetado as proporções finais. Isso significa que a simulação tem maior grau de liberdade que os outros dois métodos e, consequentemente, maiores frequências dos domínios de menor proporção simulados. Adicionalmente, um dos motivos possíveis também levantados é o fato de a SSI ser sequencial, fazendo com que geometrias e ocorrências irreais sejam propagadas ao longo de toda a simulação.

Outro fator de influência na incerteza dos volumes é o número de amostras na região avaliada. Nota-se, a partir da Figura 5.4, que as diferenças entre os volumes são baixas nas regiões com grande presença de amostra, como na banda $8941580 \mathrm{~N}$ e $8941630 \mathrm{~N}$, que mostram diferença de volume de apenas $3 \%$ e $5 \%$, respectivamente. Esta região contém elevado número de amostras do domínio (III) e contribuiu para um melhor controle da modelagem.

As mesmas considerações anteriores são válidas para o domínio (VI), uma vez que as realizações da simulação mostraram resultados acima dos volumes apresentados nos modelos interpretado e interpolado. A Tabela 5.2 contém as diferenças relativas entre os modelos por painéis de média móvel. 


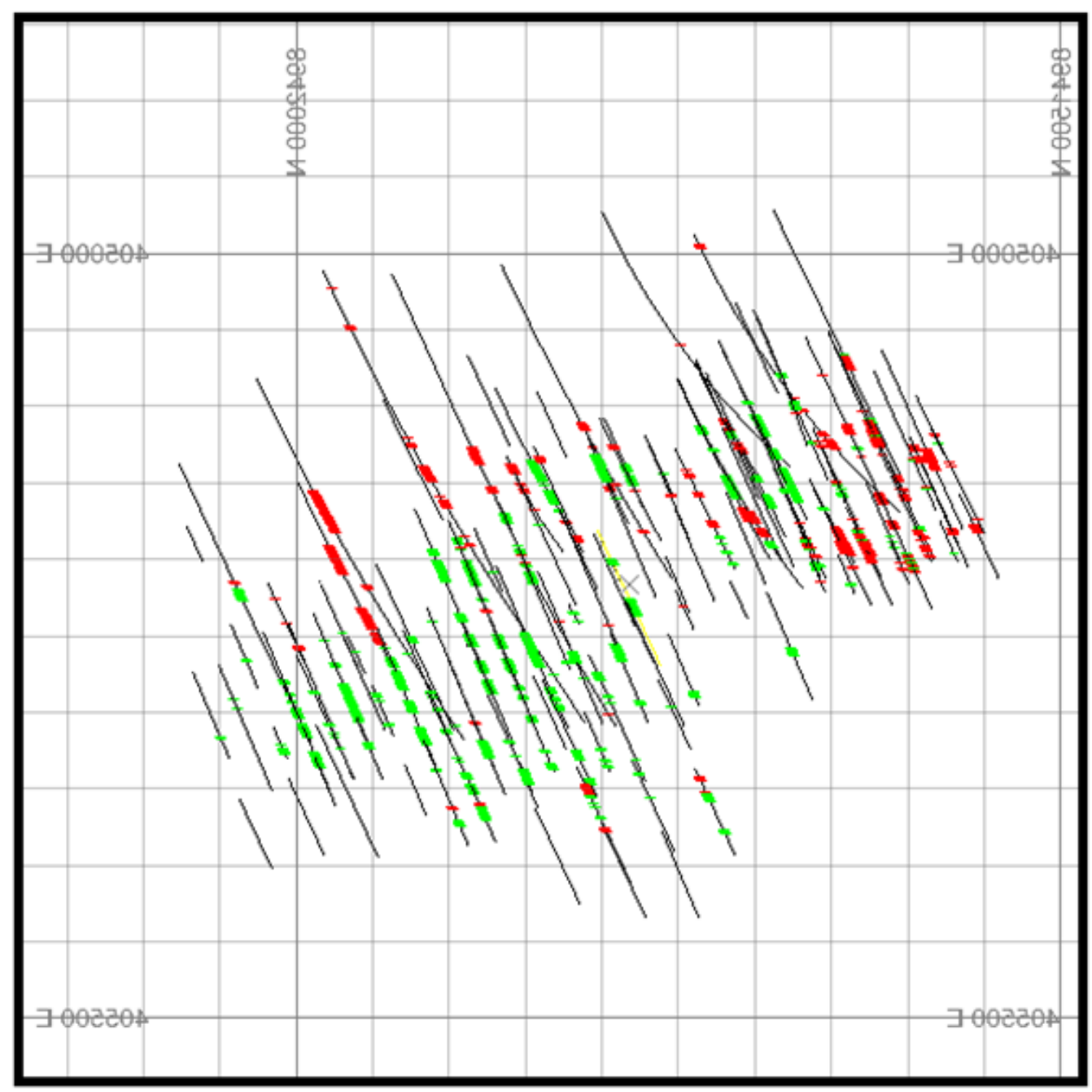

Figura 5.4 - Amostras disponíveis para a modelagem dos domínios (III), em vermelho e (VI), em verde.

A Figura 5.5 apresenta os perfis pertencentes às bandas com maior diferença em relação aos volumes modelados para o domínio (III) e domínio (VI). Esta comparação visual tem como finalidade a verificação do comportamento dos distintos métodos nas regiões de maior incerteza.

Nota-se que nos locais com espessuras mais expressivas do domínio (III) e (VI) a reprodutibilidade dos domínios entre os modelos é mais aderente. Nota-se também a reprodução aproximada da estruturação do depósito. O resultado obtido pelos métodos de interpolação e de simulação mostram mergulhos mais suaves em relação ao modelo interpretado. 
Tabela 5.2 - Diferença relativa dos volumes obtidos para os volumes do modelo geológico interpretado e interpolado em relação ao cenário de mínimo no domínio (VI)

\begin{tabular}{ccc}
\hline Banda & $\begin{array}{c}\text { Diferença - } \\
\text { Interpolado e } \\
\text { Cenário de Mínimo }\end{array}$ & $\begin{array}{c}\text { Diferença - } \\
\text { Interpretado e } \\
\text { Cenário de Mínimo }\end{array}$ \\
\hline 8941580 & -73.48 & -60.92 \\
8941630 & -34.63 & -54.71 \\
8941680 & 16.46 & -8.66 \\
8941730 & -14.17 & -25.05 \\
8941780 & -25.52 & -27.08 \\
8941830 & -11.35 & -24.44 \\
8941880 & 1.34 & -19.65 \\
8941930 & -22.69 & -22.60 \\
8941980 & -6.93 & -11.19 \\
8942030 & -20.66 & -9.70 \\
8942080 & 32.86 & -60.23 \\
\hline Total & -8.85 & -20.92 \\
\hline
\end{tabular}

O resultado obtido nas simulações apresenta características já esperadas para este tipo de método, que é a alta variabilidade dos dados, baixa continuidade geológica entre os nós, e feições que não têm correlação com a geologia local, como a presença de diversos nós de determinado domínio isolados no meio de outro domínio. Nota-se que os volumes simulados tendem a ser maiores devido a estes pontos.

Os volumes absolutos dos domínios (III) e (VI) oriundos do processo de simulação têm magnitude significativamente maior em relação aos volumes dos modelos interpretado e interpolado. Isso se deve basicamente ao grau de liberdade das simulações que criou sobremaneira blocos isolados destes domínios ao longo de todo depósito. Por isso, a utilização de volume esperado foi a mais adequada para comparação dos volumes de modelos distintos, uma vez que os domínios que nas realizações tenham ocorrido poucas vezes em determinado bloco tem probabilidade de ocorrência proporcional ao seu número de ocorrência. 

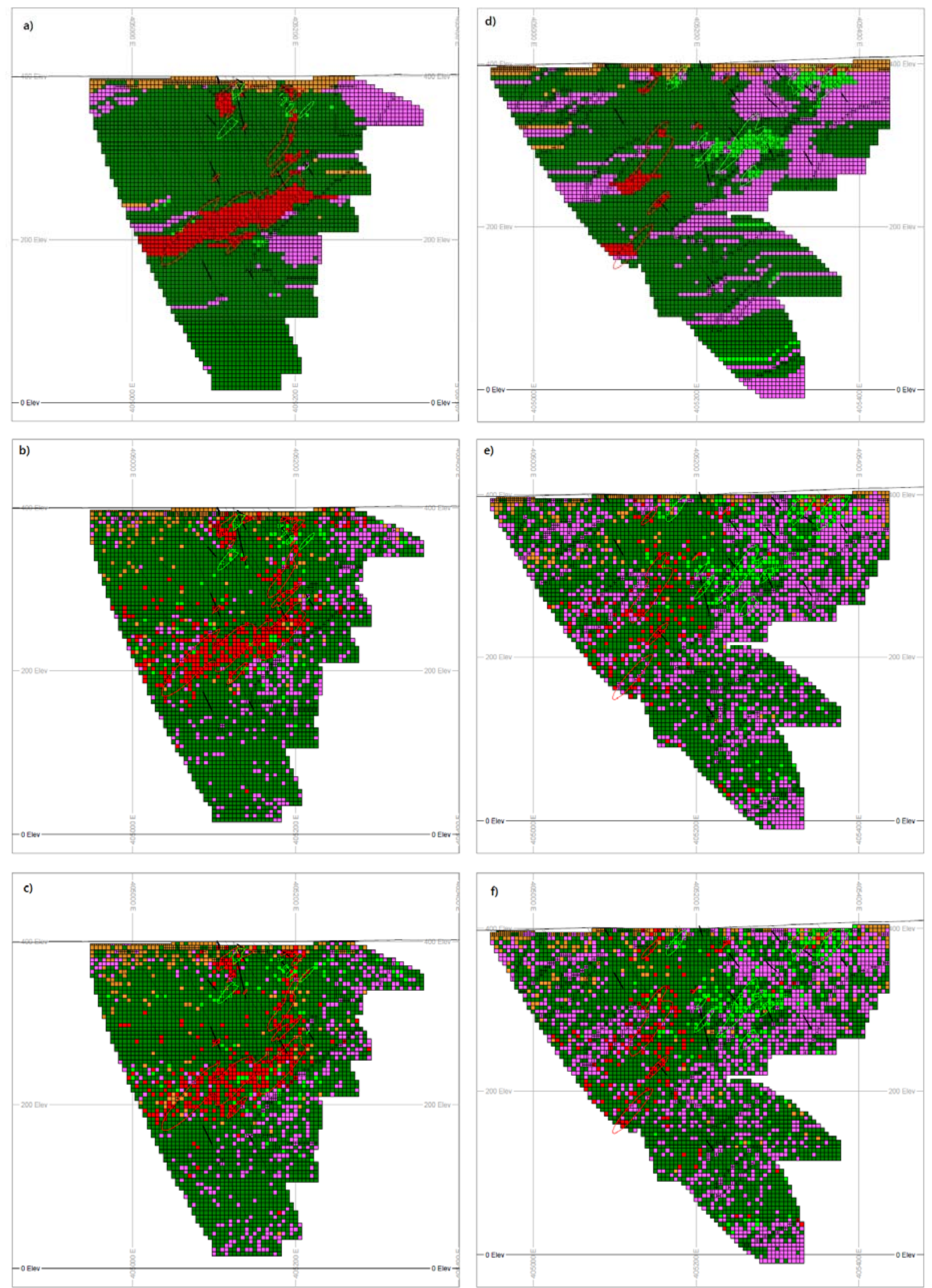

Figura 5.5 - Comparação visual entre o modelo geológico interpretado (linhas contínuas) com os modelos interpolado (a, d), cenário de mínimo (b, e) e máximo (c, f) do domínio (III) nas bandas $8941680 \mathrm{~N}$ (esquerda) e 8941780N (direita). Em laranja, domínio I; em vermelho, domínio III; em rosa domínio IV; em verde escuro, domínio V; e em verde claro, domínio VI. Traços pretos, sondagens. 


\subsubsection{Parametrização das probabilidades}

A parametrização tem como objetivo apresentar a probabilidade mínima de ocorrência por bloco para que determinado domínio possua dado volume. Os volumes obtidos por modelagem interpretativa e por interpolação foram então, comparados para se avaliar a probabilidade mínima necessária para que o volume modelado seja honrado. O resultado da distribuição de probabilidades para os domínios (III) e (VI) para todos os blocos do campo geométrico pode ser observado na Figura 5.6.
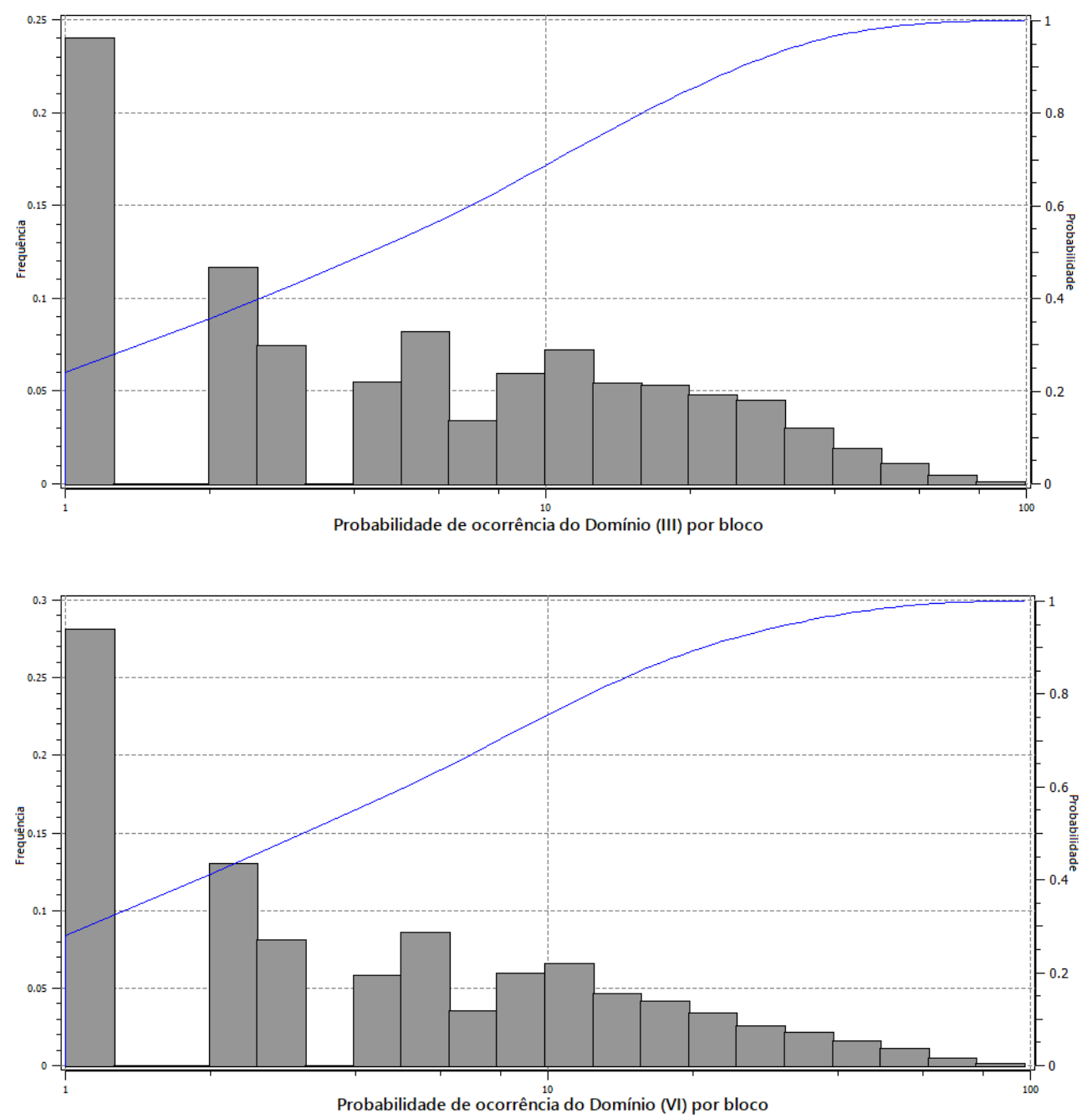

Figura 5.6 - Distribuição de probabilidades e diagrama P-P por bloco para os domínios (III) e (VI)

A estatística descritiva das probabilidades para cada domínio é apresentada na Tabela 5.3. 
Tabela 5.3 - Probabilidade de ocorrência, em \%, para os domínios, por bloco, nas 101 realizações.

\begin{tabular}{lcccccc}
\hline & Domínio (I) & Domínio (II) & Domínio (III) & Domínio (IV) & Domínio (V) & Domínio (VI) \\
\hline Numéro de Nós & 73172 & 172663 & $\mathbf{2 0 1 9 5 1}$ & 387842 & 418424 & $\mathbf{1 6 4 3 1 4}$ \\
Média & $\mathbf{2 0 . 2 2}$ & $\mathbf{4 . 7 5}$ & $\mathbf{9 . 7 7}$ & $\mathbf{2 3 . 6 6}$ & $\mathbf{6 4 . 6 5}$ & $\mathbf{8 . 2 4}$ \\
Variância & 494.18 & 34.23 & $\mathbf{1 4 4 . 7 5}$ & 345.56 & 474.60 & $\mathbf{1 2 7 . 2 9}$ \\
Máximo & 99.00 & 84.00 & $\mathbf{9 9 . 0 0}$ & 100.00 & 100.00 & $\mathbf{9 7 . 0 0}$ \\
Quartil Superior & 32.00 & 6.00 & $\mathbf{1 3 . 0 0}$ & 34.00 & 81.00 & $\mathbf{1 0 . 0 0}$ \\
Mediana & 11.00 & 2.00 & $\mathbf{5 . 0 0}$ & 20.00 & 68.00 & $\mathbf{4 . 0 0}$ \\
Quartil Inferior & 3.00 & 1.00 & $\mathbf{2 . 0 0}$ & 9.00 & 51.00 & $\mathbf{1 . 0 0}$ \\
Mínimo & 1.00 & 1.00 & $\mathbf{1 . 0 0}$ & 1.00 & 1.00 & $\mathbf{1 . 0 0}$ \\
\hline
\end{tabular}

O resultado visual das probabilidades é apresentado na Figura 5.7. A Figura mostra a mesma estruturação local do depósito. Quando maior o valor em cada bloco, maior a probabilidade de ocorrência de determinado domínio.
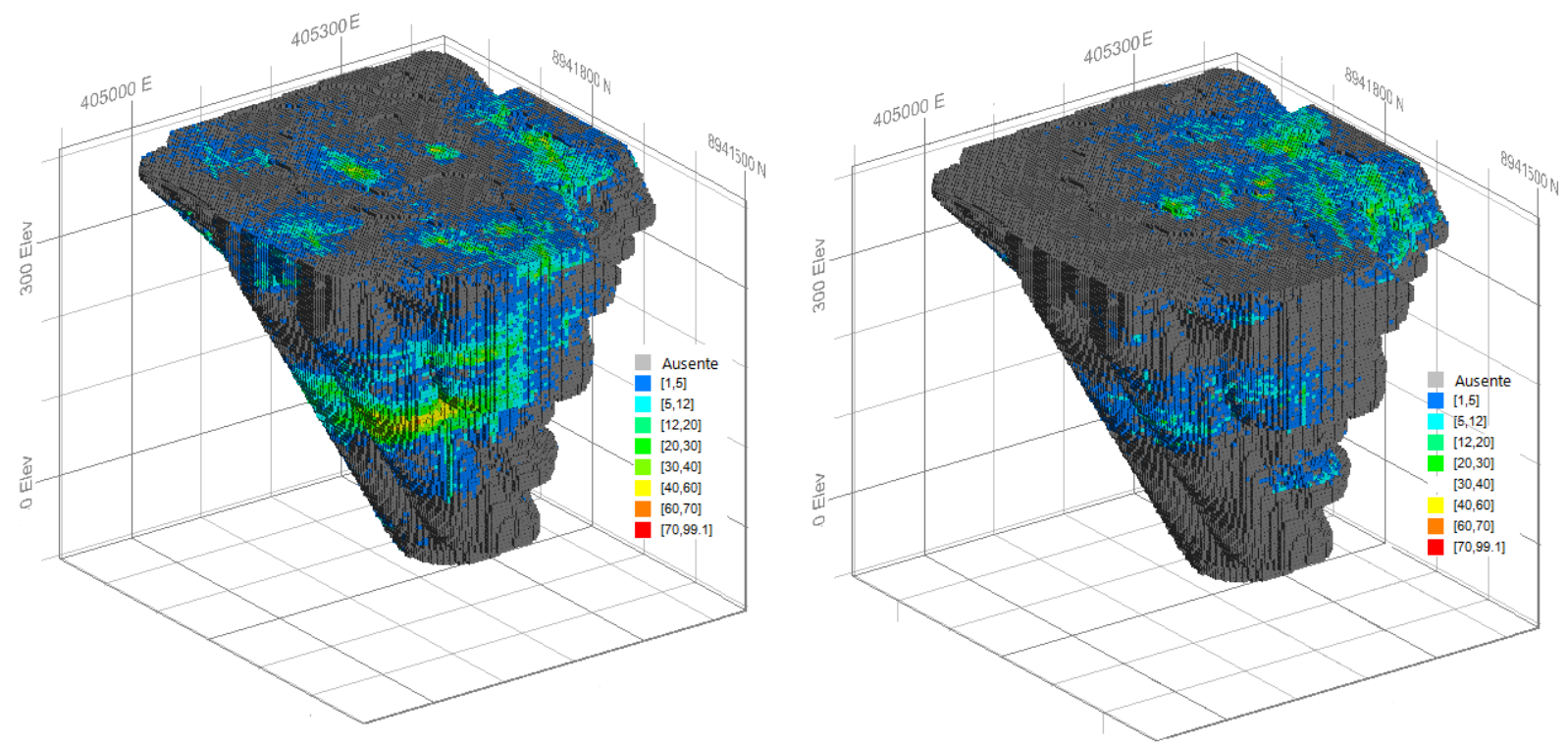

Figura 5.7 - Probabilidade de ocorrência obtida a partir das simulações para o Domínio (III), à esquerda, e (VI), à direita.

A partir dos valores de probabilidade de ocorrência dos domínios (III) e (VI) por bloco, foram realizados cortes nos valores de probabilidade de $25 \%, 50 \%$ e $75 \%$, e foram comparados os resultados obtidos nas Figuras 5.8 e 5.9, bem como a contabilização dos volumes. Os volumes obtidos para diversos cortes são apresentados na Tabela 5.4 e Tabela 5.5 . 


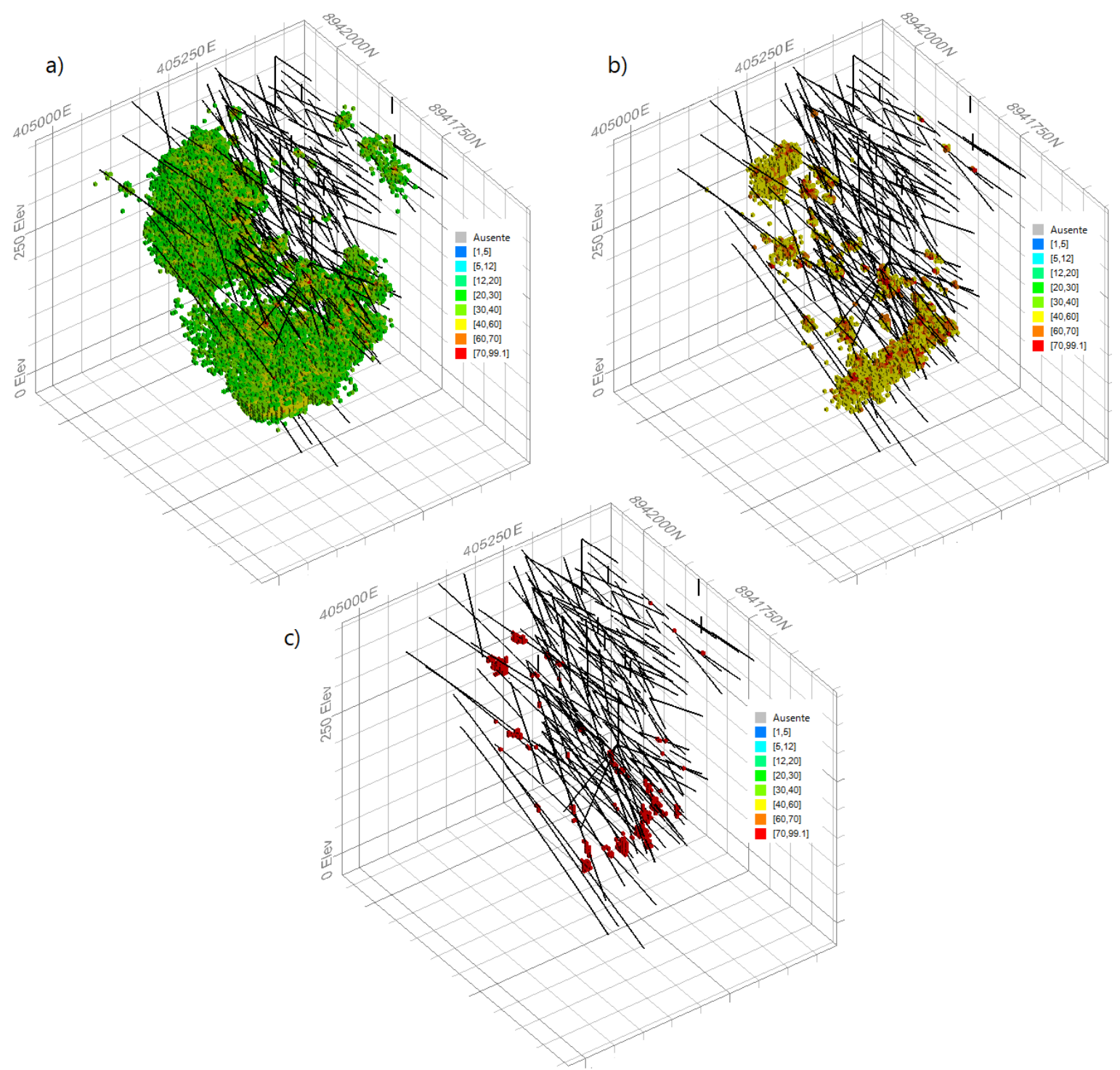

Figura 5.8 - Mapa de probabilidades para o domínio (III), com cortes de $25 \%$ (a), $50 \%$ (b) e $75 \%$ (c)

Tabela 5.4 - Parametrização dos volumes a partir de diferentes cortes de probabilidade no domínio (III)

\begin{tabular}{rc}
\hline $\begin{array}{c}\text { Volume }\left(10^{3} \mathrm{~m}^{3}\right) \\
\text { Domínio (III) }\end{array}$ & $\begin{array}{c}\text { Probabilidade de } \\
\text { ocorrência (\%) }\end{array}$ \\
\hline $19,107.52$ & 1 \\
$11,837.25$ & 5 \\
$5,345.32$ & 15 \\
$2,594.91$ & 25 \\
$1,215.77$ & 35 \\
569.88 & 45 \\
390.50 & 50 \\
262.75 & 55 \\
102.38 & 65 \\
34.38 & 75 \\
\hline
\end{tabular}




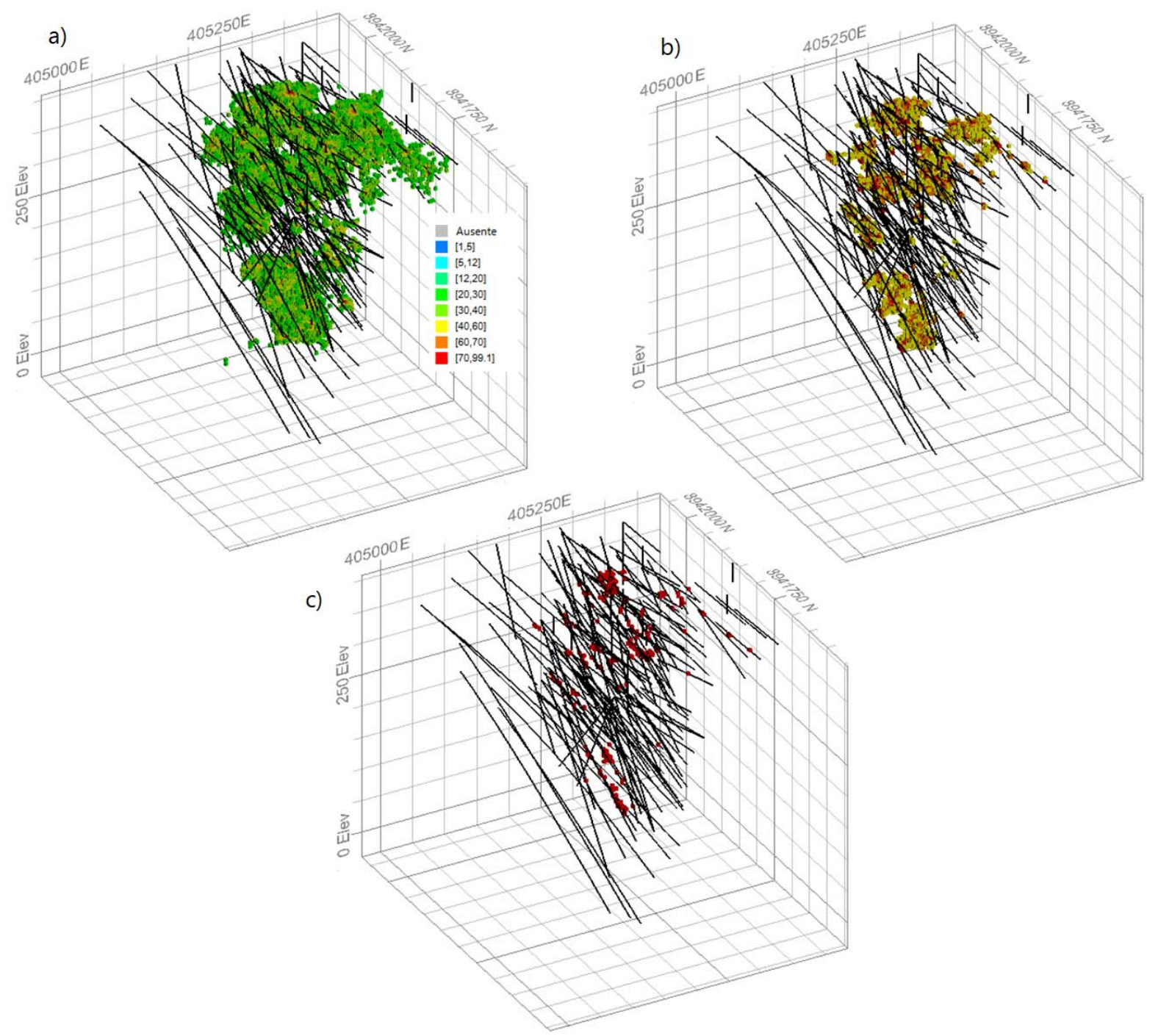

Figura 5.9 - Mapa de probabilidades para o domínio (VI), com cortes de $25 \%$ (a), $50 \%$ (b) e $75 \%$ (c)

Tabela 5.5 - Parametrização dos volumes a partir de diferentes cortes de probabilidade no domínio (VI)

\begin{tabular}{cc}
\hline $\begin{array}{c}\text { Volume }\left(10^{3} \mathrm{~m}^{3}\right) \\
\text { Domínio (III) }\end{array}$ & $\begin{array}{c}\text { Probabilidade de } \\
\text { ocorrência (\%) }\end{array}$ \\
\hline $14,669.82$ & 1 \\
$8,245.67$ & 5 \\
$3,211.19$ & 15 \\
$1,560.11$ & 25 \\
829.50 & 35 \\
435.13 & 45 \\
308.75 & 50 \\
213.00 & 55 \\
84.63 & 65 \\
28.25 & 75 \\
\hline
\end{tabular}


A partir dos dados apresentados nas Tabelas $\mathbf{5 . 4}$ e $\mathbf{5 . 5}$ foi gerado o gráfico do volume parametrizado pelas probabilidades, apresentado na Figura 5.10. O gráfico também inclui os volumes obtidos no modelo interpolado e no modelo interpretado.
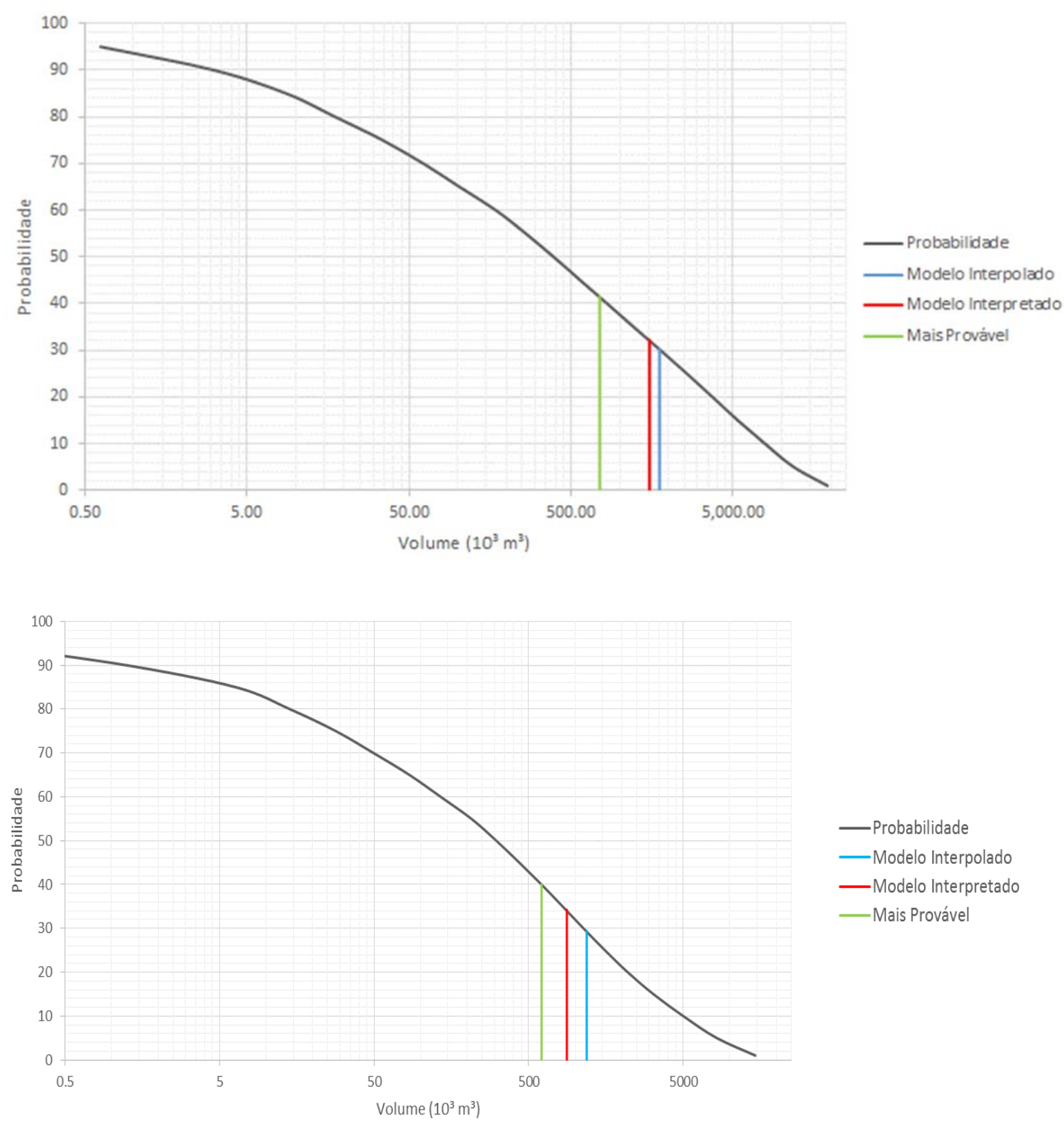

Figura 5.10 - Parametrização do volume do domínio (III) (acima) e (VI) (abaixo) para determinados cortes de probabilidade 
A análise da parametrização auxilia na determinação da probabilidade de ocorrência de determinados volumes a partir de cortes estabelecidos. Por exemplo, para que o volume do domínio (III) modelado pela interpretação geológica seja respeitado, é necessário que todos os blocos com probabilidade de ocorrência do domínio (III) maior do que 32\% sejam selecionados. O mesmo ocorre para o domínio (VI) nos dois tipos de modelos, interpolado e interpretado, onde são necessários em torno de no mínimo $30 \%$ de corte na probabilidade de ocorrência do domínio para que os volumes modelados sejam honrados. Levando-se em consideração um universo com seis domínios geológicos, o corte de $30 \%$ é uma probabilidade elevada para a ocorrência de determinado domínio.

A partir deste gráfico de parametrização, durante a etapa de gestão de riscos, podem ser estudados diversos cenários com tolerância de probabilidade para avaliação da quantificação do volume esperado.

\subsection{Quantificação da Incerteza Volumétrica por tipo de modelo}

Neste item é apresentado o resultado da incerteza em relação ao volume quantificado para os métodos de interpolação e de interpretação a partir da variabilidade das simulações, que balizará as possíveis variações em termos de previsão de volume.

O resultado das simulações, para cada domínio, apresentou uma distribuição de frequência com média e desvio padrão bem definidos, com curvas aproximadamente normais, apresentados na Figura 4.20. Devido às magnitudes distintas de volume obtido para a modelagem nas simulações e para que os modelos interpolado e interpretado tenham uma curva de frequência de volumes, foi realizada a transferência da variância das simulações para os valores obtidos nas modelagens. Esta metodologia é apresentada na Equação 3.4. 
Os valores utilizados para o cálculo das variâncias dos modelos interpolado e interpretado são apresentados na Tabela 5.6.

Tabela 5.6 - Esperança e variância para os volumes da simulação, modelo interpretado (geo) e interpolado $(\mathrm{mq})$

\begin{tabular}{crrrccc}
\hline Domínio & \multicolumn{1}{c}{$\mathrm{E}\left[\mathrm{X}_{\text {sim }}\right]$} & $\operatorname{Var}\left[\mathrm{X}_{\text {sim }}\right]$ & $\mathrm{E}\left[\mathrm{X}_{\mathrm{mq}}\right]$ & $\mathrm{E}\left[\mathrm{X}_{\text {geo }}\right]$ & $\mathrm{Kmq}$ & $\mathrm{Kgeo}$ \\
\hline (I) & $1,529.12$ & 659.47 & $2,093.46$ & $1,234.50$ & 1.37 & 0.81 \\
(II) & 995.23 & 886.00 & 675.72 & - & 0.68 & - \\
(III) & $2,444.01$ & $1,826.69$ & $1,741.50$ & $1,526.45$ & 0.71 & 0.62 \\
(IV) & $11,354.74$ & $5,364.13$ & $9,878.91$ & $11,048.03$ & 0.87 & 0.97 \\
(V) & $33,356.27$ & $8,300.75$ & $35,787.11$ & $36,676.41$ & 1.07 & 1.10 \\
(VI) & $1,689.63$ & 688.22 & $1,192.30$ & 883.61 & 0.71 & 0.52 \\
\hline
\end{tabular}

Com estes dados definidos por domínios, realizou-se a transferência das variâncias obtidas na simulação para os modelos interpolado e interpretado. Os resultados obtidos encontram-se na Tabela 5.7.

Tabela 5.7 - Incerteza calculada para cada domínio modelado

\begin{tabular}{crrcccc}
\hline \multirow{2}{*}{ Domínio } & \multicolumn{2}{c}{ Modelo interpolado } & \multicolumn{2}{c}{ Modelo Interpretado } & \multirow{2}{*}{ CV mq } & CVgeo \\
& \multicolumn{1}{c}{$\mathrm{E}[\mathrm{Xmq}]$} & $\operatorname{Var}[\mathrm{Xmq}]$ & \multicolumn{1}{c}{$\mathrm{E}[$ Xgeo } & $\operatorname{Var}[$ Xgo $]$ & & \\
\hline (I) & $2,093.46$ & $1,236.06$ & $1,234.50$ & 429.82 & 0.02 & 0.02 \\
(II) & 675.72 & 408.43 & - & - & 0.03 & - \\
(III) & $1,741.50$ & 927.48 & $1,526.45$ & 712.57 & 0.02 & 0.02 \\
(IV) & $9,878.91$ & $4,060.34$ & $11,048.03$ & $5,078.25$ & 0.01 & 0.01 \\
(V) & $35,787.11$ & $9,554.67$ & $36,676.41$ & $10,035.43$ & 0.00 & 0.00 \\
(VI) & $1,192.30$ & 342.70 & 883.61 & 188.22 & 0.02 & 0.02 \\
\hline
\end{tabular}

Os resultados apresentados na Tabela 5.7 são apresentados também em forma gráfica nas Figuras 5.11 a 5.16 . 


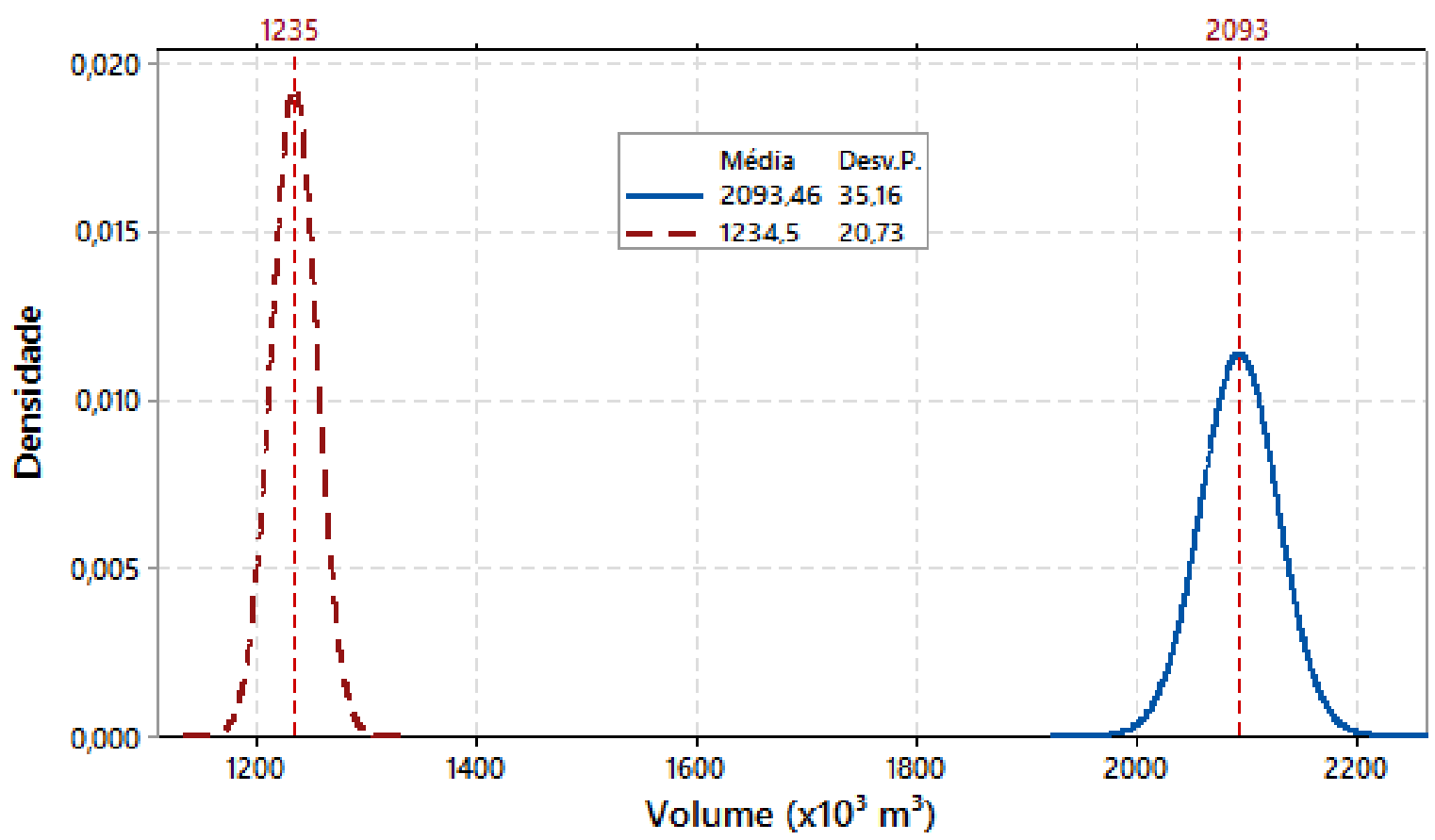

Figura 5.11 - Média e incerteza do volume para o domínio (I). Modelo interpretado (linha pontilhada) e interpolado (linha contínua)

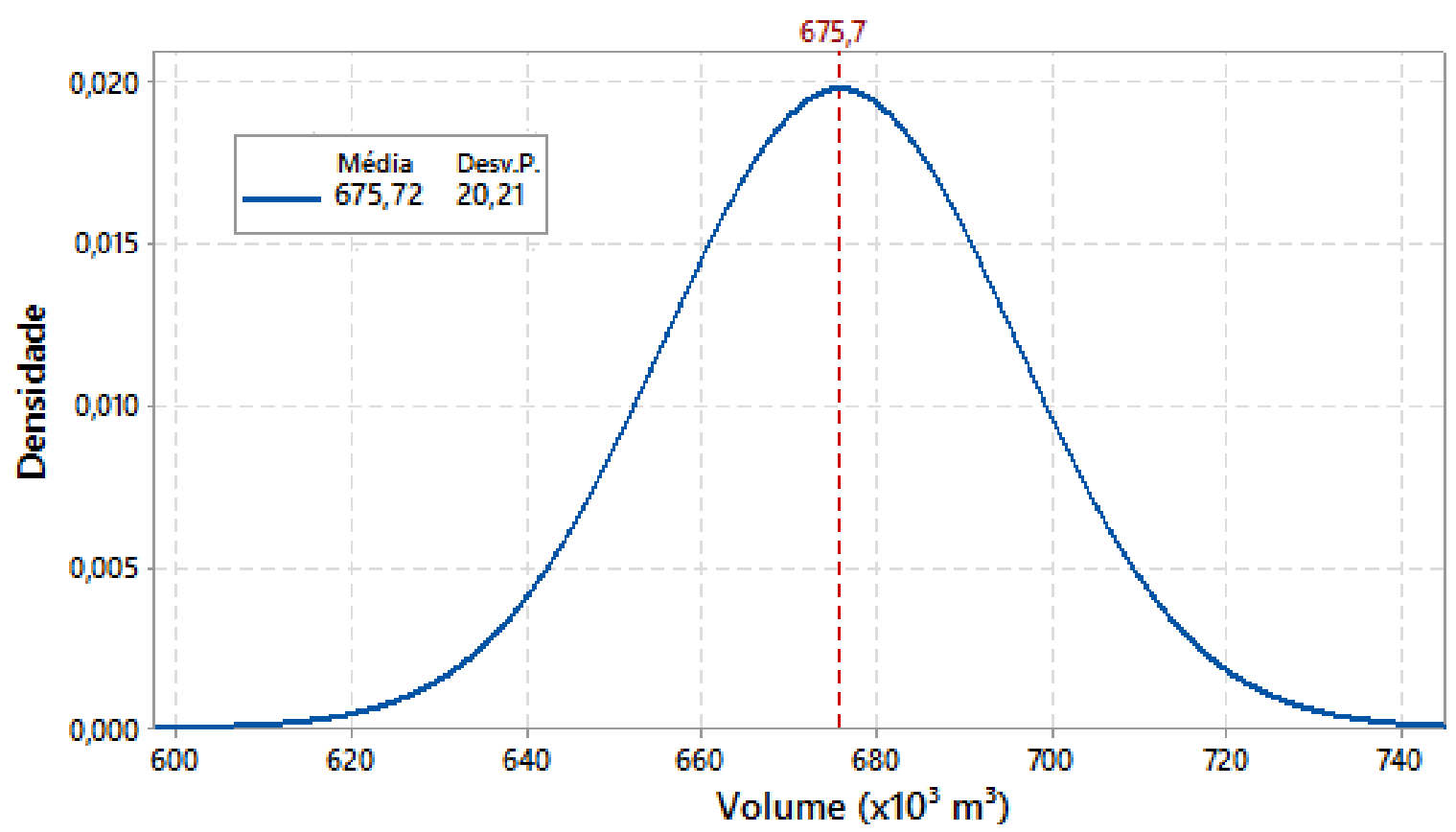

Figura 5.12 - Média e incerteza do volume para o domínio (II). Modelo interpolado 


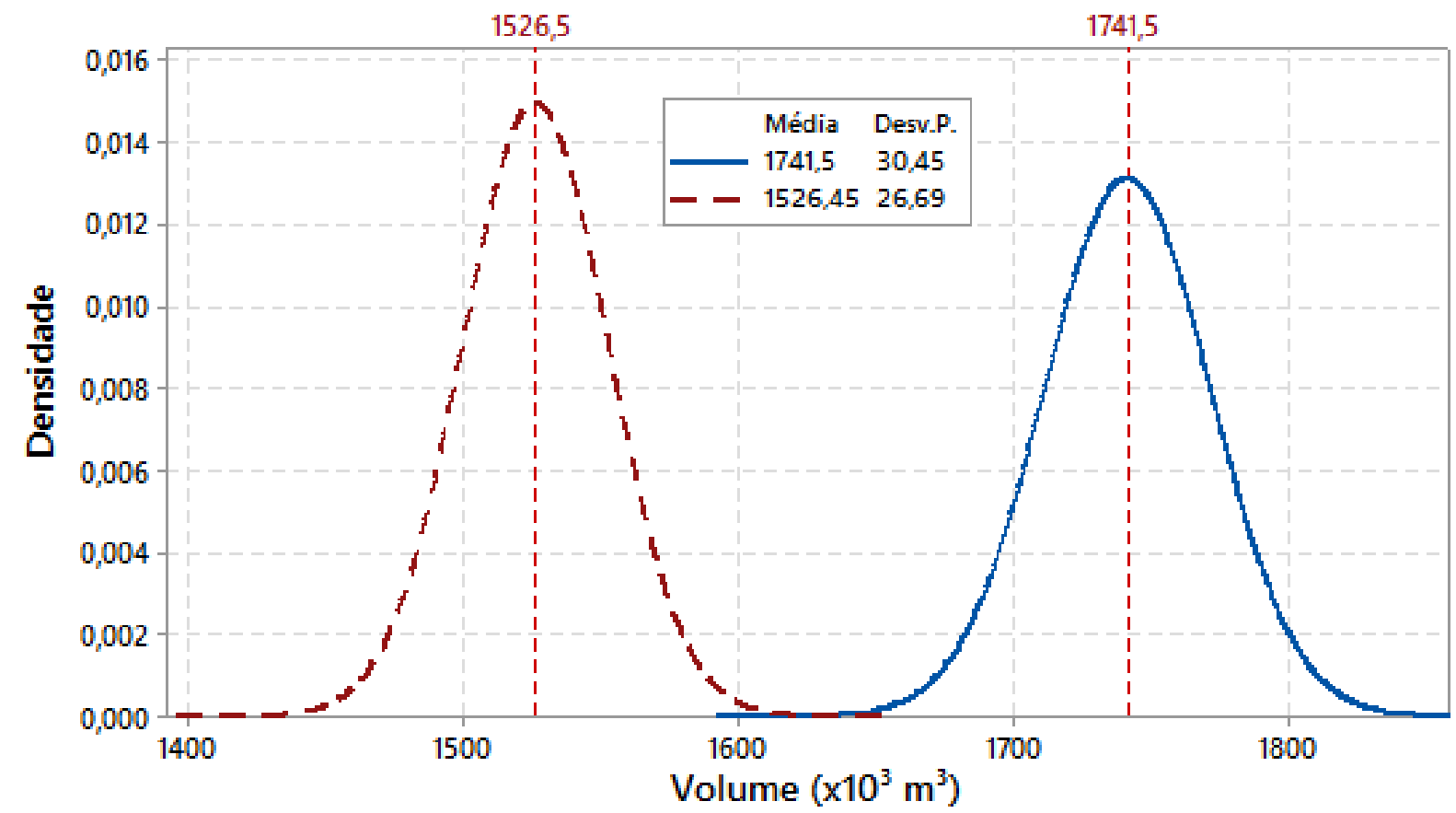

Figura 5.13 - Média e incerteza do volume para o domínio (III). Modelo interpretado (linha pontilhada) e interpolado (linha contínua)

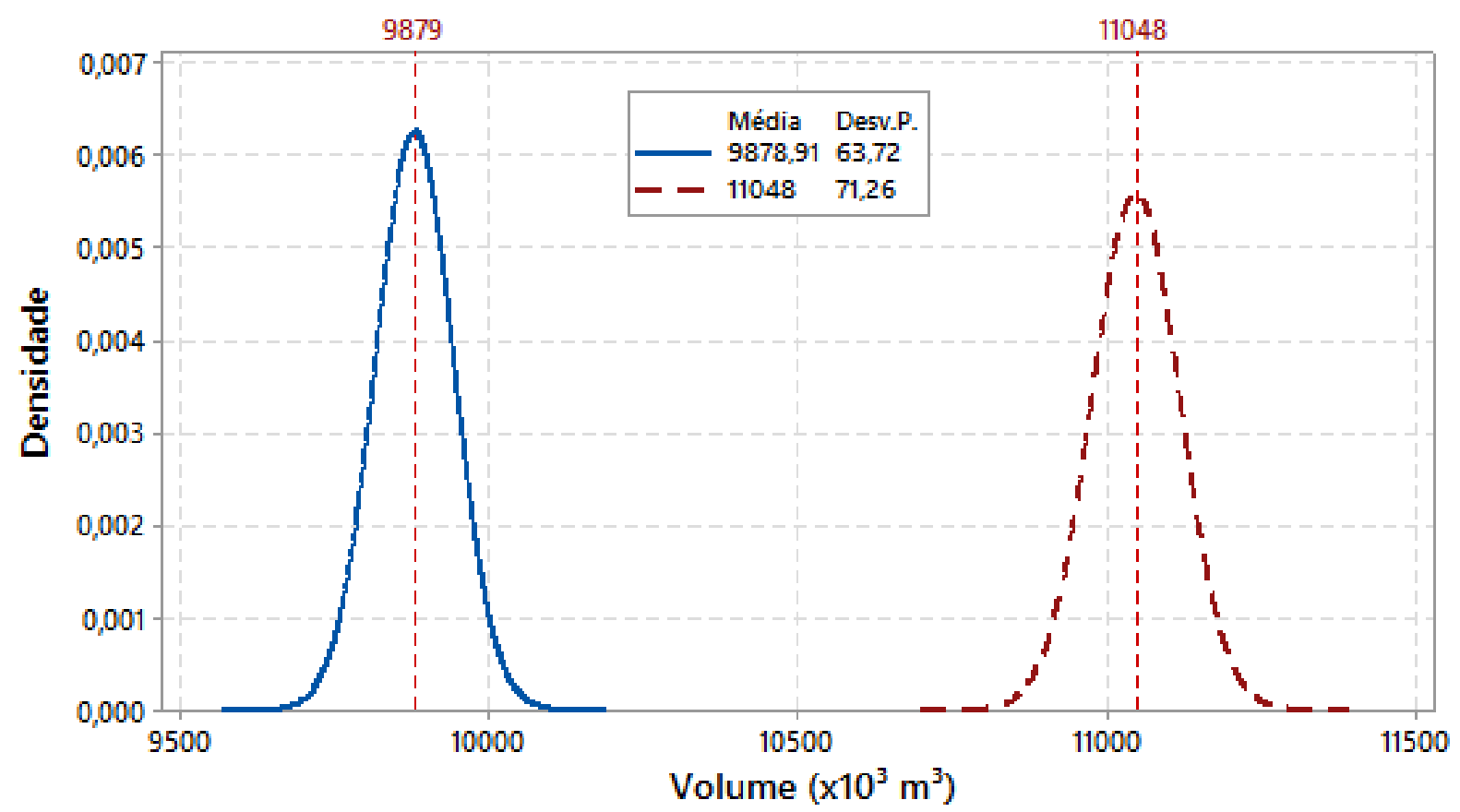

Figura 5.14 - Média e incerteza do volume para o domínio (IV). Modelo interpretado (linha pontilhada) e interpolado (linha contínua) 


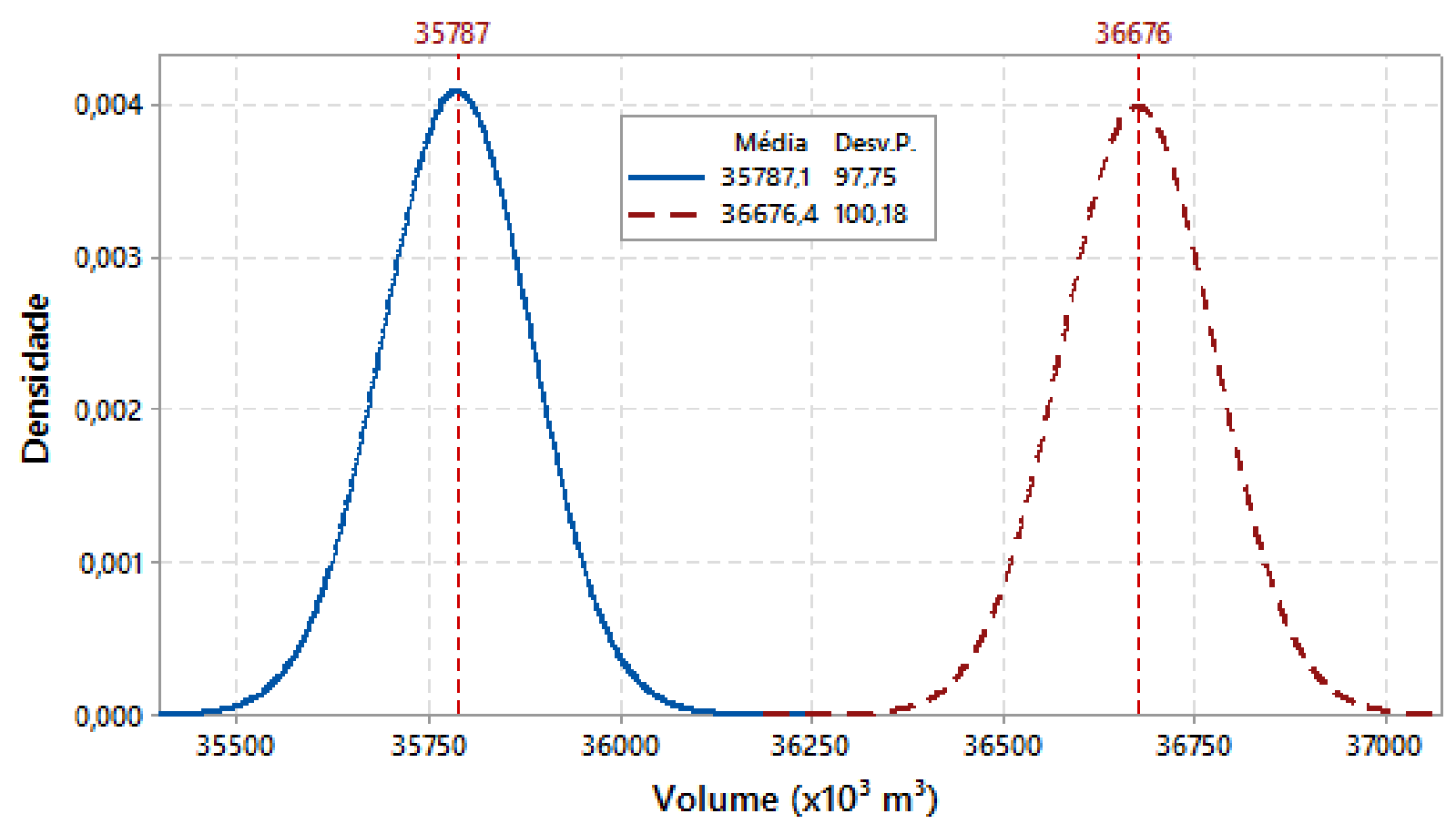

Figura 5.15 - Média e incerteza do volume para o domínio (V). Modelo interpretado (linha pontilhada) e interpolado (linha contínua)

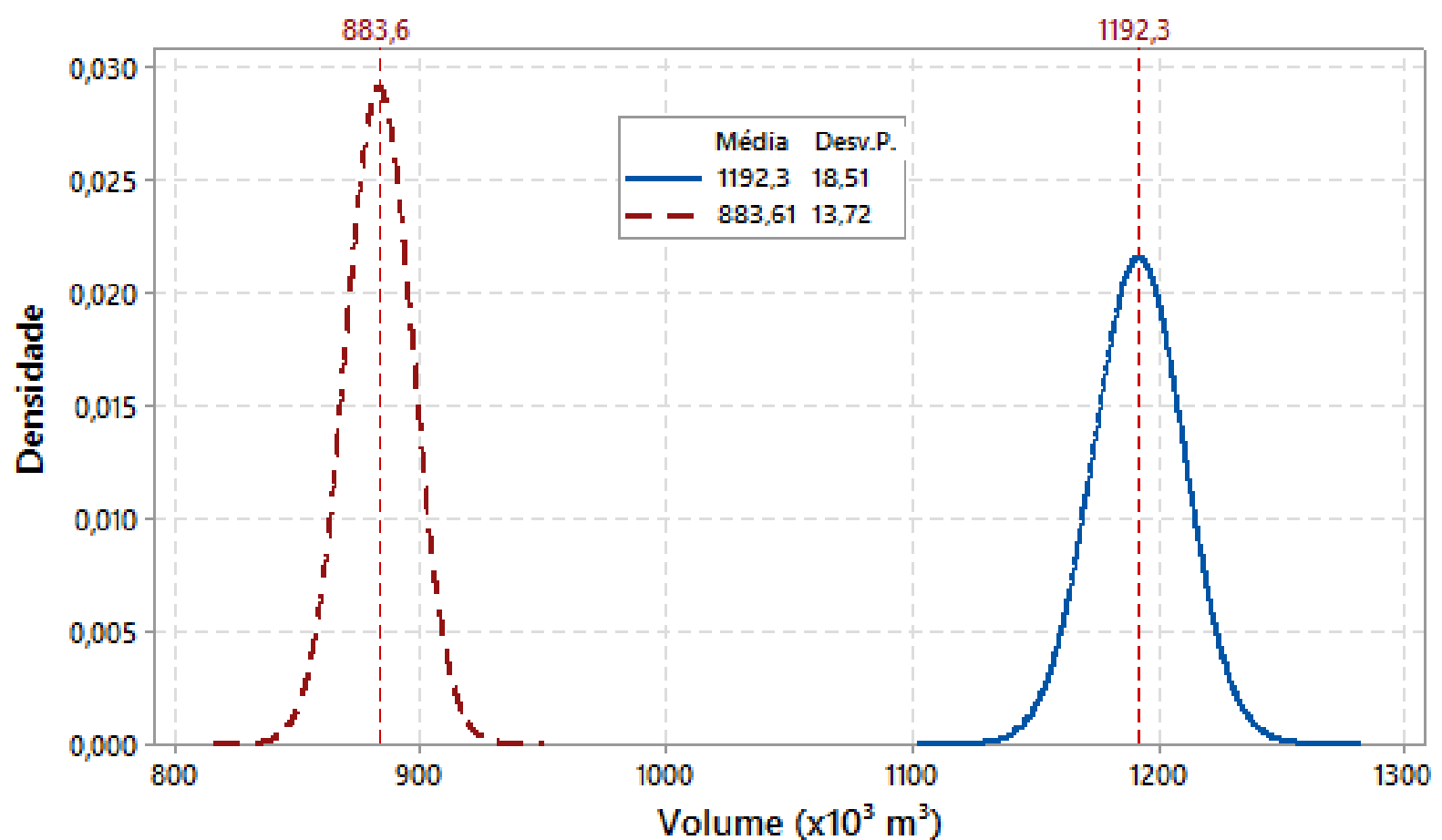

Figura 5.16 - Média e incerteza do volume para o domínio (VI). Modelo interpretado (linha pontilhada) e interpolado (linha contínua) 
A partir das curvas de distribuição de frequência para os volumes obtidos na modelagem interpretada e interpolada foi possível verificar que esses modelos apresentam menor incerteza quando os volumes do domínio são inferiores ao modelo simulado, e maior incerteza quando os volumes dos modelos interpretado e interpolado são maiores que os da simulação.

A diferença de volume obtida entre os diferentes métodos também é um resultado esperado, uma vez que são metodologias distintas de previsão da realidade.

Com estes resultados pode-se calcular o valor esperado do domínio, que é o valor modelado, e também a dispersão dos valores em termos do desvio padrão. 



\section{CONCLUSÕES}

Os resultados obtidos durante a aplicação das técnicas para quantificação da incerteza a partir dos diversos cenários de simulação se mostraram de grande importância para avaliar a dispersão dos volumes da modelagem geológica interpretada e interpolada em cada domínio no depósito de Surubim.

Os resultados de probabilidade de ocorrência, obtidos pela junção de todos os cenários realizados na simulação, aliados à dispersão dos volumes de cada domínio nestas mesmas realizações, mostraram que a quantificação da incerteza utilizando o método apresentado neste trabalho se trata de uma ferramenta de grande potencial para o gerenciamento das incertezas associadas ao empreendimento durante diversas etapas da atividade mineira.

Os swath-plots permitiram a análise da dispersão do volume em diferentes métodos, e podem auxiliar na melhor definição de planos de lavra nestas regiões incertas. Este método auxilia na identificação de zonas com maior incerteza em relação à previsão de volumes, prevenindo superestimativas do material a ser lavrado.

Já a análise de incerteza global dos volumes por domínio se mostrou uma grande ferramenta para análise a longo prazo dos possíveis cenários que podem se suceder caso seja adotado determinado modelo de estimativa de volume.

A parametrização dos volumes em relação às probabilidades de ocorrência é também uma poderosa ferramenta para a gestão da incerteza.

Neste trabalho foi possível calcular a incerteza volumétrica associada à interpretação geológica, bem como à interpolação do modelo de blocos. As realizações da simulação sequencial por indicadoras permitem obter uma distribuição de frequências de volumes, caracterizada pela média e variância. Como discutido anteriormente, o volume médio obtido nos domínios simulados são distintos em 
relação aos volumes obtidos nos modelos interpretado e interpolado. Assim, existe um fator k, para cada domínio, que multiplica os volumes interpretado e interpolado, de tal forma que se igualem ao volume simulado. Com este fator $\mathrm{k}$, pode-se calcular a variância dos volumes interpretado e interpolado, como apresentado neste trabalho. Desta forma, cada domínio geológico, em cada modelo realizado poderá ser transformado em uma curva de distribuição contendo o valor esperado de volume no modelo adotado e um espectro de variância obtido do resultado das simulações. Acredita-se ser esta a principal contribuição da pesquisa.

A aplicação destas técnicas durante qualquer etapa da atividade mineira pode contribuir significativamente na gestão apropriada dos riscos relacionados à natureza estocástica do depósito. Sugestão para estudos futuros é a comparação destes resultados com resultados de produções reais, para aprimoramento e revisão de conceitos da técnica. 


\section{REFERÊNCIAS BIBLIOGRÁFICAS}

ALFIELD, P. (1989). Scattered Data Interpolation in Three or More Variables. Em: Mathematical Methods in Computer Aided Geometric Design, p. 1-33.

ALVES DA SILVA, F. C.; CHAUVET, A.; FAURE, M. (1993). Early Proterozoic orogeny (Transamazonian) and syntectonic granite emplacement in the Rio Itapicuru greenstone belt, Bahia, Brazil. Comptes Rendus de l'Academie des Sciences. Paris II, v. 316, 1139-1146.

ARMSTRONG, M. (1998). Basic linear geostatistics. New York, Springer. 153 p

BARBOSA, J. S. F. (1986). Constitution lithologique et metamorphique de la region granulitique du Sud de Bahia - Brésil. Tese (Doutorado). Université Pierre et Marie Curie, Paris, França.

BARBOSA, J. S. F. (1990). The granulites of the Jequié Complex and Atlantic mobile belt, southern Bahia, Brazil. An expression of Archean/Early Proterozoic plate convergence. In: Vielzeulf, D., Vidal, Ph. (Eds.). Granulites and Crustal Evolution, p. 195-221. Springer Netherlands.

BARBOSA, J. S. F.; ARCANJO, A. B. J.; ALVES DA SILVA, F. C.; PINHO, I. C. A.; OLIVEIRA, M. P. S.; SAVINI, D. S. (1996). Geologia das rochas de alto grau metamórfico da região de Ipiaú-sudeste da Bahia-Brasil. Congresso Brasileiro de Geologia, v. 6, 272-279. Salvador: SBG.

BARBOSA, J. S. F.; SABATÉ, P. (2002). Geological features and the Paleoproterozoic collision of the four Archean crustal segments of the São Francisco Craton Bahia, Brazil. A synthesis. Academia Brasileira de Ciências, 74(2), 343-359. 
BARBOSA, J. S. F.; SABATÉ, P.; MARINHO, M. M. (2003). O Cráton do São Francisco na Bahia: uma síntese. Revista Brasileira de Geociências, 33(1), 3-6.

BARBOSA, J. S. F.; SABATÉ, P. (2004). Archean and Paleoproterozoic crust of the São Francisco Craton, Bahia, Brazil: geodynamic features. Precambrian Research, 133, 1-27.

BÁRDOSSY, G.; FODOR, J. (2001). Traditional and new ways to handle uncertainty in geology. Natural Resources Research 10 (3), 179-187

BAYONA, V.; MOSCOSO, M.; KINDELAN, M. (2011). Optimal constant shape parameter for multiquadric based RBF-FD method. Academic Press. Journal of Computational Physics, v. 230, 19. pp 7384-7399

BOER, R. H.; MEYER, F. M.; CAWTHORN, R. G. (1994). Stable isotopic evidence for crustal contamination and desulfidation of the cupriferous Koperberg Suite, Namaqualand, South Africa. Geochimica et Cosmochimica Acta, 58, 26772687.

BÜHN, B. M. (2013). Análise Geoquímica dos sulfetos do depósito de Caraíba. Relatório Interno, Não Publicado.

BUHMANN, M. D. (2000). Radial basis function. Acta Numerica 2000. v. 9; pp.1-38

CAWTHORN, R. G.; MEYER, F. M. (1993). Petrochemistry of the Okiep copper district basic intrusive bodies, northwestern Cape Province, South Africa. Economic Geology, 88, 590-605.

CHAMBERS, R. L.; YARUS, J. M.; HIRD, K. B. (2000). Petroleum geostatistics for nongeostaticians - Part 2. The Leading Edge, 19, 592-599. 
CHAUVET, A.; SILVA, F. C. A.; FAURE, M.; GUERROT, C. (1997). Structural evolution of the Paleoproterozoic Rio Itapicuru granite-greenstone belt (Bahia, Brazil): the role of synkinematic plutons in the regional tectonics. Precambrian Research, $84,139-162$.

CHEN, H. (2008). The Marcona-Mina Justa District, Southcentral Peru: Implications for the genesis and definition of the iron oxide-copper(-gold) ore deposit clan. Tese (Doutorado). Queen's University, Kingston, Ontario, Canada.

CHILÈS, J. P.; DELFINER, P. (2012). Geostatistics: Modeling Spatial Uncertainty. Segunda Edição. John Wiley \& Sons, Inc.

CONCEIÇÃO, H. (1992). Petrologia dos Filões Graníticos e Sieníticos Potássicos do Cinturão Móvel Salvador-Curaçá, Bahia. Geochimica Brasiliensis, 6(1), 37-54.

COX, A.L. (1982). Artifactual uncertainty in risk analysis. Risk Analysis 2 (3), 121-135

D'EL-REY SILVA, L. J. H. (1984). Geologia e controle estrutural do depósito cuprífero Caraíba, Vale do Curacá, Bahia, Brasil. Dissertação (Mestrado). Salvador: Universidade Federal da Bahia.

D’EL REY SILVA, L. J. H. (1985). Geologia e controle estrutural do depósito cuprífero de Caraíba, Vale do Curaçá, Bahia. Geologia e Recursos Naturais do Estado da Bahia, 6, 51-123.

D’EL REY SILVA, L. J. H.; GIULIANI, G. (1988). Controle estrutural da jazida de esmeraldas de Santa Terezinha de Goiás: implicações na gênese, tectônica regional e no planejamento da lavra. XXXV Congresso Brasileiro de Geologia, 1, 413-427. Belém: SBG.

D'EL-REY SILVA, L. J. H.; OLIVEIRA, J. G.; LIMA E SILVA, F. J. (1994). The Mushroom-shaped Caraíba Cu-deposit, Vale do Curaçá-Ba: Understanding the 
Structural Evolution of the Paleoproterozoic, Granulitic Ipirá-Curaçá Belt within the São Francisco Craton. XXXVIII Congresso Brasileiro de Geologia, 2, 175177. Camboriú: SBG.

D'EL REY SILVA, L. J. H.; OLIVEIRA, J. G.; GAAL, E. G. (1996). Implication of the Caraíba deposits structural controls on the emplacement of the Cu-bearing hypersthenites of the Curaçá Valley, Bahia, Brazil. Revista Brasileira de Geociências, 26(3), 181-196.

DAMSLETH, E.; TJOLSEN, C. B.; OMRE, H.; HALDORSEN, H. H. (1990). A two-stage stochastic model applied to a North Sea reservoir. 65th Annual Technical Conference and Exhibition, 791-802. New Orleans: Society of Petroleum Engineers.

DAVIS, C.J. (2002). Statistics and Data Analysis in Geology, 3rd Edition. Wiley, New York, NY.

DELGADO, I. M.; SOUZA, J. D. (1975). Projeto Cobre-Curaçá: geologia econômica do Distrito Cuprífero do Rio Curaçá - Bahia - Brasil. Salvador: Convênio CPRM/DNPM.

DELGADO, I. M.; SOUZA, J. D. (1981). Cobre no Vale do rio Curaçá, Estado da Bahia. DNPM, Série Geológica, 20. Seção Geologia Econômica, 3, 212.

DEUTSCH, C. V. (1996). A sequential indicator simulation program for categorical variables with point and block data: BlockSIS. Computers \& Geosciences, 32, $1669-1681$.

DEUTSCH, C. V. (2002). Geostatistical Reservoir Modeling. New York: Oxford University Press. 
DEUTSCH, C. V. (2011). Guide to best practice in geostatistics. Draft Version 1.0. Edmonton: Centre for Computational Geostatistics. $101 \mathrm{p}$

DEUTSCH, C.V.; JOURNEL, A. G. (1992). GSLIB Geostatistical Software Library and user's guide. Oxford University Press, New York. 340 pp

DEUTSCH, C. V.; JOURNEL, A. G. (1998). GSLIB Geostatistical Software Library and User's Guide $2^{\text {nd }}$ Edition. Oxford University Press.

DIAS, J. R. V. P.; MARQUES, J. C.; QUEIROZ, W. J. A.; FRANTZ, J. C.; GIUSTI, R. (2014) O corpo Várzea do Macaco e as mineralizações de cromo, níquel e cobre, Complexo Máfico-ultramáfico Jacurici, Cráton São Francisco, Bahia. Brazilian Journal of Geology, 44. Acesso em 01 de abril de 2015, <http://www.scielo.br/scielo.php?script=sci_arttext\&pid=S231748892014000100289\&Ing=en\&nrm=iso>.

EMERY, X. (2004). Properties and limitations of sequential indicator simulation. Stochastic Environmental Research and Risk AssessmentSpringer-Verlag, v. 18, e. 6 , pp. $414-424$.

FIGUEIREDO, M. C. H. (1976). Geologia e geoquímica da região de Poço de Fora vale do Rio Curaçá - Bahia. Dissertação (Mestrado). Salvador: Instituto de Geociências, UFBA.

FIGUEIREDO, M. C. H. (1980). Geochemistry of High-Grade metamorphics rocks, nw Bahia. Tese (Doutorado). Ontario: Universidade Western Ontario, Canadá.

FONSECA, J. S.; MARTINS, G. A. (1982). Curso de Estatística. São Paulo: Editora Atlas, 286p. 
GOODFELLOW, R.; CONSUEGRA, F. A.; DIMITRAKOPOULOS, R. (2012). Quantifying multi-element and volumetric uncertainty, Coleman Mc Creedy deposit, Ontario, Canada. Computers \& Geosciences, 42, 71-78.

GOOVAERTS, P. (1997). Geostatistics for natural resources evaluation. New York: Oxford University Press.

HARDY, R. L. (1971). Multiquadric equations of topography and other irregular surfaces. Journal of Geophysical Research, 76, 1905-1915.

HENGL, T. (2009). A practical guide to geostatistical mapping. Retirado de: https://commons.wikimedia.org/wiki/File:Universal_modeloFspatialvariation.jpg JARDIM DE SÁ, E. F.; ARCHANJO, C. J.; LEGRAND, J. M. (1982). Structural and metamorphic history of part of the high-grade terrain in the Curaçá Valley, Bahia, Brazil. Revista Brasileira de Geociências, 12, 251-262.

JOURNEL, A. G.; HÜlJBREGTS, C. L. (1978). Mining Geostatistics. Academic Press: New York, 600p.

JOURNEL, A. G.; ROSSI, M. (1989). When do we need a trend model in kriging? Mathematical Geology, 21, 715-739.

JUANG, K. W.; CHEN, Y. S.; LEE, D. Y. (2004). Using sequential indicator simulation to assess the uncertainty of delineating heavy-metal contaminated soils. Elsevier, v. 127, pp. 229-238.

KADER, G.D.; PERRY, M. (2007). Variability for categorical data. Journal of Statistics Education 15 (2), 17 Acessado em 25 de junho de 2016 em: http://www.amstat.org/publications/jse/v15n2/kader.html 
KOSIN, M.; GUIMARÃES, J. T.; ABRAM, M. B. (1999). Folha Aracaju - SW: SC.24-Y. Salvador: CPRM, Programa Levantamentos Geológicos Básicos do Brasil.

KOSIN, M.; MELO, R. C.; OLIVEIRA, E. P. (2001). Geologia do Bloco Serrinha e do segmento norte do Orógeno Itabuna-Salvador-Curaçá. In: Barbosa, J. S. F; Oliveira, E. P.; Corrêa Gomes, L. C.; Marinho, M. M.; Melo, R. C. (Eds): WORKSHOP SOBRE O ORÓGENO ITABUNA-SALVADOR-CURAÇÁ (Cap. 3, 19). Salvador.

KOSIN, M.; MELO, R. C.; SOUZA, J. D.; OLIVEIRA, E. P.; CARVALHO, M. J.; LEITE, C. M. M. (2003). Geologia do segmento norte do Orógeno Itabuna-SalvadorCuraçá e guia de excursão. Revista Brasileira de Geociências, 33, 27-32.

LADEIRA, E. A.; BROCKES Jr., H. (1969). Geologia das quadrículas de Poço de Fora, Esfomeado, Tanque Novo e Lages: Distrito Cuprífero do Rio Curaçá, Bahia. Relatório parcial para o Projeto Cobre: geologia e sondagens.

LEAKE, B. E.; FARROCO, C. M.; TOWNEND, R. (1979). A pre-2000 Myr old Granulit Facies Metamorphosed Evaporite from Caraiba, Brazil. Nature, 277(4), 49-50.

LEITE, C. M. M. (2002). A evolução geodinâmica da orogênese paleoproterozóica nas regiões de Capim Grosso - Jacobina e Pintadas - Mundo Novo (Bahia, Brasil): Metamorfismo, anatexia crustal e tectônica. Tese (Doutorado). Salvador: Instituto de Geociências, Universidade Federal da Bahia.

LEONEL, L. G. (2015). Aplicação de Variáveis Indicadoras na Avaliação da Incerteza Volumétrica em um depósito de Zn-Pb. Dissertação de mestrado. São Paulo: Instituto de Geociências, Universidade de São Paulo. 97 fls.

LEUANGTHONG, O.; KHAN, K. D.; DEUTSCH, C. V. (2008). Solved Problems in Geostatistics. John Wiley \& Sons: Hoboken, 208p. 
LINDENMAYER, Z. G. (1981). Geological evolution of Vale do Rio Curaçá and of copper mineralized mafic-ultramafic bodies. In: Geologia e Recursos Minerais da Bahia, Textos Básicos, 1, 73-10.

LINDENMAYER, Z. G. (1982). Evolução geológica do Vale do Rio Curaçá e dos corpos máfico-ultramáficos mineralizados a cobre. Dissertação (Mestrado). Salvador: Instituto de Geociências, Universidade Federal da Bahia.

LINDENMAYER, Z. G.; LOPES, C. A. M.; TEIXEIRA, João B. G. (1984). Projeto cobre Bahia. Relatório final de pesquisa.

LOUREIRO, H. S. C. (1991). Mundo Novo. Folha SC-24-Y-D-IV. Escala 1:100.000. Salvador: DNPM/CPRM/SUREG-AS, Programa Levantamentos Geológicos Básicos do Brasil.

MAIER, W. D.; BARNES, S. J. (1996). Unusually high concentrations of magnetite at Caraiba and other Cu-sulfide deposits in the Curaça valley, Bahia, Brazil: Canadian Mineralogist, 34, 717-731.

MAIER, W. D.; BARNES, S. J. (1999). The origin of Cu sulfide deposits in the Curaçá Valley. Evidence from $\mathrm{Cu}, \mathrm{Ni}$, Se and platinum group element concentrations. Bahia, Brasil. Economic Geology, 94, 165-183.

MANDETTA, P. (1982). Aspectos geológicos e petrogenéticos das associações máfico-ultramáficas da região de Caraíba, Vale do Curacá/Ba. Dissertação (Mestrado). Salvador: Instituto de Geociências, Universidade Federal da Bahia.

MANN, J.C. (1993). Uncertainty in geology. Computers in Geology-25 Years of Progress. Oxford University Press, pp. 241-254.

MARQUES, J. C.; FERREIRA FILHO, C. F. (2003). The Chromite Deposit of the Ipueira-Medrado Sill, Bahia, Brazil. Economic Geology, 98:87-108. 
MARQUES, J. C.; FERREIRA FILHO, C. F.; CARLSON, R. W.; PIMENTEL, M. M. (2003). Re-Os and Sm-Nd isotope systematics and trace elements geochemistry setting constraints in the chromite deposits of Ipueira-Medrado Sill, Bahia, Brazil. Journal of Petrology, 44(4), 659-678.

MARQUES, J. C.; FRANTZ, J. C.; CHEMALE JR.; F., BRITO; R. S. C., APOLLO; J. F. H. (2005). The mafic-ultramafic rocks and mineralizations of the Jacurici Complex, Bahia, Brazil. III Simpósio sobre o Cráton do São Francisco. Salvador.

MATHERON, G. (1963) Traité de géostatistique appliquée, tome ii. Vol. 2. Technip, Paris.

MATHERON, G. (1965). Les variables régionalisées et leur estimation: une application de la théorie des fonctions aléatoires aux sciences de la nature. Paris: Masson. $305 p$.

MATHERON, G. (1969). Le Krigeage Universal: Fascicule 1, Anais da CMMM. 82 p.

MELO, R. C. (1991). Pintadas. Folha SC-24-Y-D-V. Escala 1:100.000. Salvador: DNPM/CPRM/SUREG-AS, Programa Levantamentos Geológicos Básicos do Brasil.

MELO, R. C.; LOUREIRO, H. S. C.; PEREIRA, L. H. M. (1995). Serrinha. Folha SC24-Y-D. Escala 1:250.000. Salvador: MME/CPRM/SUREG-AS, Programa Levantamentos Geológicos Básicos do Brasil.

MYERS, J. C. (1997). Geostatistical Error Management: Quantifying Uncertainty for Environmental Sampling and Mapping. Van Nostrand Reinhold: New York. $571 \mathrm{p}$. 
OLEA, R. A. (1991). Geostatistical glossary and multilingual dictionary. Oxford: Oxford University Press. $175 p$

OLEA, R. A. (1999). Geostatistics for Engineers and Earth Scientists. Kluwer Academic Publishers.

OLIVEIRA, E. P. (1990). Novos conceitos sobre as rochas máfico-ultramáficas cupríferas da mina Caraíba, Bahia. Revista Brasileira de Geociências, 19, 449461.

OLIVEIRA, E. P.; CHOUDHURI, A. (1993). Sulphur isotope geochemistry indicative of a mantle source for the Caraíba copper sulphides: Brasil. $2^{\circ}$ Simpósio do Craton do São Francisco, 1, 351-352. Salvador: SBG.

OLIVEIRA, E. P.; TARNEY, J. (1995). Genesis of the copper-rich Caraiba noritehypersthenite complex, Brazil. Mineralium Deposita, 30, 351-373.

OLIVEIRA, E. P.; CARVALHO, M. J.; MCNAUGHTON, N. J. (2004). Evolução do segmento norte do orógeno Itabuna-Salvador-Curaçá: cronologia da acreção de arcos, colisão continental e escape de terrenos. Geologia USP, Série Científica, 4, 41-53.

PADILHA, A. V.; MELO, R. C. (1991). Estruturas e Tectônica. In: Melo, R. C. (Org.). Pintadas, Folha SC.24-Y-D-V: Estado da Bahia. Programa de Levantamentos Geológicos Básicos do Brasil - PLGB Brasília: DNPM, 49-54.

PEREIRA, L. H. M. (1992). Serrinha, folha SC.24-Y-D-VI: Estado da Bahia: texto explicativo. Escala 1:100.000. Brasília: Convênio DNPM/CPRM. (Programa Levantamentos Geológicos Básicos do Brasil). 
POLETTO, C. A. (1996). Modelagem Geológica Orientada a Objetos e Simulação Estocástica da Geometria de Reservatórios Fluviais. Dissertação (Mestrado). Campinas: Universidade Estadual de Campinas.

POMIAN-SRZEDNICKI, I. (2002). Calculation of geological uncertainties associated with 3-D geological models. Tese de Doutorado. École Polytechnique Fédérale de Lausanne. $117 p$

REIS, C. H.; REATO, M. P.; JesuS, S. S. G. P.; SAMPAIO, M. C.; NAZÁRIO, J. S. (2013) Relatório de Pesquisa Arredores de Surubim. Relatório Interno da Mineração Caraíba.

ROSSI, M. E.; DEUTSCH, C. V. (2014). Mineral Resource Estimation. Dordrecht: Springer.

SABATÉ, P. (1996). Estruturas e tectônica do embasamento Arqueano e Proterozoico Inferior do Estado da Bahia. In. Barbosa, J. S. F., Dominguez, J. M. L. (Coords.). Geologia da Bahia: texto explicativo (201-226). Salvador, SICM.

SABATÉ, P.; MARINHO, M. M.; VIDAL, P.; VACHETTE, M. C. (1990). The 2-Ga peraluminous magmatism of the Jacobina-Contendas Mirante belts (Bahia, Brazil): geologic and isotopic constraints on the sources. Chemical Geology, 83, $325-338$.

SABATÉ, P.; PEUCAT, J. J.; MELO, R. C.; PEREIRA, L. H. M. (1994). Datação por Pb-evaporação de monozircão em ortognaisse do Complexo Caraíba: expressão do acrescimento crustal transamazônico do Cinturão SalvadorCuraçá (Cráton do São Francisco, Bahia, Brasil). XXXVIII Congresso Brasileiro de Geologia, 1, 219-220. Camboriú: SBG. 
SAMPAIO, A. R. (1992). Gavião, folha SC.24-Y-D-II: estado da Bahia. 2 mapas anexos. Escala 1:100.000. Brasília: Programa Levantamentos Geológicos Básicos do Brasil, Convênio DNPM/CPRM.

SEI (2012). Estatísticas dos Municípios Baianos [recurso eletrônico] /Superintendência de Estudos Econômicos e Sociais da Bahia. v. 1 (2000 - ). Salvador: SEI, 2012.

SEIXAS, S. R. M.; MARINHO, M. M.; MORAES FILHO, O.; AWDZIEJ, J. (1975). Projeto Bahia II. Geologia das folhas Itaberaba e Serrinha. Relatório Final. Salvador: Convênio DNPM/CPRM.

SILVA, A. (2010). Reconstrução de superfícies 3D por aproximação multiquádrica. Dissertação de Mestrado. Covilhã, Portugal. 69p.

SILVA, L. C.; MCNAUGHTON, N. J.; MELO, R. C.; FLETCHER, I. R. (1997). U-Pb SHRIMP ages in the Itabuna Caraíba TTG high-grade complex: the first window beyond the Paleoproterozoic overprinting of the eastern Jequié craton, NE Brazil. $2^{\circ}$ International symposium on granites and associated mineralizations, 282-283. Salvador: SBG.

SILVA, M.G; TEIXEIRA, J. B. G.; MISI, A.; CRUZ, S. C. P.; SÁ, J. H. S. (2014). Metalogênese do setor setentrional do cráton do São Francisco. Em SILVA, M.G.; NETO, M. N. R.; JOST, H.; KUYUMIJAN, R. M. Metalogênese das Províncias Tectônicas Brasileiras. Belo Horizonte: CPRM, 2014. pg. 93-118.

SINCLAIR, A. J.; BLACKWELL, G. H. (2004). Applied Mineral Inventory Estimation. Cambridge: Cambridge University Press.

SINGER, D. A.; MENZIE, W. D. (2010). Quantitative mineral resource assessments. New York: Oxford University Press. 
SOARES, A. (2001). Direct sequential simulation and cosimulation. Mathematical Geology, 33, 911-926.

SOARES, A. (2006). Geoestatística para as ciências da terra e do ambiente. 2. ed. Lisboa: IST Press.

SOUZA, J. D.; ABRAM, M. B.; SANTOS, R. A.; MELO, R.C. (2000). The basement of the northeastern São Francisco Craton. Field trip. Salvador: CPRM/Geological Survey of Brazil.

TEIXEIRA, L. R. (1997). O complexo Caraíba e a suíte São José do Jacuípe no Cinturão Salvador- Curaçá. (Bahia, Brasil): petrologia, geoquímica e potencial metatogenético. Tese (Doutorado). Salvador: Instituto de Geociências, Universidade Federal da Bahia.

TEIXEIRA, J. B G.; SILVA, M.G.; LINDENMAYER, Z. G.; SILVA, L. J. H. D.; VASCONCELOS, P. M.; REIS, C. H. C.; ANDRADE, J. B. F. (2010). Depósitos de Cobre da região do Vale do Rio Curaçá Bahia. In: BRITO, R. S. C. de; SILVA, M. G. da; KUYUMIJAN, R. M. Modelos de Depósitos de Cobre no Brasil e sua resposta ao intemperismo. São Paulo, CPRM.

TENG, Y.; KOIKE, K. (2007). Three-dimensional imaging of a geothermal system using temperature and geological models derived from a well-log dataset. Geothermics, v. 36, p. 518-538.

TOWNEND, R.; FERREIRA, P. M.; FRANKE, N. D. (1980). Caraiba, a new copper deposit in Brazil. Transactions of The Institution of Mining and Metallurgy Section, 89, 159-164.

VANN, J.; BERTOLI, O.; JACKSON, S. (2002) "Geostatistical Simulation for Quantifying Risk. Em: Geostatistical Association of Australasia symposium. 
WANG, J. G; LIU, G. R. (2002). On the optimal shape parameters of radial basis functions used for 2-D meshless methods. Computer Methods in Applied Mechanics and Engineering, 191:2611-2630.

WELLMANN, J. F.; HOROWITZ, F. G; REGENAUER-LIEB, K. (2010). Towards a Quantification of Uncertainties in 3-D Geological Models. IAMG 2011 Conference "Mathematical geosciences at the crossroads of theory and practice", 745-758. DOI: 10.5242/iamg.2011.0147.

YAMAMOTO, J. K. (2002). Ore reserve estimation using radial basing funtions. Revista do Instituto Geológico, v. 23, n. 1, pp 25-38.

YAMAMOTO, J. K.; ROCHA, M. M. Conceitos Básicos. Em: YAMAMOTO, J.K. (2001). Avaliação e Classificação de Reservas Minerais. 1 ed. São Paulo: Editora da Universidade de São Paulo (EDUSP), p. 9-34.

YAMAMOTO, J. K.; MAO, X. M.; KOIKE, K.; CROSTA, A. P.; LANDIM, P. M. B.; HU, H. Z.; WANG, C. Y.; YAO, L. Q. (2012). Mapping an uncertainty zone between interpolated types of a categorical variable. Computers \& Geosciences, 40, 146152. DOI: 10.1016/j.cageo.2011.09.005.

YAMAMOTO, J. K.; LANDIM, P. M. B. (2013). Geoestatística: Conceitos e Aplicações. São Paulo: Oficina de Textos.

YAMAMOTO, J. K.; LANDIM, P. M. B.; KIKUDA, A. T.; LEITE, C. B. B.; LOPEZ, S. D. (2014). Post-processing of sequential indicator simulation realizations for modeling geologic bodies. Computers \& Geosciences.. 
ANEXO A - Histograma e diagrama P-P para os domínios do depósito.
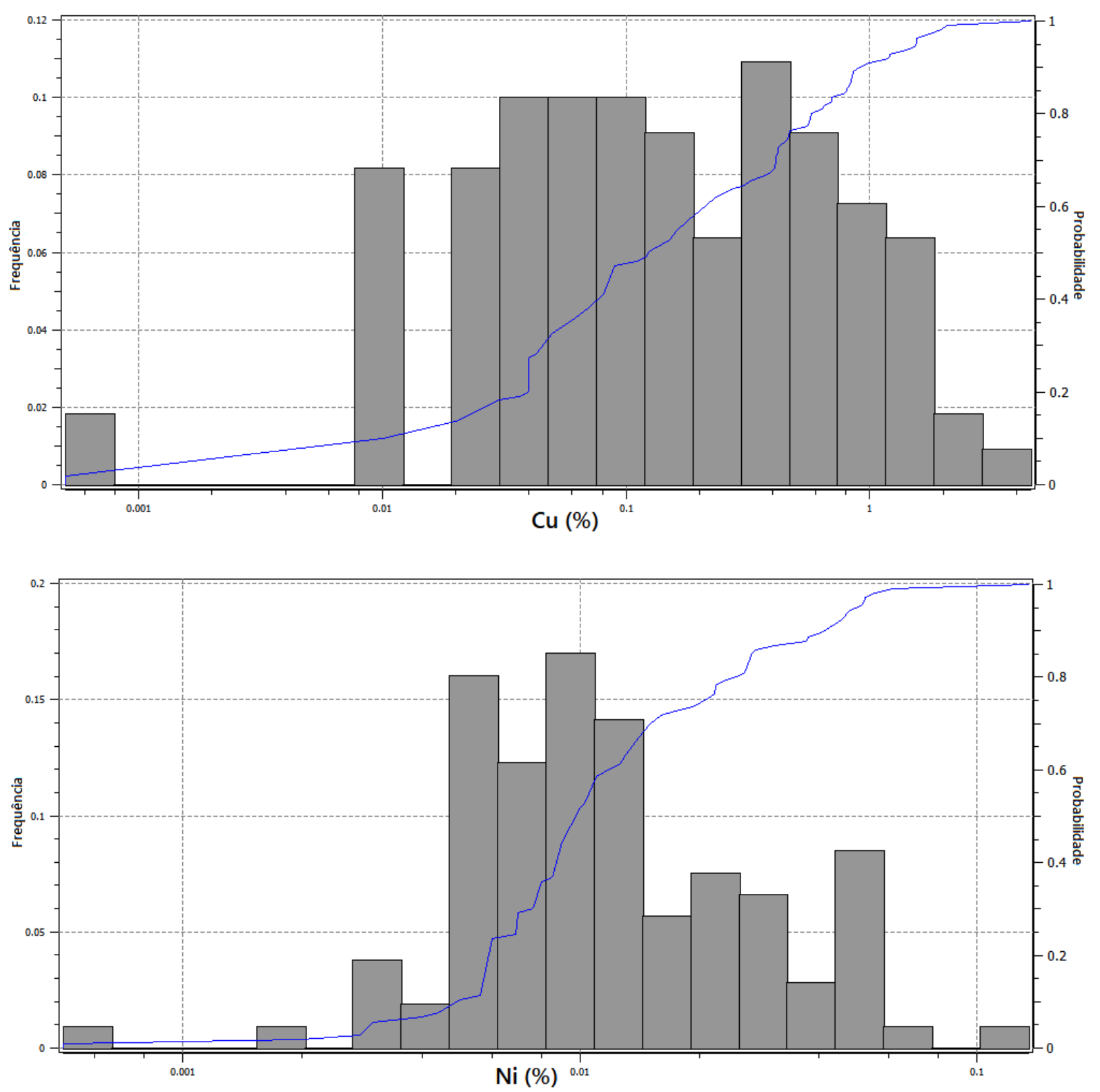

Figura A.1 - Histogramas e gráficos P.P em escala logarítmica para as variáveis Cu e Ni no domínio (I). 


\section{ANEXO A}
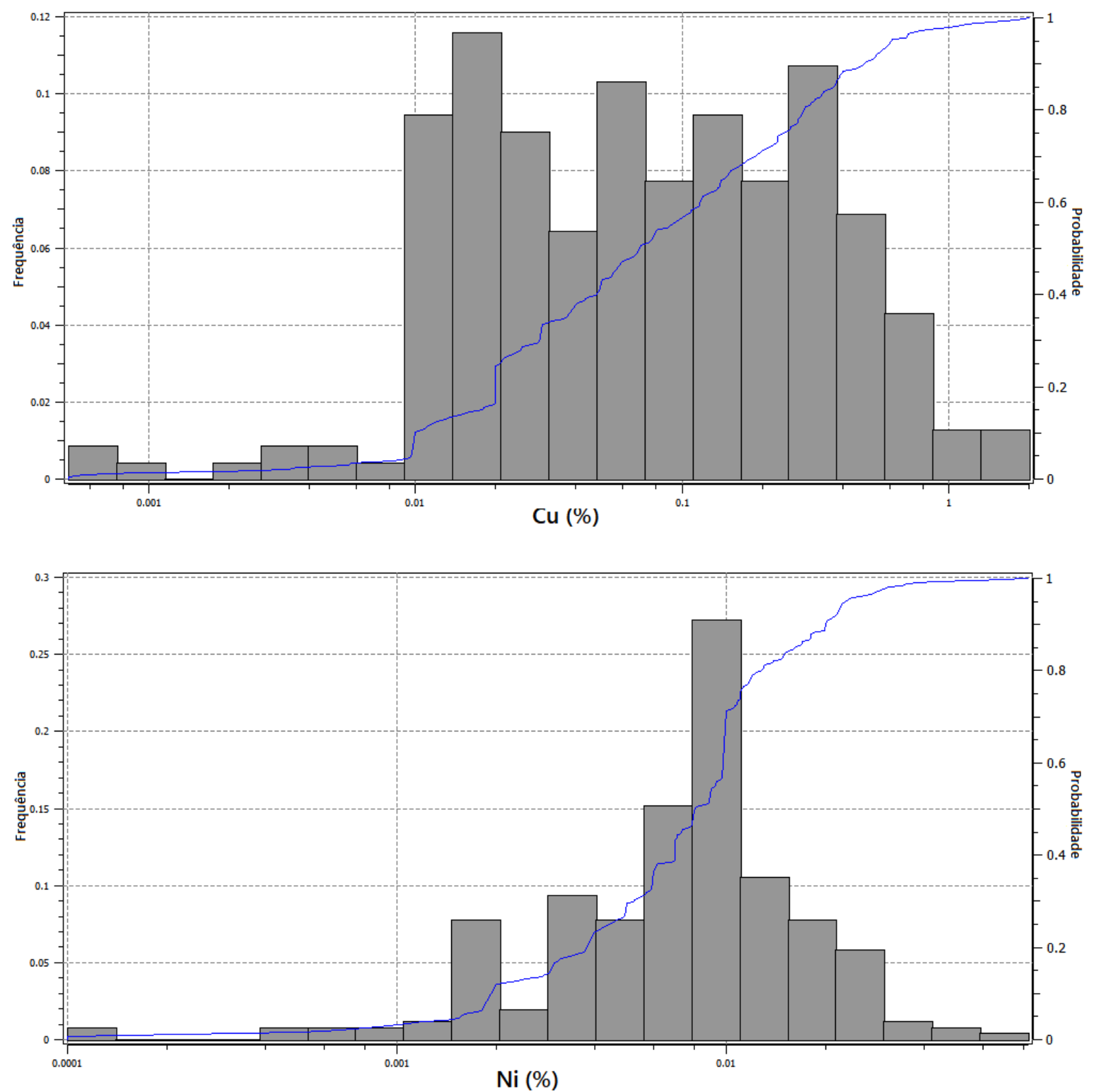

Figura A.2 - Histogramas e gráficos P-P em escala logarítmica para as variáveis Cu e Ni no domínio (II). 


\section{ANEXO A}
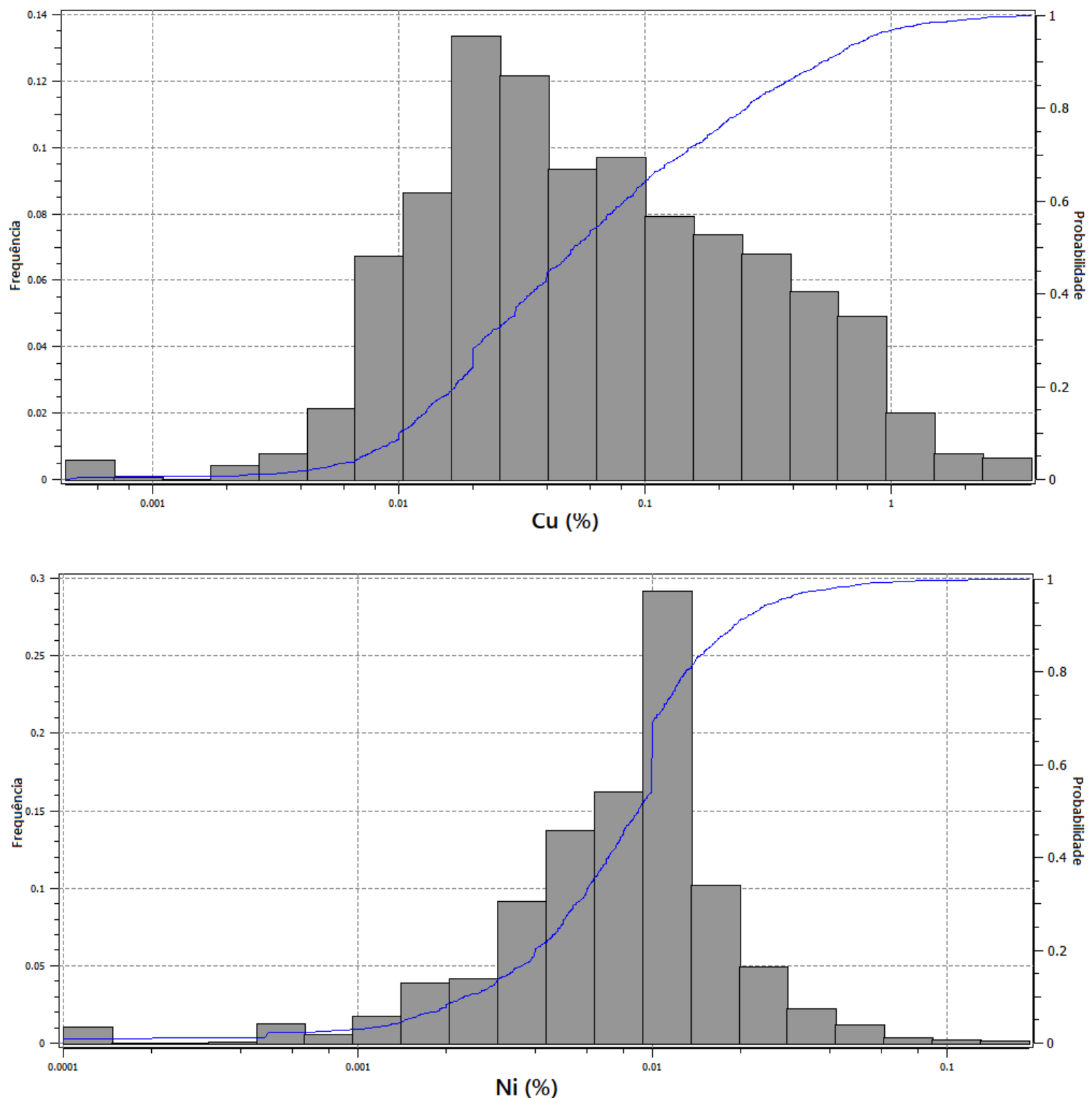

Figura A.3 - Histogramas e gráficos P-P em escala logarítmica para as variáveis Cu e Ni no domínio (IV). 


\section{ANEXO A}
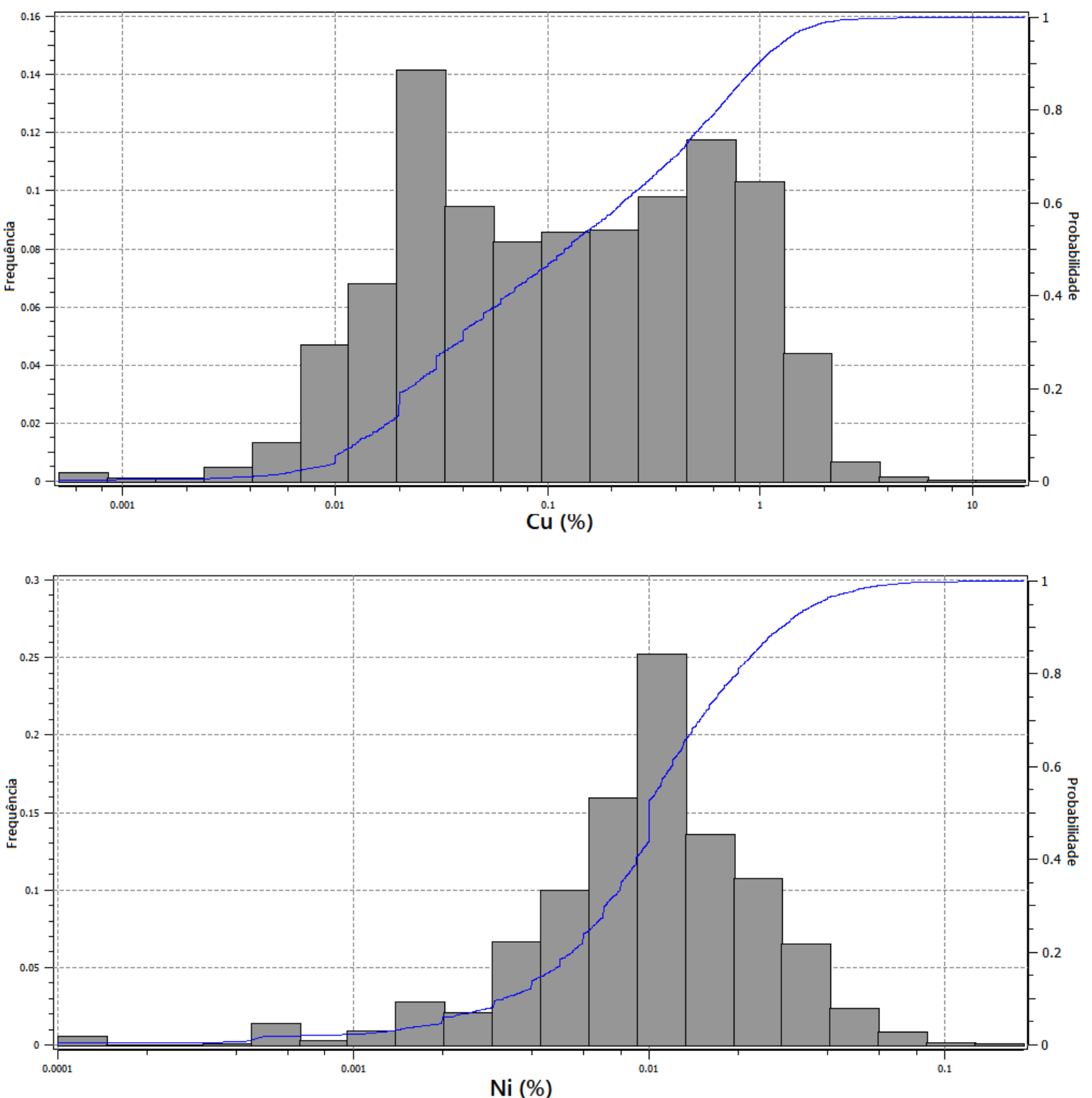

Figura A.4 - Histogramas e gráficos P-P em escala logarítmica para as variáveis Cu e Ni no domínio (V). 
ANEXO B - Resultados de volume por simulação $\left(10^{3} \mathrm{~m}^{3}\right)$.

\begin{tabular}{|c|c|c|c|c|c|c|}
\hline \multirow{2}{*}{ Simulação } & \multicolumn{6}{|c|}{ Domínio $\left(10^{3} \mathrm{~m}^{3}\right)$} \\
\hline & (I) & (II) & (III) & (IV) & $(\mathrm{V})$ & (VI) \\
\hline \#1 & $1,521.08$ & $1,025.80$ & $2,441.67$ & $11,376.55$ & $33,291.08$ & $1,712.83$ \\
\hline$\# 2$ & $1,501.86$ & $1,051.28$ & $2,437.84$ & $11,413.41$ & $33,303.94$ & $1,660.67$ \\
\hline \#3 & $1,506.53$ & 943.58 & $2,529.33$ & $11,271.27$ & $33,371.05$ & $1,747.25$ \\
\hline$\# 4$ & $1,549.92$ & $1,055.22$ & $2,446.42$ & $11,274.27$ & $33,349.42$ & $1,693.75$ \\
\hline \#5 & $1,494.09$ & $1,040.95$ & $2,454.53$ & $11,492.44$ & $33,234.41$ & $1,652.58$ \\
\hline \#6 & $1,518.23$ & 925.41 & $2,473.55$ & $11,277.38$ & $33,508.44$ & $1,666.00$ \\
\hline$\# 7$ & $1,490.41$ & 951.39 & $2,502.50$ & $11,401.61$ & $33,355.89$ & $1,667.20$ \\
\hline$\# 8$ & $1,513.91$ & $1,016.50$ & $2,513.09$ & $11,309.56$ & $33,333.84$ & $1,682.09$ \\
\hline \#9 & $1,528.25$ & 995.22 & $2,442.02$ & $11,355.42$ & $33,348.58$ & $1,699.51$ \\
\hline$\# 10$ & $1,569.03$ & 959.36 & $2,373.34$ & $11,347.02$ & $33,406.23$ & $1,714.02$ \\
\hline$\# 11$ & $1,556.77$ & 980.81 & $2,466.05$ & $11,330.42$ & $33,347.19$ & $1,687.77$ \\
\hline$\# 12$ & $1,508.59$ & $1,005.33$ & $2,467.66$ & $11,362.30$ & $33,332.41$ & $1,692.72$ \\
\hline$\# 13$ & $1,490.78$ & $1,035.02$ & $2,424.17$ & $11,234.34$ & $33,466.63$ & $1,718.06$ \\
\hline$\# 14$ & $1,531.34$ & $1,015.33$ & $2,460.27$ & $11,445.11$ & $33,238.45$ & $1,678.50$ \\
\hline$\# 15$ & $1,530.84$ & 957.73 & $2,416.11$ & $11,381.47$ & $33,385.91$ & $1,696.94$ \\
\hline$\# 16$ & $1,535.95$ & $1,000.59$ & $2,551.39$ & $11,342.88$ & $33,242.44$ & $1,695.75$ \\
\hline$\# 17$ & $1,507.53$ & $1,018.91$ & $2,433.33$ & $11,303.39$ & $33,426.83$ & $1,679.02$ \\
\hline$\# 18$ & $1,531.06$ & 997.66 & $2,462.58$ & $11,252.23$ & $33,452.34$ & $1,673.13$ \\
\hline$\# 19$ & $1,542.83$ & $1,013.38$ & $2,427.73$ & $11,415.72$ & $33,302.80$ & $1,666.55$ \\
\hline$\# 20$ & 1,511.16 & 952.70 & $2,505.75$ & $11,343.33$ & $33,357.56$ & $1,698.50$ \\
\hline$\# 21$ & $1,522.05$ & $1,002.72$ & $2,439.44$ & $11,388.00$ & $33,304.39$ & $1,712.41$ \\
\hline$\# 22$ & $1,547.34$ & 969.33 & $2,483.42$ & $11,531.05$ & $33,124.41$ & $1,713.45$ \\
\hline$\# 23$ & $1,498.75$ & 997.47 & $2,473.28$ & $11,231.86$ & $33,443.06$ & $1,724.58$ \\
\hline$\# 24$ & $1,508.23$ & 995.16 & $2,416.77$ & $11,324.02$ & $33,478.13$ & $1,646.70$ \\
\hline$\# 25$ & $1,517.11$ & 953.77 & $2,406.55$ & $11,314.81$ & $33,543.38$ & $1,633.39$ \\
\hline$\# 26$ & $1,509.48$ & 999.56 & $2,365.31$ & $11,325.38$ & $33,461.09$ & $1,708.17$ \\
\hline$\# 27$ & $1,554.75$ & 952.73 & $2,500.59$ & $11,498.81$ & $33,113.50$ & $1,748.61$ \\
\hline$\# 28$ & $1,505.44$ & $1,015.25$ & $2,414.58$ & $11,304.75$ & $33,417.70$ & $1,711.28$ \\
\hline$\# 29$ & $1,490.14$ & $1,000.72$ & $2,485.80$ & $11,389.78$ & $33,314.47$ & $1,688.09$ \\
\hline$\# 30$ & $1,483.69$ & 978.36 & $2,416.77$ & $11,255.63$ & $33,523.98$ & $1,710.58$ \\
\hline \#31 & $1,525.95$ & 980.42 & $2,468.78$ & $11,321.67$ & $33,412.94$ & $1,659.23$ \\
\hline$\# 32$ & $1,547.81$ & $1,023.78$ & $2,391.14$ & $11,317.42$ & $33,374.70$ & $1,714.14$ \\
\hline$\# 33$ & $1,556.72$ & 998.09 & $2,426.19$ & $11,385.66$ & $33,321.48$ & $1,680.86$ \\
\hline \#34 & $1,488.08$ & 973.73 & $2,464.22$ & $11,328.41$ & $33,415.52$ & $1,699.05$ \\
\hline$\# 35$ & $1,539.84$ & $1,024.84$ & $2,444.30$ & $11,381.59$ & $33,332.03$ & $1,646.39$ \\
\hline$\# 36$ & $1,496.67$ & $1,018.95$ & $2,443.31$ & $11,360.64$ & $33,342.50$ & $1,706.92$ \\
\hline$\# 37$ & $1,554.70$ & 931.55 & $2,439.59$ & $11,285.70$ & $33,460.36$ & $1,697.09$ \\
\hline$\# 38$ & $1,541.06$ & 984.02 & $2,358.84$ & $11,352.98$ & $33,437.59$ & $1,694.50$ \\
\hline \#39 & $1,513.22$ & 974.48 & $2,383.05$ & $11,439.22$ & $33,378.11$ & $1,680.92$ \\
\hline \#40 & $1,546.00$ & 955.14 & $2,414.36$ & $11,336.13$ & $33,387.03$ & $1,730.34$ \\
\hline
\end{tabular}




\begin{tabular}{|c|c|c|c|c|c|c|}
\hline \multirow{2}{*}{ Simulação } & \multicolumn{6}{|c|}{ Domínio $\left(10^{3} \mathrm{~m}^{3}\right)$} \\
\hline & ( 1 ) & (II) & (III) & (IV) & (V) & (VI) \\
\hline \#41 & $1,559.17$ & 995.69 & $2,447.59$ & $11,267.22$ & $33,436.64$ & $1,662.69$ \\
\hline \#42 & $1,599.56$ & $1,028.97$ & $2,489.20$ & $11,300.67$ & $33,326.08$ & $1,624.52$ \\
\hline \#43 & $1,525.56$ & 956.28 & $2,431.77$ & $11,487.63$ & $33,301.47$ & $1,666.30$ \\
\hline$\# 44$ & $1,524.95$ & $1,009.70$ & $2,435.30$ & $11,443.22$ & $33,282.03$ & $1,673.80$ \\
\hline \#45 & $1,509.97$ & $1,006.84$ & $2,493.06$ & $11,339.75$ & $33,347.77$ & $1,671.61$ \\
\hline \#46 & $1,524.75$ & 990.63 & $2,528.03$ & $11,398.84$ & $33,247.78$ & $1,678.97$ \\
\hline$\# 47$ & $1,561.06$ & $1,003.61$ & $2,411.39$ & $11,383.23$ & $33,320.59$ & $1,689.11$ \\
\hline \#48 & $1,527.73$ & 982.27 & $2,454.11$ & $11,405.84$ & $33,305.98$ & $1,693.06$ \\
\hline$\# 49$ & $1,510.73$ & 990.52 & $2,453.38$ & $11,397.28$ & $33,332.36$ & $1,684.73$ \\
\hline \#50 & $1,543.81$ & 935.28 & $2,430.81$ & $11,284.33$ & $33,468.28$ & $1,706.48$ \\
\hline \#51 & $1,510.19$ & $1,026.95$ & $2,451.44$ & $11,286.61$ & $33,375.66$ & $1,718.16$ \\
\hline \#52 & $1,571.30$ & $1,004.25$ & $2,511.55$ & $11,276.28$ & $33,304.02$ & $1,701.61$ \\
\hline \#53 & $1,563.27$ & $1,005.30$ & $2,383.80$ & $11,345.88$ & $33,337.94$ & $1,732.83$ \\
\hline \#54 & $1,519.94$ & 995.59 & $2,472.00$ & $11,295.23$ & $33,379.06$ & $1,707.17$ \\
\hline \#55 & $1,532.77$ & 982.78 & $2,485.63$ & $11,444.83$ & $33,244.14$ & $1,678.86$ \\
\hline \#56 & $1,513.63$ & $1,024.72$ & $2,474.75$ & $11,356.33$ & $33,255.61$ & $1,743.97$ \\
\hline \#57 & $1,557.73$ & $1,026.28$ & $2,489.59$ & $11,396.42$ & $33,238.72$ & $1,660.25$ \\
\hline \#58 & $1,514.77$ & 933.94 & $2,536.02$ & $11,343.08$ & $33,301.20$ & $1,740.00$ \\
\hline \#59 & $1,549.42$ & $1,044.17$ & $2,336.06$ & $11,280.44$ & $33,459.42$ & $1,699.48$ \\
\hline$\# 60$ & $1,535.47$ & 974.00 & $2,401.30$ & $11,340.09$ & $33,431.88$ & $1,686.27$ \\
\hline$\# 61$ & $1,563.75$ & $1,030.55$ & $2,359.38$ & $11,379.55$ & $33,356.67$ & $1,679.11$ \\
\hline \#62 & $1,567.88$ & 982.69 & $2,417.91$ & $11,211.92$ & $33,514.75$ & $1,673.86$ \\
\hline$\# 63$ & $1,556.72$ & 999.81 & $2,390.81$ & $11,418.97$ & $33,316.16$ & $1,686.53$ \\
\hline$\# 64$ & $1,525.75$ & 991.75 & $2,489.48$ & $11,150.52$ & $33,557.69$ & $1,653.81$ \\
\hline$\# 65$ & $1,529.80$ & 975.06 & $2,460.55$ & $11,274.38$ & $33,478.20$ & $1,651.02$ \\
\hline$\# 66$ & $1,508.13$ & 993.89 & $2,429.86$ & $11,322.47$ & $33,430.44$ & $1,684.22$ \\
\hline$\# 67$ & $1,472.92$ & $1,002.70$ & $2,449.91$ & $11,424.13$ & $33,331.47$ & $1,687.88$ \\
\hline$\# 68$ & $1,555.63$ & $1,000.22$ & $2,426.39$ & $11,209.83$ & $33,476.02$ & $1,700.92$ \\
\hline$\# 69$ & $1,504.33$ & $1,025.28$ & $2,380.94$ & $11,465.89$ & $33,252.00$ & $1,740.56$ \\
\hline$\# 70$ & $1,504.31$ & $1,030.52$ & $2,482.47$ & $11,305.38$ & $33,284.78$ & $1,761.55$ \\
\hline \#71 & $1,561.08$ & $1,006.58$ & $2,402.30$ & $11,383.72$ & $33,318.81$ & $1,696.52$ \\
\hline \#72 & $1,527.39$ & $1,004.77$ & $2,441.42$ & $11,478.53$ & $33,249.72$ & $1,667.17$ \\
\hline \#73 & $1,504.70$ & 986.95 & $2,499.02$ & $11,419.61$ & $33,242.34$ & $1,716.38$ \\
\hline \#74 & $1,515.23$ & $1,053.25$ & $2,420.92$ & $11,384.75$ & $33,308.36$ & $1,686.48$ \\
\hline \#75 & $1,528.72$ & 973.77 & $2,505.88$ & $11,304.03$ & $33,358.73$ & $1,697.88$ \\
\hline \#76 & $1,521.20$ & 966.42 & $2,422.92$ & $11,366.92$ & $33,384.42$ & $1,707.11$ \\
\hline \#77 & $1,497.84$ & 984.67 & $2,407.08$ & $11,403.86$ & $33,418.44$ & $1,657.11$ \\
\hline$\# 78$ & $1,535.98$ & $1,026.91$ & $2,473.44$ & $11,331.59$ & $33,319.28$ & $1,681.80$ \\
\hline \#79 & $1,508.31$ & 917.55 & $2,404.39$ & $11,447.56$ & $33,388.39$ & $1,702.80$ \\
\hline$\# 80$ & $1,544.31$ & $1,019.34$ & $2,417.80$ & $11,309.92$ & $33,380.53$ & $1,697.09$ \\
\hline
\end{tabular}




\begin{tabular}{ccrcccc}
\hline \multirow{2}{*}{ Simulação } & \multicolumn{1}{c}{ (I) } & \multicolumn{1}{c}{ (II) } & \multicolumn{1}{c}{ Domínio $\left(10^{3} \mathrm{~m}^{3}\right)$} \\
\hline$\# 81$ & $1,577.70$ & 981.42 & $2,434.23$ & $11,546.52$ & $33,108.09$ & $1,721.03$ \\
$\# 82$ & $1,551.14$ & 990.23 & $2,401.34$ & $11,384.97$ & $33,389.27$ & $1,652.05$ \\
$\# 83$ & $1,476.05$ & 988.55 & $2,405.48$ & $11,326.02$ & $33,478.55$ & $1,694.36$ \\
$\# 84$ & $1,548.22$ & $1,008.77$ & $2,436.72$ & $11,462.75$ & $33,238.28$ & $1,674.27$ \\
$\# 85$ & $1,523.91$ & $1,013.27$ & $2,437.98$ & $11,498.19$ & $33,213.77$ & $1,681.89$ \\
$\# 86$ & $1,545.47$ & 963.55 & $2,481.42$ & $11,374.23$ & $33,302.77$ & $1,701.56$ \\
$\# 87$ & $1,579.59$ & $1,039.95$ & $2,458.33$ & $11,339.80$ & $33,272.58$ & $1,678.75$ \\
$\# 88$ & $1,554.47$ & 968.77 & $2,406.00$ & $11,375.89$ & $33,386.42$ & $1,677.45$ \\
$\# 89$ & $1,582.36$ & $1,026.64$ & $2,451.06$ & $11,420.44$ & $33,245.98$ & $1,642.52$ \\
$\# 90$ & $1,495.38$ & 988.17 & $2,494.03$ & $11,391.02$ & $33,310.30$ & $1,690.11$ \\
$\# 91$ & $1,541.08$ & 996.53 & $2,445.98$ & $11,316.25$ & $33,343.61$ & $1,725.55$ \\
$\# 92$ & $1,535.28$ & $1,012.98$ & $2,383.39$ & $11,394.00$ & $33,375.38$ & $1,667.97$ \\
$\# 93$ & $1,522.80$ & $1,028.69$ & $2,520.06$ & $11,321.28$ & $33,304.47$ & $1,671.70$ \\
$\# 94$ & $1,552.56$ & 979.95 & $2,467.33$ & $11,289.66$ & $33,400.02$ & $1,679.48$ \\
$\# 95$ & $1,559.61$ & $1,007.84$ & $2,434.70$ & $11,286.80$ & $33,426.95$ & $1,653.09$ \\
$\# 96$ & $1,505.19$ & 987.63 & $2,398.70$ & $11,374.80$ & $33,402.52$ & $1,700.17$ \\
$\# 97$ & $1,519.72$ & $1,055.22$ & $2,427.64$ & $11,383.47$ & $33,264.92$ & $1,718.03$ \\
$\# 98$ & $1,486.27$ & $1,002.78$ & $2,403.23$ & $11,340.59$ & $33,455.34$ & $1,680.78$ \\
$\# 99$ & $1,524.91$ & 938.78 & $2,423.13$ & $11,330.02$ & $33,473.50$ & $1,678.67$ \\
$\# 100$ & $1,558.22$ & 997.44 & $2,382.94$ & $11,194.72$ & $33,569.67$ & $1,666.02$ \\
$\# 101$ & $1,524.48$ & 978.63 & $2,486.47$ & $11,406.67$ & $33,315.20$ & $1,657.55$ \\
\hline & & & & & & \\
\hline
\end{tabular}

